\title{
Product optimization of Zambian traditionally fermented milk - mabisi
}
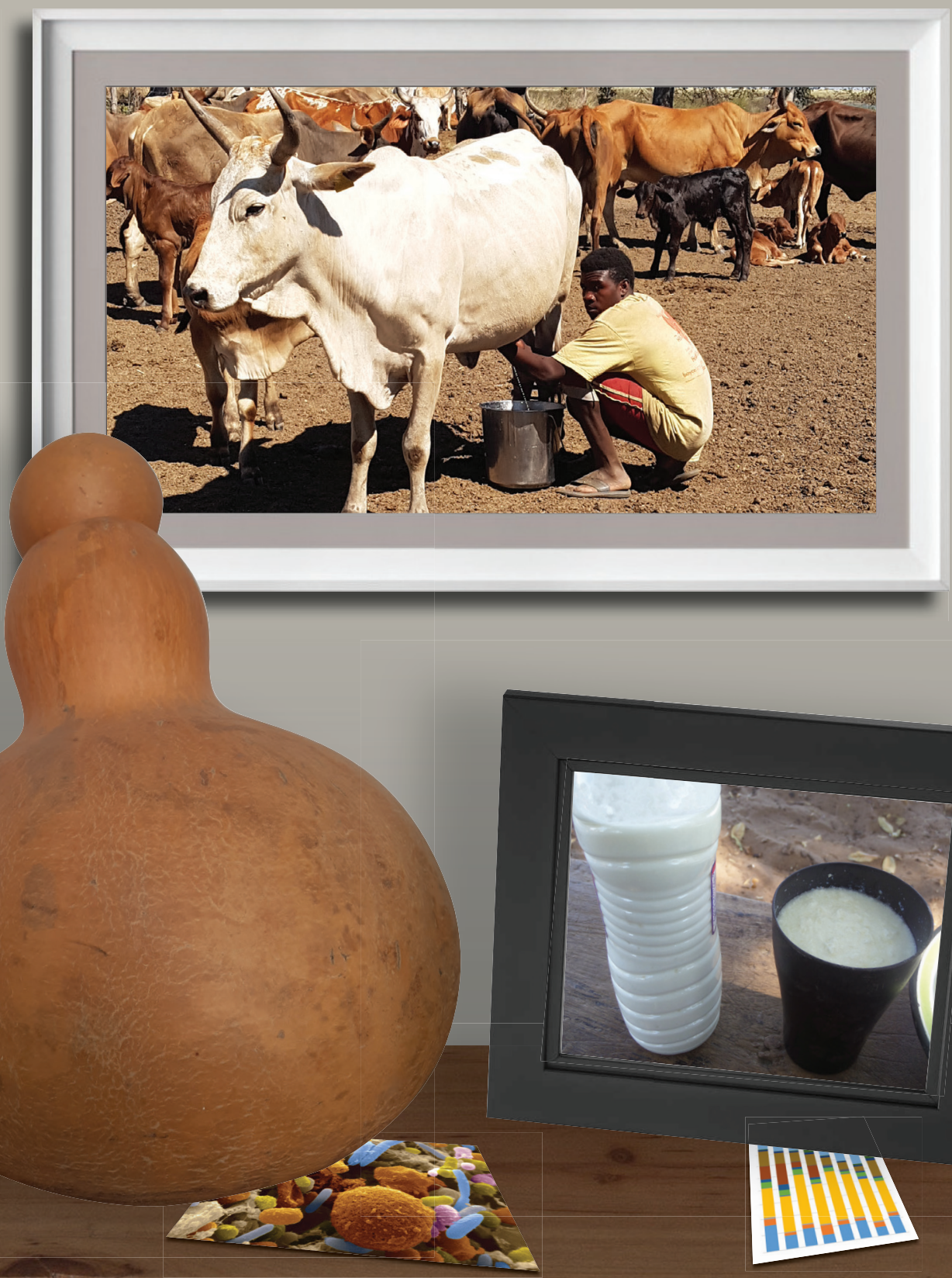

Himoonga Bernard Moonga

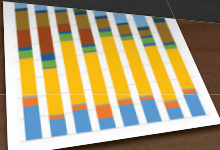


Product optimization of Zambian traditionally fermented milk - mabisi

Himoonga Bernard Moonga 


\section{Thesis committee}

\section{Promotor}

Prof. Dr E.J. Smid

Personal Chair at the Laboratory of Food Microbiology

Wageningen University \& Research

\section{Co-promotors}

Dr S.E. Schoustra

Assistant Professor, Laboratory of Genetics

Wageningen University \& Research

Visiting Professor at the Department of Food Science \& Nutrition

University of Zambia

Dr A.R. Linnemann

Assistant Professor, Food Quality \& Design

Wageningen University \& Research

Dr J. Shindano

Lecturer, Department of Food Science \& Nutrition

University of Zambia

\section{Other members}

Dr M. Serrano, CSK Food Enrichment, Wageningen

Dr P. Garbeva, Netherlands Institute of Ecology, Wageningen

Prof. Dr L. de Vuyst, University of Brussels, Belgium

Prof. Dr R. Ruben, Wageningen University \& Research

This research was conducted under the auspices of the Graduate School VLAG (Advanced studies in Food Technology, Agrobiotechnology, Nutrition \& Health Sciences). 


\section{Product optimization of Zambian traditionally fermented milk - mabisi}

\section{Himoonga Bernard Moonga}

Thesis

submitted in fulfilment of the requirements for the degree of doctor

at Wageningen University

by the authority of the Rector Magnificus,

Prof. Dr A.P.J. Mol,

in the presence of the

Thesis Committee appointed by the Academic Board

to be defended in public

on Tuesday 15 October 2019

at 4 p.m. in the Aula. 
Himoonga Bernard Moonga

Product optimization of Zambian traditionally fermented milk - mabisi, 115 pages.

PhD thesis, Wageningen University, Wageningen, The Netherlands (2019)

With references, with summary in English

ISBN: 978-94-6395-128-9

DOI: https://doi.org/10.18174/500783 


\section{Table of contents}

$\begin{array}{lll}\text { Chapter } 1 \quad \text { General introduction } & 7\end{array}$

$\begin{array}{lll}\text { Chapter } 2 & \text { The art of mabisi production } & 17\end{array}$

Chapter $3 \quad$ Microbial community composition \& diversity of mabisi 35

Chapter 4 Influence of temperature on microbial community composition of mabisi 51

Chapter 5 Microbial community dynamics of three types of mabisi 69

$\begin{array}{lll}\text { Chapter } 6 \quad \text { General discussion } & 89\end{array}$

$\begin{array}{lr}\text { References } & 100\end{array}$

$\begin{array}{lr}\text { Summary } & 105\end{array}$

$\begin{array}{lr}\text { Acknowledgements } & 107\end{array}$

$\begin{array}{lr}\text { About the author } & 111\end{array}$

$\begin{array}{lr}\text { Publications } & 112\end{array}$

$\begin{array}{lr}\text { Overview of training activities } & 113\end{array}$

$\begin{array}{lr}\text { Funding } & 115\end{array}$ 

Chapter 1

\section{General Introduction}

Himoonga Bernard Moonga 


\subsection{Fermented foods}

Fermentation is one of the oldest and most effective methods to preserve food raw materials. Fermented foods are an essential part of the human diet. They have a history of thousands of years of production and consumption. The fermentation technologies have evolved over millennia and their applications are widespread on a variety of raw materials: fruit \& vegetables, cereals, grains, tubers, legumes, meat and milk [1]. Food fermentation results in the production of food products with improved organoleptic properties, improved bioavailability of nutrients and minerals, reduced anti-nutritional factors or toxins, improved nutritional value and extended shelf-life.

The improvement in the organoleptic properties of fermented food is an important benefit as previously inedible raw materials can be converted to products that are tasty and flavourful with an extended shelflife. A good example is the fermentation of cucumber or cabbage, which are both perishable plant products with a limited shelf-life that can be fermented into pickles and sauerkraut, respectively. The resulting products have a natural acidic taste and a prolonged shelf-life of several months. Fruit fermentation on the other hand, will produce wine or vinegar, which helps with the preservation of grapes and apples. Further, the fermentation of cocoa beans is crucial for chocolate production [2].

Fermentation can also be used to reduce food associated toxins and anti-nutritional factors. For instance, the fermentation of raw cassava roots with a high content of cyanogenic glucosides, leads to a reduction in the level of released cyanide [3,4]. Raw materials such as soya beans have anti-nutritional factors such as trypsin inhibitors and lectins, which can be removed by a fermentation process. Soya fermentation has been found to improve the bioavailability of nutrients and synthesises certain vitamins e.g. vitamin B12 in tempeh $[5,6]$.

Fermentation is not only limited to plant based products but is also carried out on animal derived products to produce meat based fermented sausages or pickled fish as well as dairy based products: cheese, yoghurt and sour cream. A lot of these fermented products in general derive their recipes from traditional fermentation recipes, which are based on spontaneous fermentation.

\subsection{Traditionally fermented milk}

Milk is a white opaque liquid produced by the mammary glands of the female mammals primarily for the nourishment of their offspring. It is a nutritious product, well balanced in its composition of macro and micro-nutrients and thus, considered as complete food specifically for the neonate. As a result of its richness in nutrients, milk is a perishable product and can easily be invaded by spoilage and pathogenic bacteria. In the human diet, the most important type of milk that is widely consumed comes from ruminants and in particular cows (Bos taurus). Cow's milk is the raw material for the production of many different fermented milk products.

Traditionally fermented milk products are those produced by a natural or spontaneous fermentation process of raw or pasteurised milk. Most commercial fermented milk products such as cheese and yogurt derive their recipes and origin from traditional milk fermentation recipes. These products have been produced for millennia $[7,8]$ and the production processes have been optimised step-by-step to produce high quality and safe products all the time [1]. During the last century, this optimisation process also involved the identification of microbes and development of starter cultures [9, 10]. In addition, optimal process conditions and other key ingredients necessary to produce high quality products were developed.

In more recent times, other fermented milk products have been commercialised and these include kefir and koumiss, which are examples of traditionally fermented milk products (TFMPs) from eastern Europe and Mongolia. Others include filmjölk and langfil from Scandinavia, queso blanco from Latin American, ayran from the middle east and lassi from India [11]. 
In Africa, TFMPs are mostly produced at household level, in many cases for home consumption. During the periods of excess milk production, some of these TFMPs may be sold to neighbours and nearby communities. Production of TFMPs in many African countries are mainly associated with pastoral ethnic groups that own cattle. The rise in population and rapid urbanisation is likely to increase the demand of TFMPs. In some countries, efforts to commercialise such products are under way. However, a large proportion of the African population is lactose intolerant, which means that TFMPs are a better option for their dairy intake as they have a lower lactose content.

Some of the TFMPs produced on the African continent include: nunu from Ghana [12], kivuguto from Rwanda [13], mursik from Kenya [14], ergo from Ethiopia [15, 16], Iben from North Africa [17], omashikwa and mabisi from Namibia [18, 19], amasi from Zimbabwe and South Africa [20-23], and mabisi from Zambia [24]. The production processes for some of these TFMPs are depicted in the flow diagrams in Fig. 1. Most of them are made from unpasteurized raw milk except for a few that have a pasteurisation step e.g. mursik. In TFMPs produced in Africa, raw milk is traditionally fermented in the calabashes (gourds) or earthen pots by spontaneous fermentation at ambient temperature. In some cases, the process involves the use of a root to induce fermentation for example in omashikwa production $[15,18]$. Some TFMPs involve the transfer of part of a previous batch as starter culture for the next one in a process referred to as 'backslopping' while other products involve the removal of whey e.g. amasi [21]. Some production processes involve churning (agitation) which produces butter or ghee in addition to the fermented milk (buttermilk) e.g. argo $[15,16]$. This study will focus on mabisi, a TFMP from Zambia.
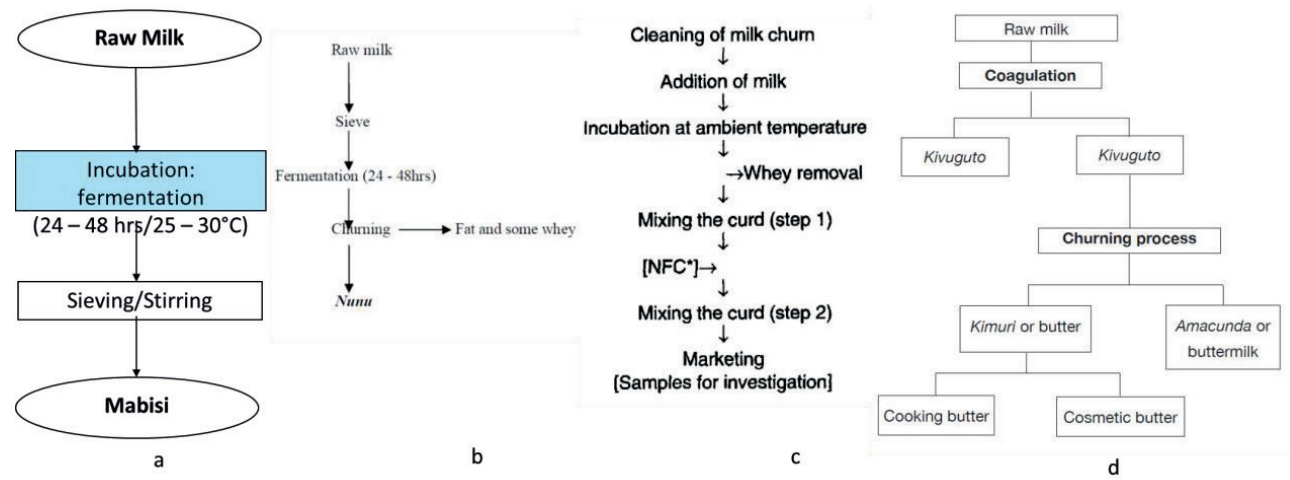

Fig. 1. Production flow diagram of selected African traditionally fermented milk products: a. mabisi, b. nunu, c. amasi and d. kivuguto. Source: $[12,13,21,24]$

\subsection{Role of TFMPs in food and nutrition security}

TFMPs play a key role in food and nutrition security in many rural communities in Africa. The reason is that they are a good source of protein, fat, $\mathrm{Ca}, \mathrm{P}$ and other nutrients such as vitamins and essential amino acids that are important for growth of young children and adolescents as well as maintenance in adults. Most of these TFMPs are produced in rural areas where the road infrastructure is poor, access to electricity and potable water are limited, which consequently, limits the amount of raw milk that can be processed through formal channels into dairy products.

Therefore, the production of TFMPs is an avenue that prevents the loss of raw milk by producing nutritious products with an extended shelf-life that can be consumed by all age groups in the household with different accompanying foods. In Southern Africa, TFMP is consumed with maize or sorghum soft or thick porridge or as a beverage. 
Mabisi is a TFMP mainly produced in the western, southern and central parts of Zambia, where large numbers of cattle are found and the people have a tradition of producing and consuming this characteristic dairy product. This nutrient rich mabisi can contribute significantly to reducing undernutrition levels, which stand at $40 \%$ stunting among children under the age of five years [25]. Moreover, it is estimated that only $50 \%$ of the total milk production in Zambia is processed through the formal trade channel, the rest is sold informally $[26,27]$. Further, during the peak production in the rainy season, a significant fraction of the milk produced is lost. These losses can be prevented by producing mabisi, which has a longer shelf life than raw milk at ambient temperature and can be sold in urban areas where the product has become popular among both the traditional and new consumers.

Furthermore, TFMPs are a source of beneficial microbes that may have probiotic effects, which can contribute to better gut health [28-30].
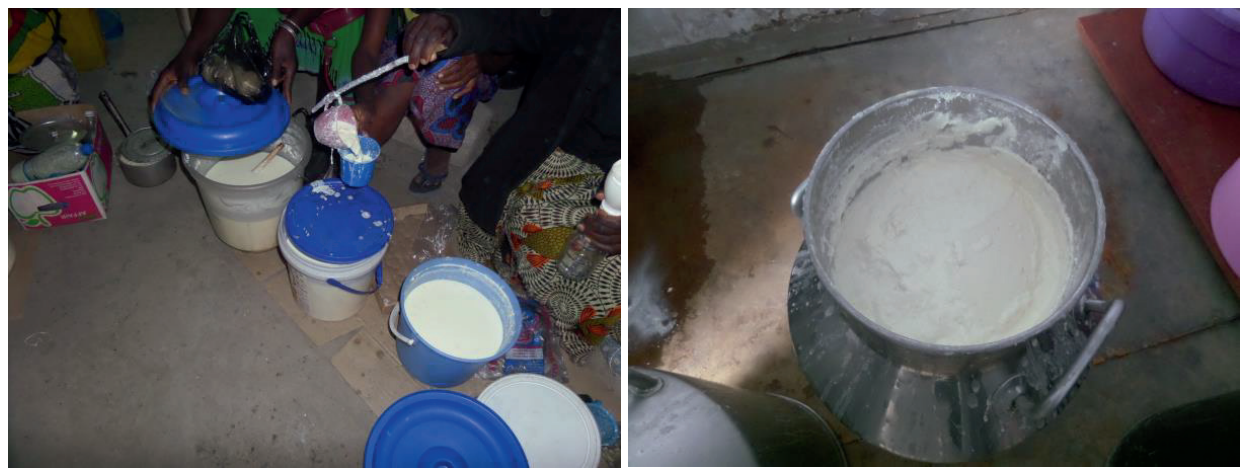

Fig 2. Mabisi sold at the market and milk collection centres (MCCs).

\subsection{Product quality and consumer perception}

Mabisi is produced by spontaneous fermentation of raw milk at ambient temperature, which results in the conversion of lactose into lactic acid by the fermenting microbes present in the product. This leads to a sour milk product with a pH range of 4.0 to 4.5 [24] and a thick consistency, which can either be smooth or lumpy. The pH ranges of other African TFMPs are shown in table 1 . The sourness and thickness of mabisi may vary considerably depending on the producer and consumer preference.

Table 1. The $\mathrm{pH}$ of African traditional fermented milk products

\begin{tabular}{|l|l|l|}
\hline Names of product & pH range & Source \\
\hline Sethemi & $4.1-4.3$ & {$[31]$} \\
\hline Amasi & $3.5-4.3$ & {$[21,22]$} \\
\hline Ergo & $4.3-4.5$ & {$[16,32]$} \\
\hline Kivuguto & $<4.5$ & {$[13]$} \\
\hline Lben & $<4.7$ & {$[17]$} \\
\hline Nunu & $3.55-4.0$ & {$[12]$} \\
\hline
\end{tabular}

Consumers can be divided into two categories: traditional and new consumers. Traditional consumers are those associated with consuming mabisi since childhood or for a long time whereas new consumers are supposed to have a shorter history of consumption (<5yrs). Some traditional consumers in certain regions of the country prefer a more sour product than others while new consumers mostly prefer a less sour product and tend to add sugar as a sweetener during consumption. 
Consumers often complain about product quality inconsistencies among producers with some producers being accused of milk adulteration because of the poor consistency of the product and high whey content, which is considered to be undesirable.

Neither are there established quality standards for mabisi nor are there studies on consumer preferences and quality attributes of mabisi. Such standards and information are crucial for product development and optimisation and will lead to products that meet consumer demands.

\subsection{Economic potential of mabisi}

Sub-Sahara-Africa is divided into three regional economic blocks: Southern Africa Development Community (SADC), East African Community (EAC) and Economic Community of West African States (ECOWAS). All respective member states of each regional economic group are involved in trade within their block as well as with members of other economic blocks for various goods and services, which include milk products.

The consumption of TFMP and other fermented milk products is common in the SADC and EAC regions with two of the largest producers of milk in each of these regions are South Africa and Kenya, respectively. The most common TFMPs in SADC are amasi, omashikwa and mabisi whereas mursik and kivuguto are common in EAC. Amasi and mabisi have a similar production process, which implies that amasi consumers may easily consume mabisi.

Zambia produces an estimated 1.2 billion litres of milk per annum [33] and only $50 \%$ of it, is processed by dairy companies into different dairy products $[26,27]$, which include a commercial product known as "lacto-mabisi" produced from pasteurized (or sterilised) milk fermentation using a defined starter culture. The rest of the milk is sold either as raw milk or made into mabisi but some of this milk goes to waste, especially during the rainy season when the production reaches its peak. The establishment of milk collection centres (MCCs) around the country has improved data collection on milk production and provided a formal marketing channel for farmers to sell their milk to dairy processing companies. However, some of the milk production areas have poor road infrastructure, and inadequate and erratic power supply, which leads to losses of milk as a result of the breakdown in the cold chain [26].

Mabisi is stable at ambient temperature for several days and its production can be a solution to the current losses that farmers and their cooperatives experience. However, there is need to optimise and standardise the product to ensure that the same quality of mabisi can be produced all the time. The current price of raw bovine milk is ZMW 4 (0.3 Euro) per litre, this means that during peak milk production season the farmers would make an estimated income of $€ 90 \mathrm{~m}$ from the sale of mabisi that would have otherwise been wasted. Higher incomes from the mabisi sales will improve the livelihood of their households, which will in turn help the farmers to send their children to school and improve their production capacity.

Once the local market has been satisfied due to increased production, the extra product can be exported to member states in SADC region as well as other regional blocks.

\subsection{Microbial composition and ecology}

As mentioned earlier, most TFMPs are produced by spontaneous fermentation. Thus, the microbes involved in the fermentation mostly come from the immediate production environment: raw milk, production utensils (buckets and calabashes), air and hands of the milking personnel. This can lead to variation in the microbial composition of the product as it depends on the microbiological quality of raw milk, the health of the cow, personal hygiene and the cleaning practices of the utensils and surrounding 
environment. The temperature of the environment may also have a bearing on the microbial composition.

Since TFMPs are not produced using defined starter cultures, they consist of a group of microbes referred to as 'microbial communities'. These microbial communities are responsible for the fermentation process in the TFMPs with each of them playing a specific role during the process. As a result, the microbial community composition of these products changes over time. For instance, raw milk is the starting material and has its own microbiota composed of different bacteria [34]. Other microbes from the surrounding environment also enter the system and form the initial microbial community. The initial stages of fermentation are usually dominated by Gram-negative bacteria since the milk is at almost neutral $\mathrm{pH}$ and rich with nutrients that supports their fast growth. Thereafter, the lactic acid bacteria will join and breakdown the lactose to lactic acid thereby, reducing the $\mathrm{pH}$. When the $\mathrm{pH}$ reaches 4.6 (the isoelectric point of the kappa casein) the milk will coagulate and form a sour milk with a thick coagulum $[35,36]$.

The gradual changes in nutrient content and $\mathrm{pH}$ of the milk during the fermentation process will lead to changes in the microbial community composition. This implies that there will be differences in the microbial composition present at the start, in the middle and at the end of the fermentation process. However, the changes in the microbial community may not only be linked to the availability of nutrients and $\mathrm{pH}$, but may also be associated with competition and microbial interactions. If we consider the fermenting milk as an ecosystem, other external factors may also influence the microbial community composition such as temperature, the material of the fermentation container, addition of ingredients or starter cultures (back-slopping), removal of whey/butter, dilution with raw milk and agitation. All of these factors may exert a certain effect on the microbial community composition, which can be referred to as 'selection pressure'. The internal factors can collectively be referred to as 'biotic factors' whereas the external factors can be referred to as 'abiotic factors'.

The TFMPs in Africa are subjected to different biotic and abiotic factors that exert selection pressure on their microbial communities, which results in different outcomes in terms of microbial community structure. In section 1.2, the different production flow processes were highlighted for several African TFMPs. There limited studies that associate microbial community composition with production practices of TFMPs and their related production factors. Most studies that have been carried out on TFMPs, have focussed on the characterisation of the microbes in these products. Furthermore, in respective countries the focus has usually been on one type of TFMP from a particular region with few samples and the majority of these studies were conducted using culture-based analytical techniques for microbial analysis $[12,13,20,22,31]$.

Microbial analysis using culture-based techniques has limitations in the sense that, the method depends on the microbes growing on the selected solid media and being enumerated. However, in some cases certain microbes may not grow, which will lead to conclusions that those microbes are absent.

Fortunately, culture independent methods have been developed over the last several years and the cost of analysis per sample has steadily been reducing, which makes it an interesting approach to investigate whole microbial communities in these products. The main advantage of this method is that it is based on the DNA of the microbes present in the product, which is extracted, purified and sequenced for identification by comparison with already sequenced data of microbes on established databases such as the NCBI. For example, studies in raw milk microbial composition have found more bacterial species using this technique [34].

Few studies have been conducted on African TFMPs using these techniques [24, 37-39] compared to extensive studies that have been carried out and are still on-going for other fermented milk products such as cheese $[40,41]$. These new DNA based analytical techniques provide the opportunity to carry out more comprehensive analysis of the microbial community composition and their dynamics during the course of fermentation. And this can be coupled with the study of volatile compounds produced in TFMPs products, which can be linked to microbial functionality. The use of both of these analytical techniques can be instrumental in the development of starter cultures and product optimisation. 
The volatile compounds are important because they deliver aroma to the TFMP and can also be called 'aroma compounds'. These compounds are products of the metabolism of the combined microbial community during fermentation, which gives each respective product the characteristic aroma. Different methods can be used to determine these compounds but one of the most commonly used is the Headspace-Solid Phase Micro-extraction Gas Chromatography-Mass Spectrometry (HS-SPME GC-MS).

\subsection{Study approaches and indigenous knowledge}

Africa is endowed with a rich heritage of natural resources. The most prominent resources are minerals, timber and oil that are part of the larger international trade domain. However, there are other riches of Africa, which are not at the front row of the global discussion and these are related to indigenous knowledge of food preparation.

The transfer of indigenous knowledge throughout human civilisation has been through storytelling, writing and drawing. In African society, storytelling and guiding the next generation on a particular skill were by far the most popular means of knowledge transfer. However, these practices changed after colonisation and introduction of formal education, which led to certain aspects of the traditional ways being considered backward and archaic. As a result, a fair amount of knowledge and skills of various traditional and herbal medicine, weather forecasting, agro-practices as well as food preservation have been lost.

TFMPs such as mabisi are still produced using indigenous knowledge and skills handed down from one generation to another. However, with a changing world and advances in science and technology, there is need to harness these skills and knowledge base in order to meet the demand of the growing world population projected to increase by 2 billion towards the year 2050. Utilising the indigenous knowledge of mabisi production and combining it with current analytical techniques will result in the development of products with added value, consistent quality and safety. Therefore, it is critical to investigate the traditional ways of mabisi production and identify the key aspects of its production. Thereafter, with the application of current scientific knowledge, better quality and safe products can be developed and optimised on the basis of TFMPs.

Collecting this information requires systematic planning and meticulous execution. Researchers need good local contact persons that are known to the target communities who are able to guide the researchers on the social norms of the respective societies. The local contact person can either be a government Agricultural Extension Officer or Environmental Health Technician depending on the need. These officers are usually supervised by a senior officer at District level, who also reports to someone at Provincial level. It is important to respect and follow these lines of authority and communication for the research to be successful. At local community level, the contact person understands the local procedures of paying a courtesy call on the Chief and Headman depending on the study areas. Only after satisfying all the relevant stakeholders' requirements or expectations, can the researchers then proceed with information gathering either through interviews with questionnaires or focus group discussions. These processes can take time and are complex, making thoughtful planning of activities a key success factor.

\subsection{Rationale and problem description}

Mabisi is a popular TFMP in Zambia, made from raw milk through a spontaneous fermentation process. In Zambia, the legislation does not permit the sale of milk that has not undergone pasteurisation and mabisi falls into this category (milk). Unpasteurized raw milk is sold and can be used to produce mabisi at household level. Some traders buy raw milk and make mabisi for sale at local markets or in some cases, they buy already made mabisi at wholesale scale from farmers for subsequent, re-sale at the market. Mabisi is also sold at milk collection centres (MCCs). 
Most dairy farmers are members of cooperatives and a number of these cooperatives have MCCs where the farmers deliver their milk and bulk it up for sale to the dairy processing companies. The establishment of these MCC has improved the income levels of the dairy farmers because they have an assured market. However, due to erratic power supply, poor road infrastructure and other logistical challenges, there are disruptions in the cold chain, which leads to milk being rejected by the dairy processors. Once the milk has been rejected it is either disposed of or fermented into mabisi and sold to the public. There are no documented cases of food poisoning and food-borne illnesses linked to the consumption of mabisi. In fact, there are assertions that mabisi cures diarrhoea and improves digestion, which raises questions about the kinds of microbes present in mabisi.

There are limited studies on the microbial composition of mabisi. Schoustra, Kasase [24] reported that mabisi is composed of 6-8 species of lactic acid bacteria (LAB) and acetic acid bacteria (AAB). These are findings from samples collected from Southern (Zimba, Choma and Monze districts) and Central (Mumbwa district) provinces. However, mabisi is also produced in Western province and with internal migration of people from one province/region to another as well as the promotion of dairy farming by the Government and other stakeholders around the country, mabisi production has spread to other parts of the country that are not traditionally associated with its production. In addition, Zambia has a rich ethnic diversity of 73 different tribes spread across the country, for which mabisi is an important part of the diet to many of them. Mabisi consumption has spread among ethnic groups through cultural exchange fostered by inter-tribal marriages, migration to other regions as well as urbanisation. It has become a popular product in the cities mainly consumed with the staple maize porridge, dehulled maize or taken as a beverage.

Because Zambia is a vast country $\left(752,000 \mathrm{~km}^{2}\right)$ with different ethnic groups, there may be differences in the way mabisi is produced from one region to another, which can be referred to as 'production methods'. Furthermore, there are different geographical regions that can be distinguished within the country either by average ambient temperatures or amount of rainfall received, also referred to as 'agroecological zones'. There may also be different types of containers used for the fermentation. All these constituent abiotic factors that may exert a certain degree of selection pressure on the microbes found in mabisi, which may lead to a particular outcome in the microbial community structure. Therefore, there is need to determine microbial community composition of mabisi and identify the key factors that influence its composition.

The composition of the microbial community is important because it gives information on presence and relative abundance of certain types of bacteria that are involved in the fermentation. In addition, knowledge of the microbial community composition provides suggestions for the selection of key microbes that can be used to develop starter cultures for mabisi production and finally, this also helps to assess product safety under existing production practices. These microbial communities can be assessed for resilience against pathogen invasion in order to allay concerns of microbial hazards in mabisi. Knowledge of the composition of the microbial community and the production method can be used for product optimisation, which is expected to lead to the production of standardised products with established quality, safety and shelf-life.

\subsection{Study aim and objectives}

Traditionally fermented milk products such as mabisi are a rich source of nutrients and potentially beneficial microbes because they are produced through a spontaneous fermentation of raw milk at ambient temperature. The product remains stable at room temperature for several days and is an important part of the diet in many households in Zambia.

Therefore, the aim of this study was to characterise the microbial community composition of mabisi and determine the factors that influence their composition. The conceptual framework of the study is illustrated in Fig. 3 and specific objectives of this study are: 
- To determine the existing production practices, identify key process parameters and uses of mabisi in Zambia

- To characterise the microbial community composition of mabisi produced across Zambia

- To determine the influence of fermentation temperature on microbial community composition and physicochemical properties of mabisi.

- To determine the effect of three production methods and producers on the mabisi microbial community composition

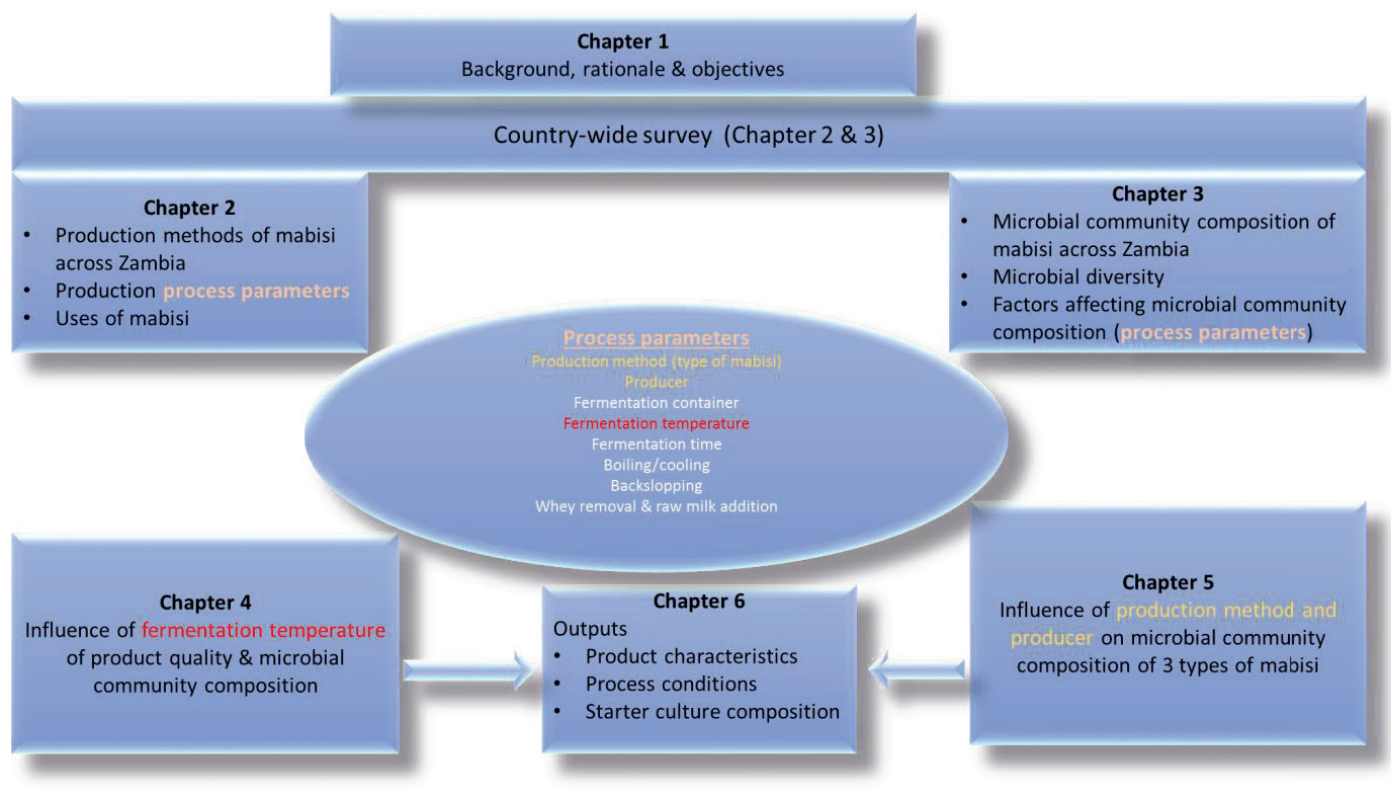

Fig. 3. The conceptual framework of the thesis chapters.

\subsection{Outline of the thesis}

This thesis has six (6) chapters: chapter 1 gives the general introduction and background on mabisi and other traditionally fermented milk products. It describes the problem, rationale and states the objectives of the study. Chapter $\mathbf{2}$ describes in detail, the indigenous knowledge on different mabisi production methods practiced throughout Zambia, which was collected through a country-wide survey. In addition, the critical production process parameters are identified and the uses of mabisi are explained. Chapter $\mathbf{3}$ elucidates the microbial community composition of mabisi samples collected during the country-wide survey and highlights the factors that causes variation in microbial composition and diversity. Then fermentation temperature, which is one of the key production process parameters identified in chapter 2 is investigated in chapter $\mathbf{4}$. This chapter, shows that temperature has large bearing on the quality (consistency) of mabisi produced and it influences the microbial composition of certain types of mabisi (production method). Thereafter, the factors that influence microbial community composition of mabisi samples identified in the chapter 3 survey, are investigated in chapter 5. It demonstrates that both the producer and the production method of mabisi over several production cycles exerts sufficient selection pressure on its microbial communities, which leads to changes in the outcome of the microbial community structure. And lastly, chapter $\mathbf{6}$ synthesises the study findings and gives perspectives on future research and applications of the findings. 



\section{Chapter 2}

\section{The art of mabisi production: a traditional fermented milk.}

Himoonga Bernard Moonga1,2,3,4, Sijmen E. Schoustra ${ }^{3,4}$, Anita R. Linnemann², Elias Kuntashula ${ }^{5}$, John Shindano ${ }^{4}$ and Eddy J. Smid ${ }^{*}$

Published in Plos ONE (2019)

\section{Affiliation:}

1. Laboratory of Food Microbiology, Wageningen University, Wageningen, The Netherlands

2. Laboratory of Food Quality \& Design, Wageningen University, Wageningen, The Netherlands

3. Laboratory of Genetics, Wageningen University, Wageningen, The Netherlands

4. Department of Food Science \& Nutrition, School of Agricultural Sciences, University of Zambia, Lusaka, Zambia

5. Department of Agricultural Economics \& Extension, School of Agricultural Sciences, University of Zambia, Lusaka, Zambia 


\section{Abstract}

Fermented dairy products can be rich in beneficial microbes and one such product with potential is mabisi. Mabisi is a traditional fermented milk product from Zambia made through spontaneous fermentation of raw milk at ambient temperature using a calabash (gourd), clay pot, plastic or metal container. The fermentation takes about 48 hours after which the product is stirred and ready for consumption. This study was aimed at determining the types of production methods of mabisi and identifying the critical production process parameters. A survey was conducted using interviews and observations to determine the existing production practices/technologies and to capture indigenous knowledge on mabisi production in nine provinces of Zambia. We found seven different production methods which we coined; tonga, thick-tonga, illa, barotse, backslopping, cooked and creamy types. Interestingly, the tonga-type mabisi was produced throughout the country by different ethnic groups. The main process parameters were found to be fermentation time and temperature, type of containers, presence/absence of backslopping, agitation, heating and cooling, removal of whey and addition of raw milk. And further found that mabisi is a versatile product consumed with a wide variety of foods. This basic information is crucial for production process optimisation and microbial communities dynamics studies. 


\section{Introduction}

Most fermented food products found on the market originate from traditional recipes that have evolved and have been optimised over the years. A good example is cheese of which the production can be traced back to $5,500 \mathrm{BC}$ in present day Poland, where filtering clay pots were found with remnants of milk fat, $[7,42]$. The production of fermented milk products has from that time evolved in different regions and countries in Europe leading to various specific types of cheeses for example Parmesan cheese from Parma in Italy, Swiss cheese from Switzerland, Gouda from The Netherlands, Brie from France and Cheddar from the UK.

Sub-Sahara Africa is not renowned for cheese production and does not have famous indigenous fermented milk products such as yoghurt or kefir. However, there are definitely traditional popular fermented milk products in most countries, which are still produced using traditional methods at household level and for which production processes have not or scarcely been documented. An example is mabisi, a traditional fermented milk product from Zambia, which according to Schoustra, Kasase [24] is made by spontaneous fermentation of raw milk at room temperature for 48 hours in a calabash (gourd) then stirred/sieved before consumption.

Zambia is a vast country with 10 provinces and 73 tribes (ethnic groups). It has a total cattle population of $4,984,909$ out of which $70 \%$ are under traditional (small-scale) production system while $30 \%$ are under a commercial (large-scale) production system [33]. The total estimated annual milk production is $1,179,000,000$ litres [33] but less than $50 \%$ is processed by dairy companies, [26, 27]. The rest is sold through informal channels either as fresh raw milk or as mabisi which is also referred to as 'sour milk' and of which the total annual production is also unknown. The low commercial milk processing levels are mainly because most dairy companies are situated in urban areas (large cities). In contrast, the highest cattle and milk production is in the rural areas, where the road infrastructure is poor and access to cold storage facilities is limited due to erratic or inadequate power supply. Mabisi production is one way of preserving milk in these areas. Moreover, it is a popular product because of its taste and other organoleptic properties, and is mainly consumed as a beverage or with the staple maize meal thick porridge.

Other studies on traditional fermented milk in Africa have revealed products such as amasi in Zimbabwe and in the Republic of South Africa (RSA) [20], Omashikwa in Namibia [18, 19], Mursik in Kenya [14], Kivuguto in Rwanda [13], Nunu in Ghana [12] and Aewsso in Ethiopia [15]. Most of these studies were conducted in specific regions or parts of those countries where the products are mostly produced and consumed. These studies highlight that for most traditional products, many variations of processing exist and this processing relies on traditional knowledge, for which in some cases modern standardized procedures have been developed.

Mabisi is traditionally produced in the western, central and southern parts of Zambia, where a larger proportion of cattle raised under the traditional production system are located. However, with internal migration and promotion of dairy production by the Government and non-governmental organisations (NGOs) in other regions, the likelihood that mabisi production has spread to those regions has not been ascertained. The drivers of internal migration have largely been the search for fertile agricultural land in areas with high rainfall (towards the northern regions) as well as employment which lead to mixing of different ethnic groups and exchange of cultural practices. A previous study by Schoustra, Kasase [24] reported that only one production method of mabisi making was practiced in 6 sites located in southern ( 3 sites), central ( 2 sites) and central-north ( 1 site) parts of the country. The study excluded one traditional mabisi production region which is the western part and also a non-traditional mabisi production region, the eastern part of the country. Overall, there is currently limited documentation of the different traditional technologies that are used for producing mabisi.

Therefore, this study aimed at determining and documenting the different mabisi production practices and technologies throughout the country and to analyse how they are influenced by region and ethnicity. The study further elucidates the key processing steps and parameters that are critical to product quality and safety, evaluates the hygiene practices as well as uses of the final product. We envisaged that this comprehensive approach of gathering indigenous knowledge on traditional fermentation practices of milk when added to other regional contributions from the different parts of Africa will give an overall picture of these products for potential improvement and up-scaling of production to the levels of other renowned fermented milk products in the world. 


\section{Material and Methods \\ 2.1 Study area and sampling}

A cross-sectional study was conducted country-wide covering 9 out of 10 provinces of Zambia. Since mabisi is mostly produced in Southern, Western and Central provinces, more districts were sampled in those provinces as shown in table 1. Out of the rest of the other provinces, Eastern province had more districts sampled despite not being a renowned region for producing mabisi but because of its high cattle population. Lusaka and Copperbelt province are more cosmopolitan and urban with the former being the capital city and the latter being a mining region. The selection of the districts was based on information on dairy production activities and cattle population provided by the Ministry of Fisheries and Livestock (MFL) officials as shown in table 1 . Luapula province was excluded due to low cattle population $(21,564)$ compared to rest $[27,33]$.

Table 1. Study sites, cattle population and dairy cooperatives per province

\begin{tabular}{|l|l|l|l|}
\hline Province & $\begin{array}{l}\text { Cattle } \\
\text { population }\end{array}$ & $\begin{array}{l}\text { No. of Dairy } \\
\text { Cooperatives } \\
\text { interviewed }\end{array}$ & Districts sampled \\
\hline Western & 890,288 & 2 & Kaoma, Mongu, Kalabo, Senanga, Sioma, Sesheke \\
\hline Southern & $2,105,890$ & 6 & $\begin{array}{l}\text { Choma, Sinazongwe, Namwala, Kalomo, Zimba, } \\
\text { Monze }\end{array}$ \\
\hline Eastern & 844,839 & 1 & Lundazi, Chipata, Sinda \\
\hline Central & 576,169 & 2 & Chibombo, Mkushi, (Mumbwa, Itezi-tezi)* \\
\hline Copperbelt & 69,616 & 2 & Luanshya, Chingola \\
\hline North-western & 93,508 & 1 & Solwezi, Kabompo, Zambezi \\
\hline Muchinga & 175,801 & 2 & Mpika, Isoka \\
\hline Northern & 79,044 & 1 & Mbala \\
\hline Lusaka & 128,190 & 1 & (Chongwe)* \\
\hline
\end{tabular}

Source for cattle population: Ministry of Fisheries \& Livestock (MFL), 2017

*For districts in brackets, only focus group discussions were conducted.

\subsection{Data collection}

The data were collected using structured questionnaires (S1 Questionnaire) which were administered in one-on-one interviews by the researchers in English and/or local languages that the respondents were most familiar with. At least 30 questionnaires were administered per district and they had several sections which included socio-demographic information, mabisi production methods, processing parameters and hygiene practices. Districts with fewer respondents were combined with proximal districts within the same province. The respondents were selected randomly from a list of livestock farmers in each veterinary camp (VC) within the district that was selected based on recommendations given by the Ministry of Fisheries and Livestock personnel. Districts are divided into VCs for administration purposes. Focus group discussions (FGDs) were conducted with farmer groups of 8-12 people and 1-2 FGDs per district were carried out depending on the number of respondents available. Semi-structured interviews with key informants who included chairpersons of dairy cooperatives, managers of milk collection centres (MCCs) and local Headmen or Chiefs as well as Ministry of Fisheries and Livestock officers at provincial and district level were also carried out using a set of questions (S2 Checklist) on the detailed production process of mabisi, product safety and uses. Data were also collected by observation of production practices and equipment used. In all cases, consent for the interviews was formally requested and granted. In addition, ethical approval from ethical review committees both at the University of Zambia (UNZA) and Wageningen University was granted for this study.

\subsection{Data analysis}

The data from the questionnaires were entered in a datasheet in IBM SSPS statistics version 22 software. Then, the data were analysed using both IBM SSPS statistics 22 and Microsoft excel software for descriptive statistics of mean, percentage as well as correspondence analysis (CA). 


\section{Results}

The main objective of this study was to determine the traditional production practices of mabisi used by local households $(\mathrm{HH})$ and dairy cooperatives. Out of the 537 respondents, $76 \%$ were male and $24 \%$ were female mainly because mabisi is largely produced by the households that own cattle (93\%) which mostly belong to the men. A higher proportion of these $\mathrm{HH}$ were headed by men ( $88 \%)$ and the highest $\mathrm{HH}$ size was between 6-10 (43\%). Most respondents were married (83\%) with the dominant (24\%) age group being between 40-49 years as shown in table 2 .

Table 2. Demographic information of the respondents

\begin{tabular}{|c|c|c|c|c|c|c|c|c|c|c|}
\hline \multirow{2}{*}{$\begin{array}{l}\text { Parameter } \\
\text { Descriptor }\end{array}$} & \multicolumn{2}{|c|}{ Gender } & \multicolumn{4}{|c|}{ Marital status } & \multicolumn{2}{|c|}{$\begin{array}{l}\text { Households } \\
\text { with Cattle }\end{array}$} & \multicolumn{2}{|c|}{$\begin{array}{l}\text { Household } \\
\text { head }\end{array}$} \\
\hline & Male & Female & Single & Married & Divorced & Widow(er) & Yes & No & Male & Female \\
\hline$\%$ & 76 & 24 & 9 & 83 & 2 & 6 & 93 & 7 & 88 & 12 \\
\hline Parameter & \multicolumn{3}{|c|}{ Household size } & \multicolumn{5}{|c|}{ Age (years) } & & \\
\hline Descriptor & $0-6$ & $6-10$ & $>10$ & $<18$ & $18-29$ & $30-39$ & $40-49$ & $50-59$ & $>60$ & \\
\hline$\%$ & 33 & 43 & 24 & 1 & 13 & 21 & 24 & 20 & 21 & \\
\hline
\end{tabular}

\subsection{Mabisi production methods}

This study revealed seven (7) distinct methods of mabisi processing, each yielding a distinct type (Fig. $1)$, which are described in this section.

\subsubsection{Tonga \& thick tonga type}

The production of mabisi begins with milking, the raw milk is milked by hand into a bucket which is either made of plastic or metal. Traditionally, gourds (calabash) with large openings and earthen pots were used for this purpose, $[20,43]$. The raw milk is then sieved mostly using a plastic tea strainer $(64 \%)$, stainless steel strainer $(21 \%)$ or a cloth $(7 \%)$. The plastic tea strainer is the most popular because it is cheap and readily available in most local markets. The raw milk is then poured into a plastic bucket $(21 \%)$ or plastic container with a smaller opening $(56 \%)$, metal can or pot $(12 \%)$, calabash (gourds)(6\%), or an earthen pot (nongo)( $2 \%$ ) covered with a lid and placed in a cool place in the house in most cases ( $91 \%$ ) as shown in Fig 1 . To speed up the fermentation, the container can be put in direct sunlight (3\%) during the day or placed in the kitchen (2\%) especially in the colder months of June and July when ambient temperatures $\left(10-22^{\circ} \mathrm{C}\right)$ are lower. Sometimes, the milk is incubated outside the house in the shade but the FGDs revealed that a cold waterbath may be used during the hot months of September - November $\left(20-30^{\circ} \mathrm{C}\right)$.
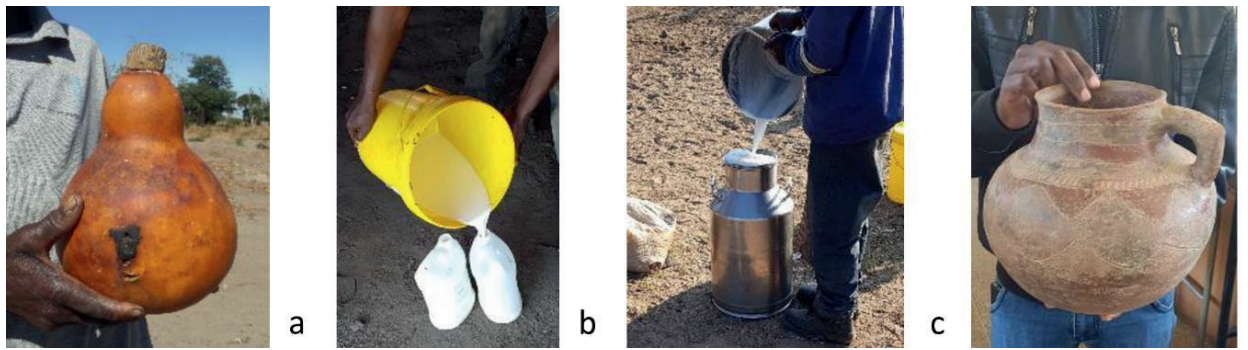
Fig 1. Types of fermentation containers used. These include: a. calabash, b. plastic bucket \& 2.5 litre containers, c. metal container and d. earthen pot.

The container is left to ferment spontaneously for mostly 1-3 days (86\%) but it can actually go up to 7 days depending on the type of mabisi production method. The most common fermentation time was 1 day (30\%) followed by 2 days (26\%) and 3 days (20\%). But this variation in fermentation time was also linked to the prevailing ambient temperatures which are influenced by seasons. For instance, during the cold season (June to July) the fermentation took longer as noted by $93 \%$ of the respondents by an additional 1-2 days. The endpoint of fermentation was mainly noted by the product becoming thick $(55 \%)$, tasting sour $(10 \%)$, formation of whey fraction $(13 \%)$ and lumpiness $(9 \%)$ but other observations included the expansion of container (plastic), formation of gas (bubbles), product turning yellowish on top or simply counting the number of days of fermentation. The frequencies of the key processing parameters mentioned above are summarized in Fig 2.

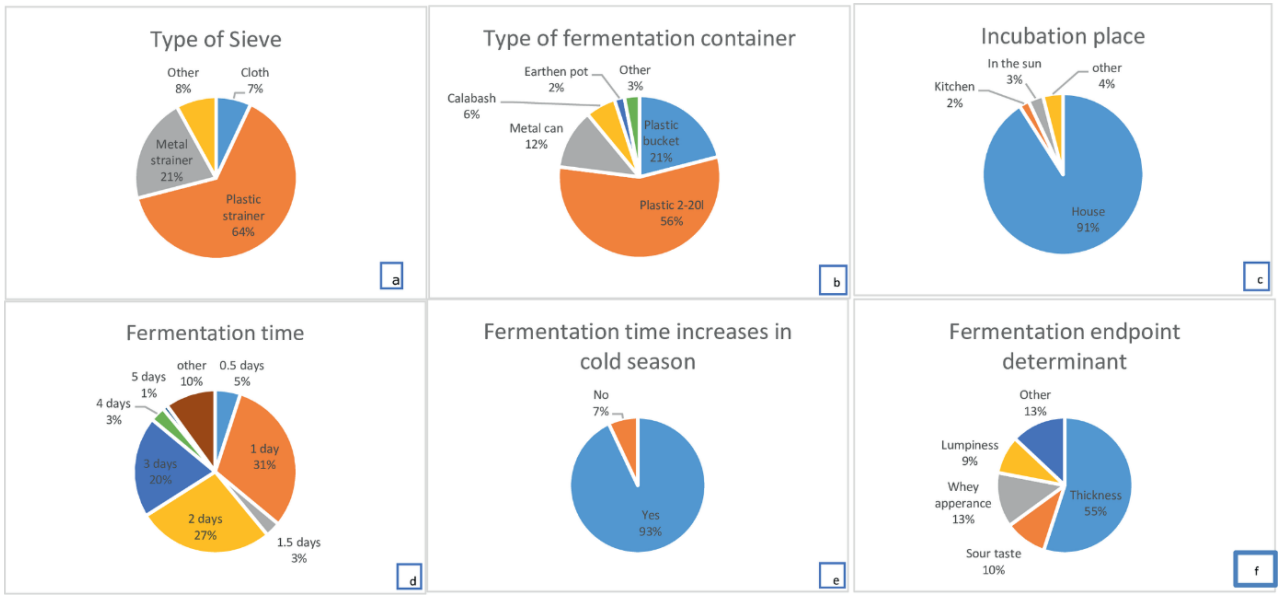

Fig 2. Proportions of key mabisi production process parameters of the respondents' responses. The parameters include the following: a. type of sieve used, b. type of fermentation container, c. incubation place during fermentation, d. period of fermentation (time), e. increase in fermentation time (period) during the cold season, and $\mathrm{f}$. the determinants of the end fermentation.

At the end of fermentation, the product is stirred to make it homogeneous and considered ready for consumption thereafter. This process describes the typical production of "tonga type" mabisi which is illustrated in a flow diagram in Fig 3 (process I). However, there is a variation to this method in the case of high whey content in the final product which is usually undesirable. In that case, after fermentation a portion of the whey is drained off before stirring so that a good thickness and homogeneity is retained in the product. The resulting product is referred to as "thick tonga type" of which the production process is illustrated in Fig 3 (process II). It should be stated that until now, the different types of mabisi were all known as "mabisi" or "sour milk" and it became necessary in this study to differentiate the types by coining new names as can be found in this and the following sections. The term tonga type has been derived from the name of the tribe that mostly associated with this method.

The whey fraction has several uses which include: (i) cooking porridge with maize meal, (ii) making "instant mabisi" by adding it to fresh raw milk which coagulates immediately due to its low $\mathrm{pH}$ and then giving it to children as a drink and finally (iii) feeding it to dogs and pigs. However, in areas with high milk production during the rainy season from December to April such as Southern and Western provinces, the whey is simply discarded. 


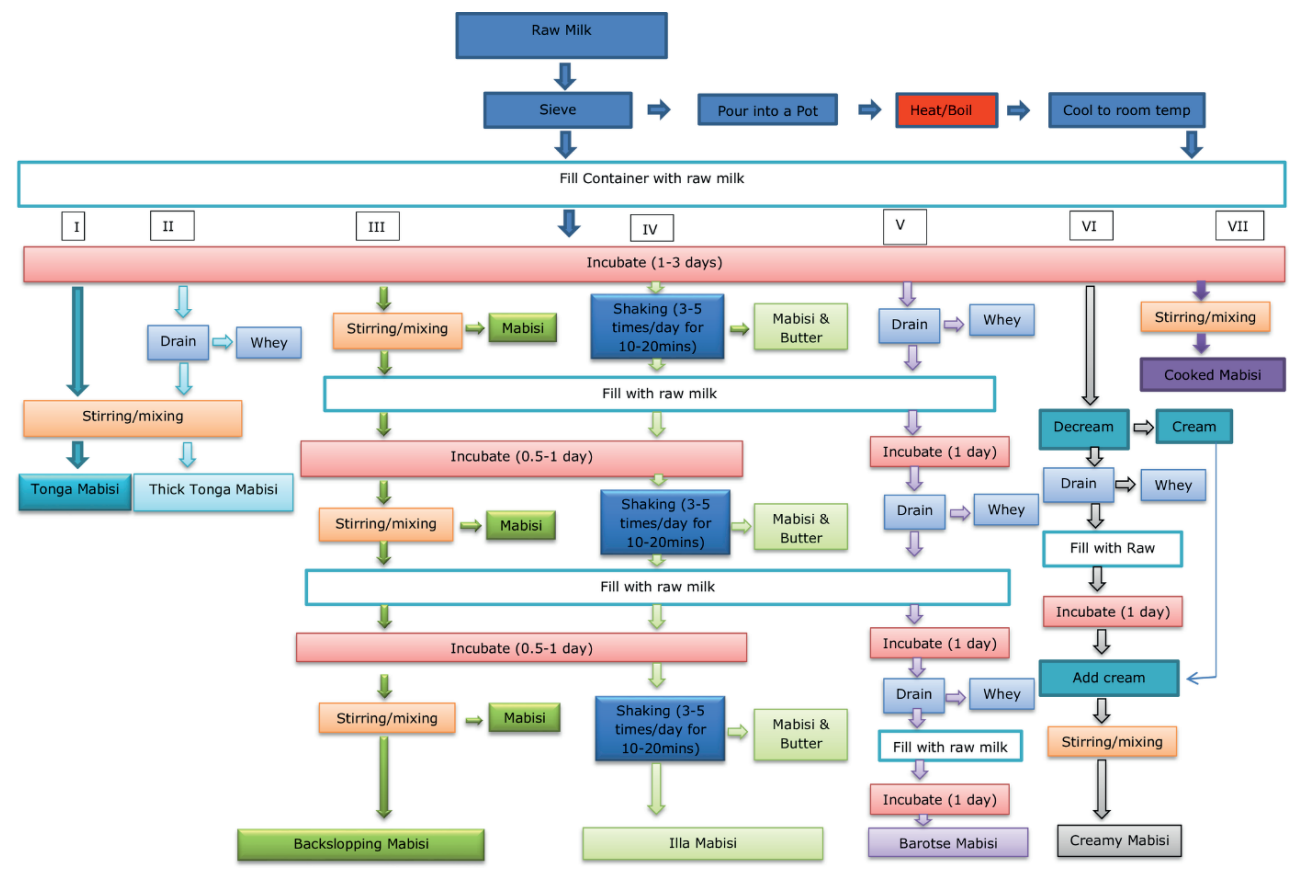

Fig 3. Flow diagram of 7 mabisi production methods. Each method is denoted by a roman numeral from I-VII, which are as follows: I-Tonga, II-Thick tonga, III-Backslopping,IV-Illa, V-Barotse, VI-Creamy and VII- Cooked.

\subsubsection{Creamy thick type}

The production process to make creamy-thick-type of mabisi is illustrated in Fig 3 (process VI). Its production follows the typical tonga-type mabisi production process from raw milk up until the end of fermentation but has a slightly longer fermentation period of usually 2-3 days. Then the cream is removed from the top layer of the product using a spoon and transferred to a separate container such as a cup which is stored in a refrigerator or a cool place. Thereafter, the whey is drained off and the mabisi is allowed to ferment for an additional day after which the cream is added back and mixed with the rest of the product. The final product is creamy and thick, hence the name of the product.

\subsubsection{Cooked type}

This type of mabisi is produced the same way as the typical tonga type except that there is a cooking step after sieving. The milk is heated in a pot until the foam appears on top and boiling begins, then it is removed from the fire or stove and allowed to cool slowly. Thereafter, it is put in the container for fermentation and left for 2-3 days. Finally, it is stirred and ready for consumption as shown in Fig 3 (process VII).

\subsubsection{Backslopping type}

The production process for this type of mabisi is shown in Fig 3 (process III). This follows the steps in the typical tonga type production process up to stirring without any removal of whey. A proportion of the product is removed for consumption but a certain amount is left in the fermentation container as starter culture for the next batch. Since milking is done either once or twice a day, the mabisi for consumption is usually all removed at once in the morning from the fermentation vessel leaving some for the next fermentation. Then fresh raw milk is added and allowed to ferment for half to one day. In some cases, by evening the product is ready and can be consumed for dinner and/or breakfast the following morning. 
The amount removed for consumption depends on the family size and can vary from half of the container to nearly emptying it (approximately 90-95\%). At no time during the production, is whey removed and the mixing tends to be quite vigorous making the product less viscous. There is also a special stirrer called mpeso, which is basically a stick with three branches at one end and the stirring is done by putting it between the hands then rotating it back and forth so that the branched part breaks the lumps in the product. Traditionally, the cycles of backslopping mabisi production can go on for several months especially when milk production is high during the rainy season because the container is always filled to the top. When milk production is low and the container does not get filled leaving a big gap at the top which may result in an unpleasant smell after approximately 10 days due to proteolytic breakdown of the product on the walls of the container. Once this happens, the container is emptied and subsequently, washed after which the production process can start all over again.

\subsubsection{Illa type}

This type of mabisi is similar to the backslopping type but it has a churning or agitation process which produces butter granules as illustrated in Fig 3 (process IV). The process starts the same way as the tonga type, once the raw milk becomes sour after a day, the calabash is shaken back and forth either on a mat on the ground or on the laps of the producer. This task was traditionally done by the elderly men, usually a grandfather or the head of the $\mathrm{HH}$. The calabash is shaken for 5-20 minutes each time for several times in a day. If the shaking starts in the morning the product can be ready at noon and should have been shaken at least 3-5 times. This shaking leads to the formation of butter granules which float on top of the mabisi and are removed with a wooden spoon then placed in a small pot or cup. The mabisi is poured out of the calabash but some of it is left as starter culture for the next batch. The raw milk is then added to the calabash which it given a gentle stir and left to ferment for a few hours. Shaking starts again in the late afternoon, into the evening and the following morning. Around mid-morning, the butter and mabisi are removed and raw milk is added again then the process continues. This process is continuous for up to a year or longer. This method of production was given the name 'Illa type' because its production was dominated by the Illa speaking people.

The butter is washed with water and stored in a small pot or cup in a cool area of the house. It is mostly used for cooking porridge, vegetables, fish and meat but it can also be used as lotion after a short heating and cooling process. Traditionally, the lotion was used by everyone in the $\mathrm{HH}$ but nowadays, it is only used for babies with sensitive skins.

\subsubsection{Barotse type}

This type of mabisi is mainly produced in the Western province of Zambia (formerly, known as 'Barotseland' and hence the name of the product, 'barotse type') and illustrated in Fig 3 (process V). It is made in a calabash or plastic container with a small opening on top. The raw milk is placed in a calabash after sieving and left to ferment for 2-3 days until there is clear whey separation. The calabash has a draining hole at the bottom with a plug which is removed to drain the whey and subsequently, plugged back. Once all the whey has been drained, fresh raw milk is added to the calabash without stirring and the lid is closed. The product is left to ferment for a day, after which the draining plug is removed to drain off the newly formed whey. The drain plug is plugged back and fresh raw milk is added again and allowed to ferment for another day. The whey is drained for a third time and fresh raw milk is added again and fermented for another day. Usually at the fourth time of whey draining, there tends to be little or no whey to drain which signifies the end of the process. The resulting product is shaken vigorously and poured out into a bucket or pot. This product is usually very acidic and very thick like a cottage cheese and is called "mafi". The end point of production differs from producer to producer with some draining the whey only twice whereas others drain several times until there is no more whey being produced which can be up to 4-5 times. This also leads to a slight variation in the thickness of the product. The product is generally called "mabisi yatemile" which means sour milk when it is not as thick as "mafi". If the product is too thick or too sour, fresh raw milk is added to it and mixed and then it can be consumed. When using a plastic container for fermentation, there is no drain plug at the bottom of the container. So the draining is done by making a small hole through the curd using a thin long stick but usually a fresh grass straw is used and the container is tilted to allow the whey to drain out through the opening in the curd at the top of the container. These containers have a 2.5, 5 and 20 litre capacity. Whey that is removed from the barotse-type mabisi is usually feed to the dogs or simply discarded. During the periods of low milk production, the milk will be added to a container daily and allowed to 
ferment simultaneously until it is full and that is when the whey is drained and the process continues as described above.

\subsubsection{Other practices of coagulating milk}

Also other practices were found in Zambia that involve milk coagulation without a fermentation step and strictly speaking cannot be called mabisi. These include adding lemon juice to fresh raw milk which causes the milk to coagulate due to the lowering of the $\mathrm{pH}$ of milk to less than 4.6 as a result of the citric acid in the lemon juice. This practice was not only common among herd's men and boys who coagulated the milk in the bush as a quick meal/snack while looking after the cattle but also in areas where mabisi production was not so popular such as parts of Eastern province. Raw milk is also coagulated by addition of local fruits such as baobab fruit pulp powder to make a product called chivalavati (a product similar to Mutandabota of Zimbabwe [44]), fruit pulp from tamarind (busiika) and nkula(nchenje), the bark of the mukololo tree as well as juice extracted from the roots of a tree called 'kabodo'. These practices were common in Southern province.

\subsection{Distribution of the mabisi production methods throughout Zambia}

The overall proportions of the most frequently used production methods among the respondents are shown in Fig 4 with the tonga type being the most popular followed by barotse type, then backslopping type, with thick-tonga type being fourth and the rest accounting for less than $5 \%$ each. The tonga type was produced in all provinces of the country by all the different tribes interviewed but the barotse type was mostly popular in Western province, parts of Southern, Central, Copperbelt, North-western and Muchinga provinces. In Western province, this was practiced in all the districts visited mostly by the Lozi and Nkoya people. Backslopping was widely practiced in Southern, Western and Central provinces but was less popular in Eastern, Muchinga and Copperbelt provinces. The thick-tonga type was found in all provinces studied except for Northern province. The illa type was mainly practiced in Southern and Central provinces mostly among the Illa and Tonga people of Namwala, Choma, Monze and Itezi-tezi districts but it was also practiced to a lesser extent in Western province. The creamy type was exclusively practised on the Copperbelt province (Luanshya district) by different tribes. And lastly, cooked type was practiced in Central (Mkushi district) Western (Kalabo, Kaoma and Sioma districts) and Southern (Monze, Zimba and Sinazongwe districts) provinces by Lala, Lozi/Luvale and Tonga people, respectively. 


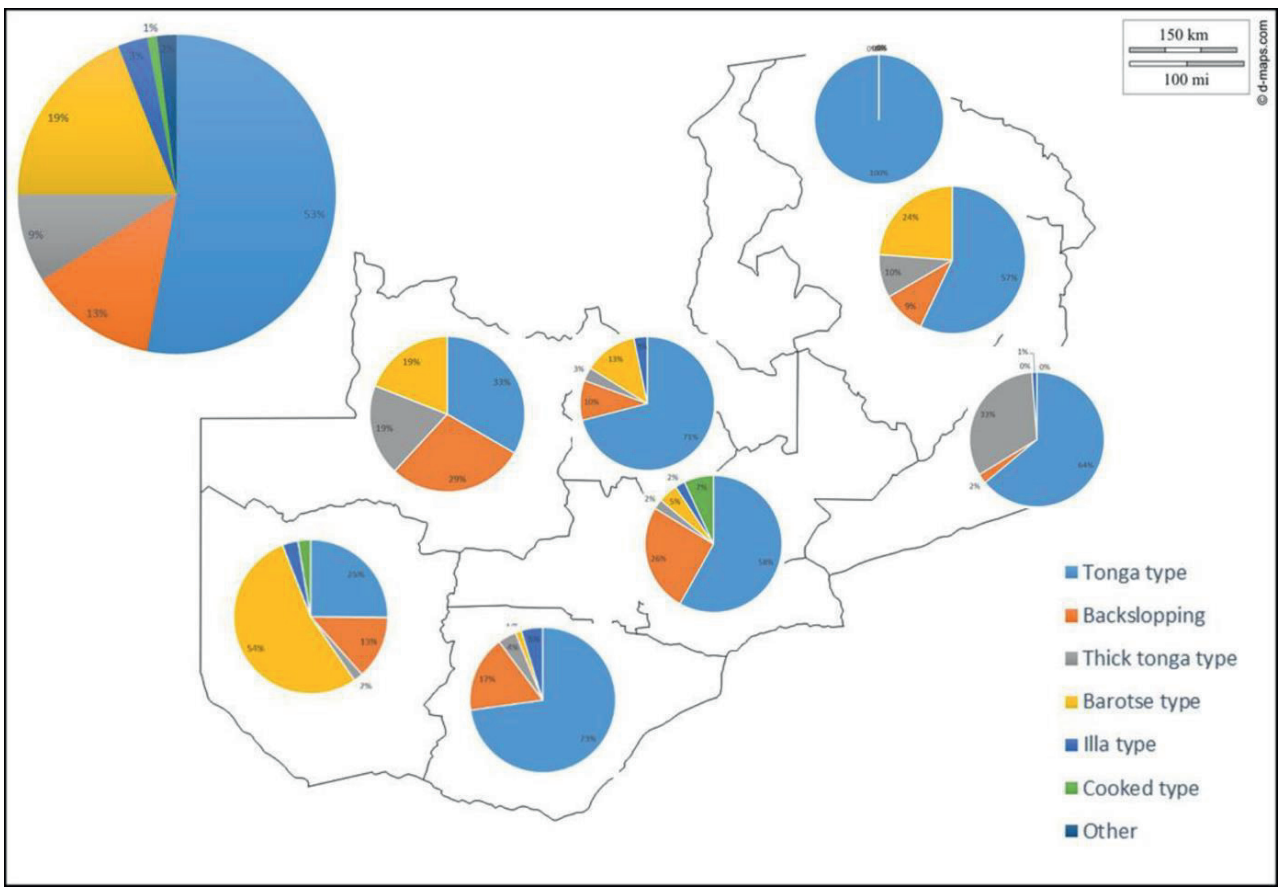

Fig 4. Regional distribution of different mabisi production methods. The large pie chart outside the map shows the overall proportion of the production methods for the country whereas each of the ones inside map shows the regional distribution. (Blank map courtesy of d-maps.com)

\subsection{Distribution of tribes (ethnic groups) that produced mabisi}

There are a total of 73 tribes in Zambia but the respondents $(n=532)$ from this survey were only drawn from 22 tribes as depicted in Fig 5 . The most predominant tribe that was involved in mabisi production were Tongas followed by Lozis and these are mostly found in the Southern and Western provinces of Zambia, respectively. The Tongas were found in all the provinces but the Lozis were mainly found in Western province. The former were found all over the country due to migration in search of grazing land as well as better agricultural land for crop production in high rainfall regions. The tribes that have a tradition of making mabisi are generally cattle keepers and these include: Tonga, Lozi, Illa, Lenje, Nkoya, Namwanga and Mambwe and mainly originate from Southern, Western, Central and Muchinga provinces. However, despite some tribes from Eastern province also raring cattle, only some Tumbuka and Ngoni people were associated with mabisi production traditionally. Copperbelt province had the most diversity in tribes because it is a mining area which attracts peoples from different regions. 


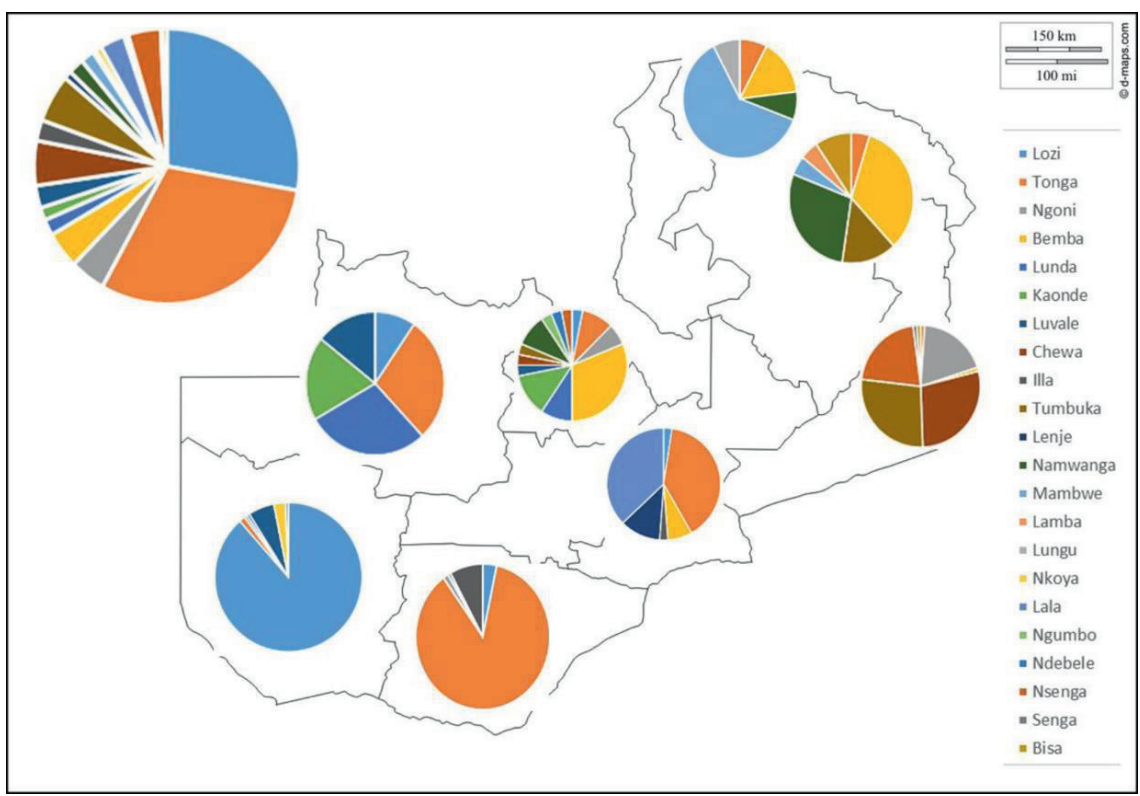

Fig 5. Distribution of proportion of mabisi producing respondents' tribes (ethnic groups). The overall proportion is shown in the large pie chart outside the map and regional distribution are shown inside in the map. (Blank map courtesy of d-maps.com)

\subsection{Relationship between production practices and ethnic groups}

The association between production practices and ethnic groups was analysed using correspondence analysis (CA) which shows that about 9 tribes clustering around tonga type mabisi in Fig 6 . Tonga type is different from the barotse type as they are on opposite ends of the first dimension but tonga type with whey removed (thick tonga type) is closer to backslopping, illa and cooked types. The barotse type is strongly associated with Lozi, Luvale and Lunda tribes while the cooked type is associated with the Lala tribe of central province. The tonga type is associated with the Tonga, Bemba, Mambwe, Kaonde, Ngoni and Nkoya tribes. Illa type is associated with the Illa tribe. The second dimension shows that illa type is different from the rest and Ndebele tribe is also more separated from the rest. 

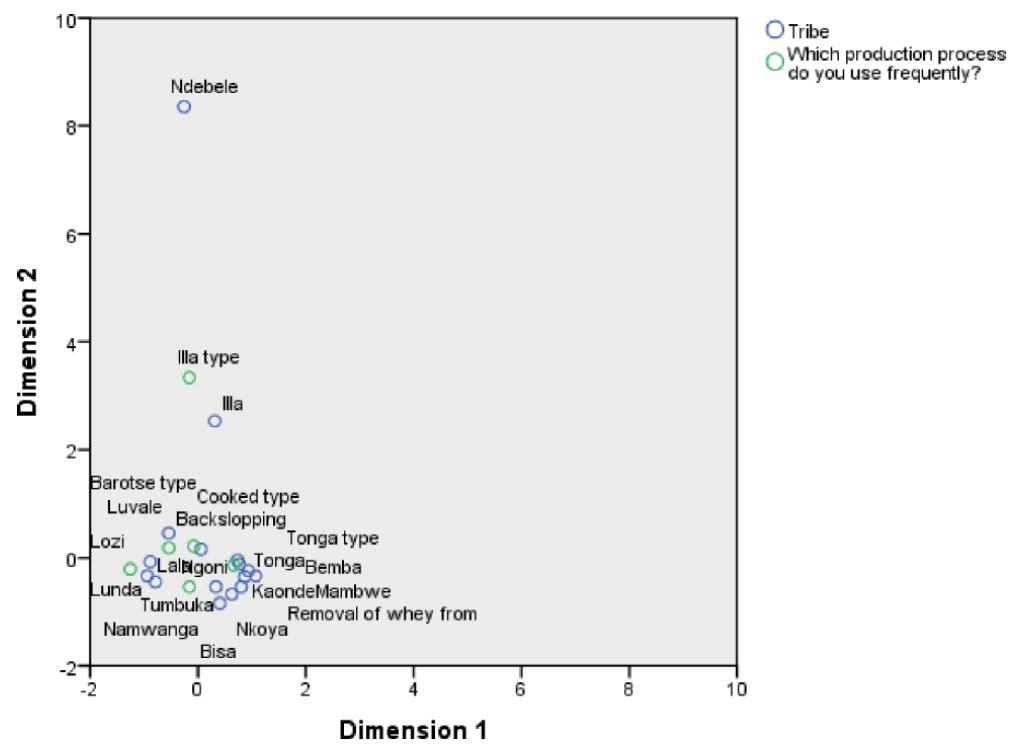

Which production process
do you use frequently?

Fig 6. Correspondence analysis (CA) of production practices and tribes (ethnic groups). The Fig shows the tribes that practice a certain production method are grouped around it. The production methods in this Fig are; tonga, thick tonga (Removal of whey), cooked, illa and barotse types whereas the tribes are listed in Fig 5.

\subsection{Relationship between production practices and geographic location}

The association between the production practices and geographic location was also examined using CA and it shows that tonga type and barotse type are different and with the highest degree of differentiation on the first dimension as shown in Fig 7. Tonga type is closely associated with whey removed (thick tonga type), backslopping and illa type as well as several provinces namely: Southern, Copperbelt, Northern, Muchanga and Eastern provinces. Barotse type was associated with Western provinces. On the second dimension, the cooked type was furthest away from the rest and so was Central province from the other provinces but the two were closely associated. 


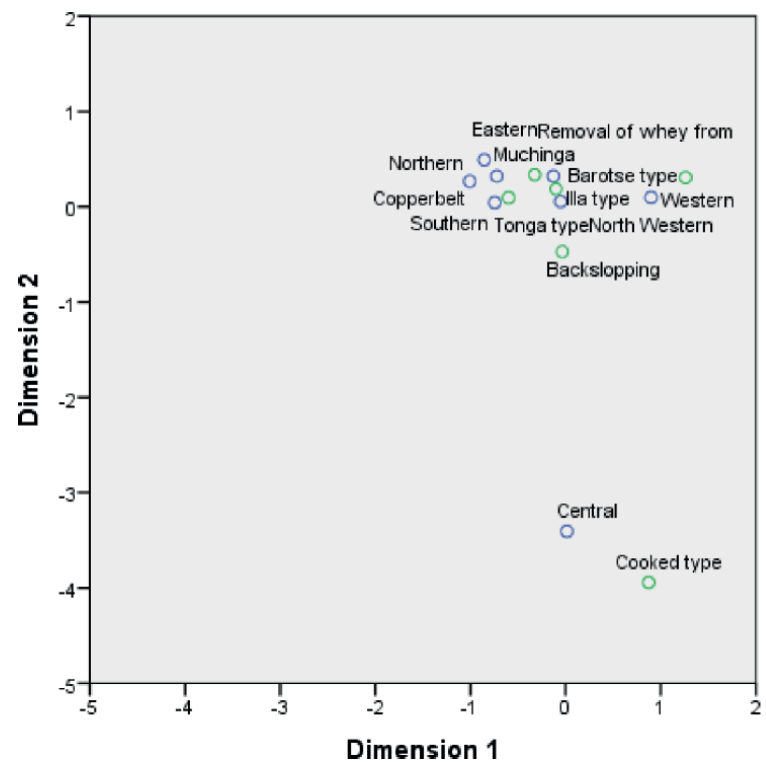

OProvince

Which production process

do you use frequently?

Fig 7. Correspondence analysis of production practices and geographic location. The Fig shows provinces grouped around the production methods mostly practiced in their regions.

\subsection{Relationship between production practices and fermentation time}

Fermentation time is an important process parameter in mabisi production and its association with production practices was analysed with CA. The results of CA show that barotse and tonga types are furthest from each other on the first dimension with the former closely associated with fermentation times of 4 and 5 days whereas the latter is associated with 1 and 1.5 days (Fig 8). Cooked type is associated with 3 days fermentation time. This can be explained by the fact that this production-type involves a boiling process which kills the initial microbiota and therefore the fermentation takes longer incubation times. Dimension 2 shows that illa type is less associated with the rest of the other production practices but is closely associated with the fermentation time of half a day. 


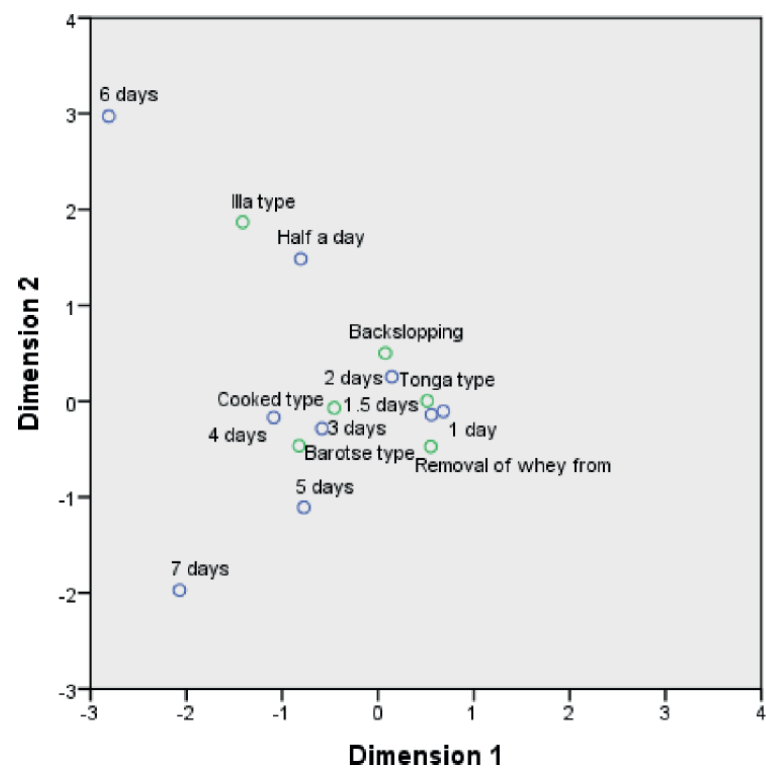

\section{OFermentation time}

Which production process

do you use frequently?

Fig 8. Correspondence analysis of production practices and fermentation time. The Fig shows the fermentation time associated with the production methods.

\subsection{Relationship between production practices and type of fermentation}

\section{container}

The type of fermentation container (shown in Fig 1) is another important process parameter and the association with production practices was also analysed with CA as shown in Fig 9. We found that tonga type mabisi is associated with plastic bucket and earthen pot while the plastic container with a small opening at the top is associated with the barotse, cooked and backslopping types. The illa type is closely associated with the calabash. The metal container is furthest apart from the rest but only closest to the whey removal (thick tonga type) as shown on dimension 2. 


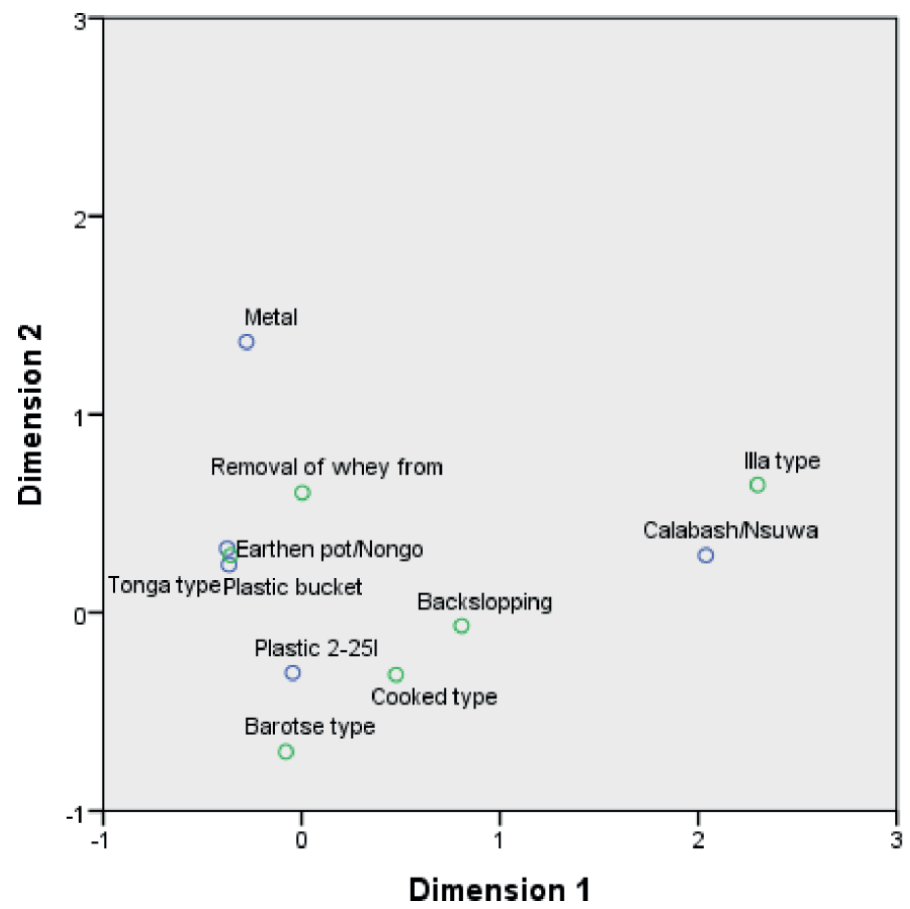

Type of container used Which production process

do you use frequently?

Fig 9. Correspondence analysis of production practices and fermentation container. The Fig shows the type of fermentation container linked to a particular mabisi production method.

\subsection{Hygiene practices}

Mabisi is made using different types of containers which include: calabash, plastic buckets, metal cans/pots and earthen pots. Since these containers are made from different types of material, the cleaning method will have different effects on each container. Ninety four percent (94\%) of the respondents reported that they washed their containers at the end of mabisi production depending on the type of production method used. Out of these, the highest proportion of up to $48 \%$ washed their containers with water only, out of which $26 \%$ used hot water, $16 \%$ used warm water and $6 \%$ used cold water as shown in Fig 10. The total proportion of the producers that used detergent to wash their container was $39 \%$ with $17 \%$ of them using hot water, $15 \%$ using warm water and $7 \%$ using cold water. From the remainder, $3 \%$ used water with sand, $1 \%$ used water with ash, $2 \%$ used water with maize meal to wash their containers. These different ways of cleaning the fermentation container are likely to have different effects on the surface of the container which might lead to the formation of biofilms in some cases, [45]. With the fermentation mostly done in the same container and with over half of the producers only washing their containers with water, there is a high likelihood of biofilm formation in most of these containers which eventually play a part in subsequent fermentations as well as quality and safety of the final product. The main reason for some of the respondents not to use detergent to wash their containers was because of residual odours of the detergent in the product which was regarded as extremely undesirable. 


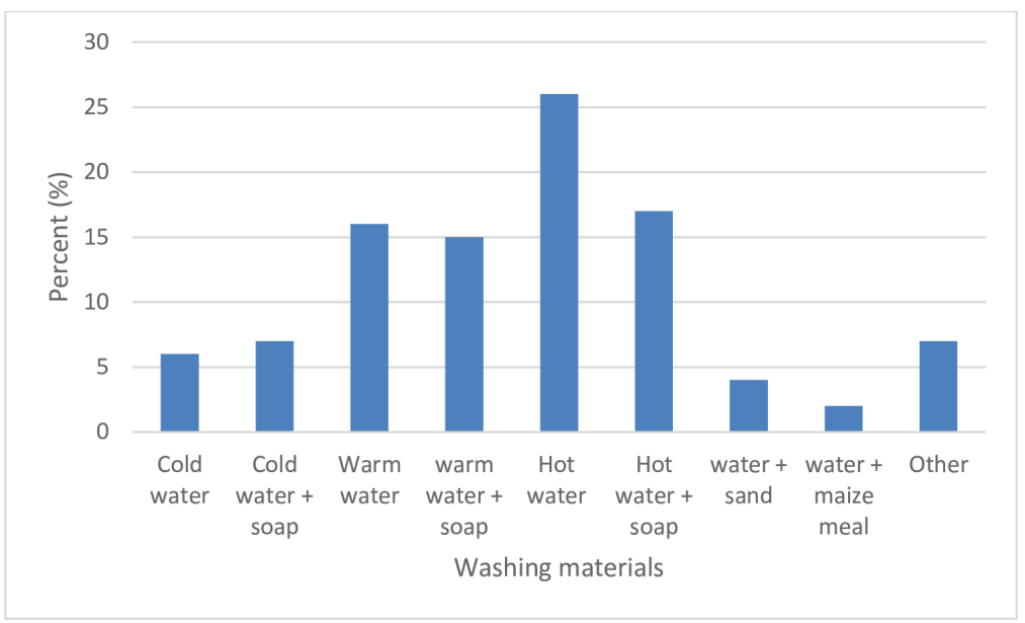

Fig 10. Washing practices of fermentation containers and their proportionate use.

\subsection{Uses of mabisi}

Mabisi is mostly consumed directly by drinking or mixed with a thick or light maize porridge. The thick maize porridge locally called 'nshima' is a staple food and can also be made from other cereal crops as well such as sorghum and millet or in some cases a blend of maize and cassava meal. This thick porridge is eaten with mabisi for breakfast and lunch or as a dessert after lunch or dinner. The light porridge with mabisi is mostly eaten for breakfast especially by the children. Mabisi can also be eaten with boiled grains of sorghum, millet, whole grain maize (magwaza), dehulled maize (samp) or grits (masembe for cooking porridge). Other cereals include rice and pasta but the latter is only consumed in a few urban areas. Root and tuber crops such as cassava, sweet potato and irish potato can be boiled and eaten with mabisi as a main meal. Mabisi is also consumed with both local and exotic fruits as well as different types of pumpkins. Furthermore, it is also consumed with baked products, cooked legumes and used during cooking of dishes such as meat, fish and vegetables. The various types foods that are consumed with mabisi are shown in table 3.

Table 3. Foods consumed with mabisi

\begin{tabular}{|l|l|}
\hline Product category & Type \\
\hline Cereals & Maize porridge from meal or grits (chelee, Illya)* \\
& Sorghum/millet porridge (chelee)* \\
& Boiled immature sorghum grains called 'mututu' (muselu)* \\
& Boiled whole maize grain (titili, dwobo, chibobole, magwaza)* \\
& Dehulled maize (samp, musohya)* \\
& Boiled fresh maize cob \\
& Roasted maize grains called 'chiwaya' \\
& Rice \\
& Pasta \\
& Fermented cereal drink called 'chibwantu' \\
& Opaque beer (sibamu)* \\
\hline Fruits & $\begin{array}{l}\text { Pawpaw, boiled unripe mango, avocado, baobab powder (chivalavati, } \\
\text { mulondo)*, tamarind (mpalwe)*, masuku (chimvwe, chilimbu)*, banana, ripe } \\
\text { mango }\end{array}$ \\
\hline Pumpkins & $\begin{array}{l}\text { Yellow \& green pumpkins } \\
\text { Green pumpkin with boiled fresh maize (chidyobo)* }\end{array}$ \\
\hline Baked confectionery & $\begin{array}{l}\text { Bread \& buns (chikandi)* } \\
\text { Scones }\end{array}$ \\
\hline
\end{tabular}




\begin{tabular}{|l|l|}
\hline Tubers & Boiled cassava, sweet potatoes, \& irish potatoes \\
\hline Legumes & Beans \\
& Beans with rice \\
& Roasted groundnuts called 'musuka' \\
\hline Cooked side dishes & $\begin{array}{l}\text { Beef } \\
\text { Fish (tilapia, tigerfish) } \\
\text { Vegetables }\end{array}$ \\
\hline
\end{tabular}

*Noted the local name of the product eaten with mabisi is indicated in brackets

\section{Discussion and Conclusion}

This study shows that there are at least seven different methods of producing mabisi in Zambia. This complements the study by Schoustra, Kasase [24], who only reported on one prevailing production method, which we have now coined as tonga type mabisi. This tonga type is the most popular amongst all ethnic groups and found throughout the country which suggests that it is acceptable for a broad range of consumers. The production process of the thick tonga type shows that it only differs from the tonga type by the step of whey removal which in turn produces thicker product and suggests that the two products are quite similar in characteristics. The creamy type has a skimming step in addition to whey removal and generally produces a thick creamy product. The latter production method has some similarities with amasi of Zimbabwe which is also produced by a method that involves whey removal and addition of fresh cream to the product producing a thick product, [21].

The cooked type involves a heating and cooling step before fermentation and was the least practiced. However, it was widely practiced in Mkushi district of Central province among the Lalas who reported that they learnt the technique of mabisi making from the Tongas that migrated there from the early 1990s though the latter did not heat their raw milk but made the tonga and backslopping types instead. This practice can be attributed to the public health messages from the Ministry of Health that advocates boiling raw milk before consumption as a way of preventing foodborne infections from raw milk consumption. This practice was also observed in Monze and Sinazongwe districts but to a much lesser extent. A similar product called "mursik" from Kenya has been reported by Nduko, Matofari [14] although, the other one called "amabere amaruranu" involves both boiling and backslopping. The Illa type and backslopping type are similar as they both involve backslopping steps and several fermentation cycles though the former also has an additional agitation step which leads to the production of butter. This method produces a buttermilk-like product which might be similar to aewsso from Ethiopia [15], kivuguto of Rwanda [13] and nunu of Ghana, [12]. The barotse type involves the repeated alternate removal of whey and the addition of raw milk which eventually produces a very thick and sour product which is sometimes referred to as "mafi". This name is also used to refer to a type of traditional fermented milk product from South Africa $[20,46]$. Further, the practice of continuously adding daily batches of raw milk to a container until it is full and removing the whey thereafter is reported for a product which is also called "mabisi" from Northern Namibia, $[18,47]$. This region is close to the Western province of Zambia where the barotse type is most popular. One explanation could be migration of tribes during the Mfecani wars in the time of King Shaka of the Zulu people of present day South Africa in the 1820s [48]. Some displaced tribes settled in parts of Zimbabwe, Botswana, Namibia, Zambia, Malawi and Mozambique. In Zambia for example, the Makololo tribe crossed the Zambezi river and settled in present day Western province [49] while the Ngoni went east and settled in Eastern province [48] but this production practice is not common there. A product called "omashikwa" from Namibia is reported [18, $19]$ to be made by fermenting raw milk with a root which can be similar to the other methods of coagulating milk reported in this study where roots and tree barks were used.

This study also suggests that migration of ethnic tribes can spread production practices (technology transfer) and consumption of certain foods to other regions. For example, the Tongas migrated to Central (Mkushi) and Muchinga (Mpika) provinces and most likely introduced the tonga type mabisi. However, some production practices can also evolve as a result of this as was observed with cooked type. There can also be barriers to adopting other production practices such as Illa and backslopping that were also practiced by the tongas which may be related to strong consumer preferences. This is an area that requires further investigation. Furthermore, our study also suggests that barotse type mabisi only spread to parts of Southern and Central province that are proximal to Western province which may suggest that the Lozis migrated less or adapted quickly to the tonga type when they did. The study also points out 
that the Lalas and Bembas (from the Northern parts) were more receptive to mabisi than the Chewas, Nsenga, Senga (from Eastern Province). However, a comprehensive study needs to be undertaken to ascertain these dynamics.

The most important mabisi production parameters observed were the type of containers, fermentation time and temperature, backslopping, agitation, removal of whey, addition of raw milk, heating and cooling, and washing method. All these have a bearing on the quality of the final product which need further investigation. The use of calabashes and earthen pots for fermentation of milk have been reported in other studies [14, 20,43,50] but an increased use of plastic and metal containers has been observed in this study largely due to their robustness and availability though their effects on the quality of final product are not known. Fermentation times ranging between 1 and 2 days have been reported in some traditional fermented dairy products $[21,24]$. This study shows that fermentation time is a function of temperature as clearly shown with increasing fermentation times by 1 to 2 days during the cold season. The effect of fermentation time and temperature on the quality of mabisi is largely unknown.

Mabisi is produced through a spontaneous fermentation process which involves microbes from the raw milk, containers and immediate environment. These microbes repeatedly produce mabisi in different locations using a variety of production methods whose microbial profiles are essentially unknown. In case of backslopping, there is a transfer of the microorganisms involved from one batch to another and this has been reported in different fermented products, $[40,51]$. However, the optimal transfer ratio for backslopping in mabisi production and its effect on product quality is not known. The removal of whey reduces the liquid fraction in the product and leads to the production of highly viscous product such as the thick tonga and barotse mabisi types. The whey contains lactose which is the energy source for the microbes and may influence the microbial composition and quality of the product. This however requires a comprehensive investigation to determine the type of bacteria present which can later be used to develop starter cultures for industrial mabisi production. Food safety is of paramount importance especially for a product that is produced by spontaneous fermentation of raw milk which in some cases is produced under poor hygiene conditions. Therefore, it is imperative that the safety of mabisi needs to be assessed.

In conclusion, seven different methods of producing mabisi were found throughout Zambia. The main process parameters were found to be fermentation time and temperature, type of containers, presence or absence of backslopping, agitation, heating and cooling, removal of whey and addition of raw milk, and washing method. Ethnicity, culture and location have a bearing on the type of production method used, highlighting the effect of regional migration and adopting new foods and food production methods. Mabisi is quite versatile in terms of usage as it can be consumed with a wide variety of foods. However, further studies need to be conducted on microbial composition of the different types of mabisi, production process optimisation, starter culture development, product quality and safety, and consumer perception and preferences. This study shows diverse traditional technologies for fermented milk, which are similar with certain products from other parts of Africa and this underpins the importance of carrying out systematic research in product development and up-scaling production of these products. These products have the potential to reduce food and nutrition insecurity and improve livelihoods of local communities. With more research, mabisi has the potential grow in statute on the African continent and beyond to the level of cheese in the world. 


\section{Chapter 3}

\section{Microbial community composition and diversity of mabisi, a traditionally fermented milk.}

Himoonga Bernard Moonga1,2,3,4, Sijmen E. Schoustra ${ }^{3,4}$, Joost van den Heuvel ${ }^{3}$, Anita R. Linnemann ${ }^{2}$, Md $^{2}$ Sainur Samad ${ }^{5}$, John Shindano ${ }^{4}$ and Eddy J. Smid ${ }^{1}$

Affiliations:

1. Laboratory of Food Microbiology, Wageningen University and Research, Wageningen, The Netherlands

2. Food Quality and Design, Wageningen University and Research, Wageningen, The Netherlands

3. Laboratory of Genetics, Wageningen University and Research, Wageningen, The Netherlands

4. Department of Food Science \& Nutrition, School of Agricultural Sciences, University of Zambia, Lusaka, Zambia

5. Department of Microbial Ecology, Netherlands Institute of Ecology, Wageningen, The Netherlands 


\section{Abstract}

Many traditionally fermented milk products such as mabisi involve spontaneous fermentation, which can result in bacterial community composition variation due to selection pressure. The aim of this study was to determine the composition of bacterial communities in the different types of mabisi produced across Zambia and identify the factors that influence their composition. Samples of mabisi were collected across the country and analysed for $\mathrm{pH}$ and bacterial communities using $16 \mathrm{~S}$ rRNA amplicon sequencing. We found that the mean $\mathrm{pH}$ of mabisi was $4.08 \pm 0.51$ with samples from Western province having the lowest mean $\mathrm{pH}$ of $3.66 \pm 0.42$ and those from Eastern province having the highest $(\mathrm{pH}=4.66 \pm 0.52)$. The bacterial community composition was dominated by members of two phyla, Firmicutes and Proteobacteria, from which the top 10 most abundant genera were Lactococcus, Lactobacillus, Streptococcus, Enterobacter, Citrobacter, Klebsiella, Kluyvera, Buttiauxella, Aeromonas and Acinetobacter. The most dominant genus was Lactococcus, which was present in all types of mabisi produced from all regions. The mabisi products from traditional mabisi production regions (TMPRs) were dominated by lactic acid bacteria (LAB) whereas products from non-TMPRs were dominated by non-LAB species with Lactococcus as the main driver of the fermentation process. Tonga mabisi had the most complex and diverse bacterial community composition and was the most popular type of mabisi produced in non-TMPRs compared to the other types, which included barotse, backslopping, creamy and thicktonga mabisi. Other factors that influenced bacterial community composition were type of fermentation container, type of producer, fermentation duration and $\mathrm{pH}$. This information provides a basis for starter culture development and product optimisation. 


\section{Introduction}

Fermented milk products are popular around the world and are important for delivering nutrients, for providing beneficial microbes to promote a balanced gut microbiota and for imparting desirable organoleptic properties on foods $[28,29,52]$. The common fermented dairy products on the world market include cheese, yoghurt, kefir and many others. Most of these products derive their recipes from artisanal or traditional processes that involve spontaneous fermentation by complex microbial communities [1]. In Africa, many traditional fermented (dairy) products made at household level exist, whose recipes and production techniques are handed down from one generation to another, i.e. from mother to daughter or father to son. These production techniques vary from one region/country to another and this may have a bearing on the microbial composition of the respective products. To gain more insights on such products and to understand, if variation in production method may impose a selective pressure leading to variations in microbial composition, we took mabisi as a case study.

Mabisi is a Zambian traditionally fermented milk made by spontaneous fermentation of raw milk at ambient temperature for two days $[24,53]$. This product is popular and widely consumed with the staple maize porridge (nshima) as well as other types of foods such as rice, sweet potatoes, pumpkins and fruits [53]. Zambia is a large country $\left(752,000 \mathrm{~km}^{2}\right)$ with a population consisting of a variety ethnic groups (73 tribes) [25] and mabisi production is traditionally practiced in regions or provinces with high cattle population. However, the demand for the product has steadily been rising in the cities. A previous study by Moonga, Schoustra [53] has shown that there are seven production methods of mabisi: tonga, illa, backslopping, creamy, cooked, barotse, and thick-tonga spread around the country with tonga type being the most popular and widely practiced in all regions and by all ethnic groups. This study further highlights the key production parameters as being temperature, type of fermentation containers types, season, backslopping and alternate whey removal and addition of raw milk. However, there are limited studies on the microbes involved in this spontaneous traditional fermentation.

The spontaneous fermentation of mabisi relies on microbes from the surrounding production environment: the raw milk, production utensils (containers and buckets), hands of producers and the air. A study by Schoustra, Kasase [24] has shown that mabisi samples collected in the southern and central parts of Zambia contain 6-8 species of lactic acid bacteria (LAB) and acetic acid bacteria (AAB). However, that study was limited in the number of samples that were analysed and did not cover all mabisi production regions representative of all variation in production methods in the country. As in all natural species communities in nature, the microbial communities in spontaneously fermented food products are shaped by both abiotic and biotic factors $[54,55]$. With the different production practices in the country, we hypothesise that the microbial community composition varies as a function of production region, producer, type of fermentation container and type of mabisi. Studies across the African continent have shown variation in microbial composition of traditional fermented milk products from country to country $[12,37,38]$ but these have not been linked to variations in production practice or sampling location, which may exert key selection pressures on the microbial ecosystem impacting their species composition and dynamics. This motivated us to investigate the composition of the microbial communities of mabisi samples country-wide in Zambia using high throughput DNA sequencing techniques.

In this study, we investigated the bacterial community composition of mabisi across the provinces of Zambia, and subsequently, identify the key factors that determine the anticipated diversity in bacterial community composition. We used culture independent methods and focused on the bacterial community composition as earlier work has shown that yeast was rarely detected in mabisi (Schoustra et al 2013). We believe that this study will provide insights into the types of microbes that are involved in the fermentation of mabisi and the factors that shape their community structure. This information is important for understanding the ecology of these microbial communities and will form a basis for more fundamental research on how selective forces may affect microbial dynamics and functionality. More practically, it gives an overview of the potential candidate microbes to be used in starter culture development, which will be crucial for product optimisation in order to meet the demand of both the rural and urban consumers. 


\section{Materials and methods}

\subsection{Sample collection}

A total of 168 mabisi samples (Table 1) were collected across eight provinces of Zambia between May and August 2016 (Fig. 1).

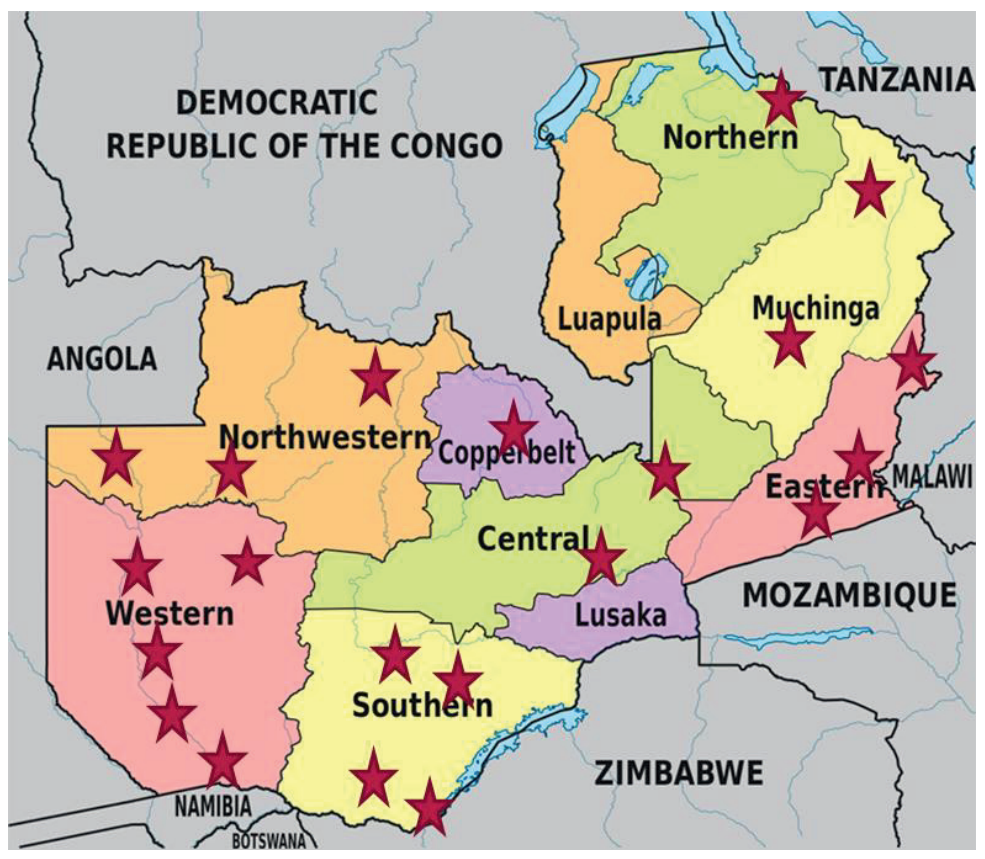

Fig. 1. Map of Zambia showing all provinces and the sampling sites, which are denoted by the red stars. (Map adapted from https://www.researchgate.net/figure/Map-of-Zambia-showing-itsprovinces-and-neighbouring-countries_fig1_332258490)

The samples were collected during the dry and cold season of the year when milk production is low and as a result certain regions with fewer cattle farmers had fewer samples. The samples were collected from farmers, traders in the local markets and Milk Collection Centres (MCCs) of farmer Cooperatives. However, for the purpose of this study the latter two were both treated as traders. The farmers that provided samples were identified through their Cooperatives with the assistance of the Ministry of Fisheries and Livestock (MFL) of the Zambian Government personnel and were part of those interviewed during a survey on mabisi production practices conducted by Moonga, Schoustra [53]. The following information was recorded for all samples collected: sampling location (province and district), production method, age of mabisi (fermentation time in days), type of fermentation containers used (calabash, plastic and metal) and type of producer. The mabisi samples collected were produced using five production methods: tonga, backslopping, barotse, creamy and thick-tonga mabisi (see chapter 2 Fig. 3).

Table 1. Number of mabisi samples collected from each sampling location.

\begin{tabular}{|l|l|c|}
\hline \multicolumn{2}{|c|}{ Sampling location } & Number of samples \\
\hline Traditional mabisi & Western province & 55 \\
\cline { 2 - 3 } production region (TMPR) & Southern province & 40 \\
\hline
\end{tabular}




\begin{tabular}{|l|l|c|}
\hline \multirow{4}{*}{ Non-TMPR } & Central province & 11 \\
\cline { 2 - 3 } & Eastern province & 25 \\
\cline { 2 - 3 } & Copperbelt province & 8 \\
\cline { 2 - 3 } & North-western province & 14 \\
\cline { 2 - 3 } & Muchinga province & 11 \\
\cline { 2 - 3 } & Northern province & 4 \\
\hline Total & & $\mathbf{1 6 8}$ \\
\hline
\end{tabular}

Mabisi samples were collected using $500 \mathrm{ml}$ sterile plastic bottles which were immediately stored on ice in a cool box to stop the fermentation and transported to the laboratory where physicochemical analysis and DNA extraction were carried out. The samples were analysed for $\mathrm{pH}$ and titratable acidity (TTA) upon arrival at the Food Chemistry Laboratory, Department of Food Science \& Nutrition of the University of Zambia. The samples for microbial analysis were separated prior to these analyses. Microbial community analysis was performed by culture independent techniques which involved DNA extraction and high throughput 16S rRNA amplicon sequencing. To do this, mabisi samples were pipetted into $1.5 \mathrm{ml}$ eppendorf tubes and centrifuged $(12,000 \mathrm{rpm})$ for two minutes after which the supernatant was poured out and the pellet was frozen at $-20^{\circ} \mathrm{C}$ for subsequent DNA extraction.

\subsection{Physicochemical properties}

The $\mathrm{pH}$ for the mabisi samples was analysed using a digital $\mathrm{pH}$ meter.

\subsection{Amplicon sequencing}

The frozen mabisi samples pellets were thawed and the DNA was extracted and purified as described by [24]. For DNA extraction, the thawed pellet cells were re-suspended in a mix of 64 $\mu \mathrm{L} \operatorname{EDTA}(0.5 \mathrm{M}), 160 \mu \mathrm{L}$ Nucleic Lysis Solution, $5 \mu \mathrm{L}$ RNAse, $120 \mu \mathrm{L}$ lysozyme and $40 \mu \mathrm{L}$ pronase $\mathrm{E}$. After an incubation time of 60 minutes at $37^{\circ} \mathrm{C}$ and agitation of $350 \mathrm{RPM}, 400 \mu \mathrm{L}$ icecold ammonium acetate ( $5 \mathrm{M}$ ) was added and the mixture was cooled on ice for 15 minutes. The mixture was spun down and $750 \mu \mathrm{L}$ of supernatant was transferred to a tube containing $750 \mu \mathrm{L}$ phenol. This tube was vortexed and its content spun down ( 2 minutes, 12000 RPM) and $500 \mu \mathrm{L}$ of supernatant was transferred to a tube containing $500 \mu \mathrm{L}$ chloroform. This tube was vortexed and its content spun down ( 2 minutes, $12000 \mathrm{RPM}$ ) and $400 \mu \mathrm{L}$ of supernatant was transferred to a tube containing $1 \mathrm{ml} 100 \%$ ethanol and $40 \mu \mathrm{L}$ sodium acetate $(3 \mathrm{M})$. This DNA containing tube was left to precipitate at $-20^{\circ} \mathrm{C}$ overnight. The next day, the tube was spun for 20 minutes at 12000 RPM at $4{ }^{\circ} \mathrm{C}$. The supernatant was carefully aspirated, and the DNA pellet was washed by adding $1 \mathrm{~mL} 70 \%$ ethanol. The tube was spun for 10 minutes at $12000 \mathrm{RPM}$ at $4{ }^{\circ} \mathrm{C}$, after which the supernatant was aspirated again. The DNA pellet was left to dry at room temperature and dissolved in $20 \mu \mathrm{L} 10 \mathrm{mM}$ Tris $\mathrm{pH} 7.5$.

The extracted DNA was subsequently, sent for bacterial 16S rRNA gene amplicon paired-end sequencing of the V4 hypervariable region (341F-785R) on the MiSeq Illumina platform performed by LGC genomics (Berlin, Germany).

For further data processing and statistics, the QIIME pipeline [56, 57], modified by Bik, Costello [58] was used. Paired-end reads were joined using join_paired_ends.py (with minimum overlap 10 basepairs) after which sequences were trimmed and filtered using cutadapt ( $v 1.11-q$ 20, $-\mathrm{m}$ 400, [59]) using the known primer sequences CCTACGGGNGGCWGCAG and GACTACHVGGGTATCTAAKCC to trim both sides of the sequence. These trimmed sequences were then checked for chimera's, using uchime (v4.2.20, gold database, [60]), sequences with a lower chimera score than 0.28 were retained. The sequences were filtered by Qiime script (split_libraries_fastq.py, phred offset value: 33) and then clustered into Operational Taxonomic Units (OTUs) at 97\% sequence similarity using the SILVA reference database (version 132) [61] 
and UCLUST [62] using "pick_open_reference_otus.py" Qiime script. For assigning taxonomic classification, BLAST analysis (with default e-value) was done against the SILVA database [63] (version 132). All downstream analysis were performed in R ( $\mathrm{R}$ Development Core Team 2008).

\subsection{Statistical and data analysis}

The data was analysed using one way analysis of variance (ANOVA) at 95\% significance level and mean comparisons were performed by Tukey test at 95\% significance level using SPSS version 22. The relationship between bacterial community diversity, location and mabisi production methods was analysed using non-metric multidimensional scaling (NMDS).

\section{Results}

The mabisi samples were analysed for physicochemical properties: pH and titratable acidity (TTA), and for bacterial community composition using 16S rRNA amplicon sequencing. All the 168 mabisi samples collected around the country were classified according to different production factors identified: production method, duration of fermentation (age), type of fermentation containers used and type of producers (Fig. 2). Most of the samples collected were produced using tonga-type production method whose final product is referred to as "tonga mabisi" (76\%) and the least product type produced was "creamy mabisi" $(2 \%)$. The most popular container used for fermentation was the plastic container (\%). A large proportion of the samples were produced by farmers ( $83 \%)$ and the commonest fermentation duration was 1 day\%.

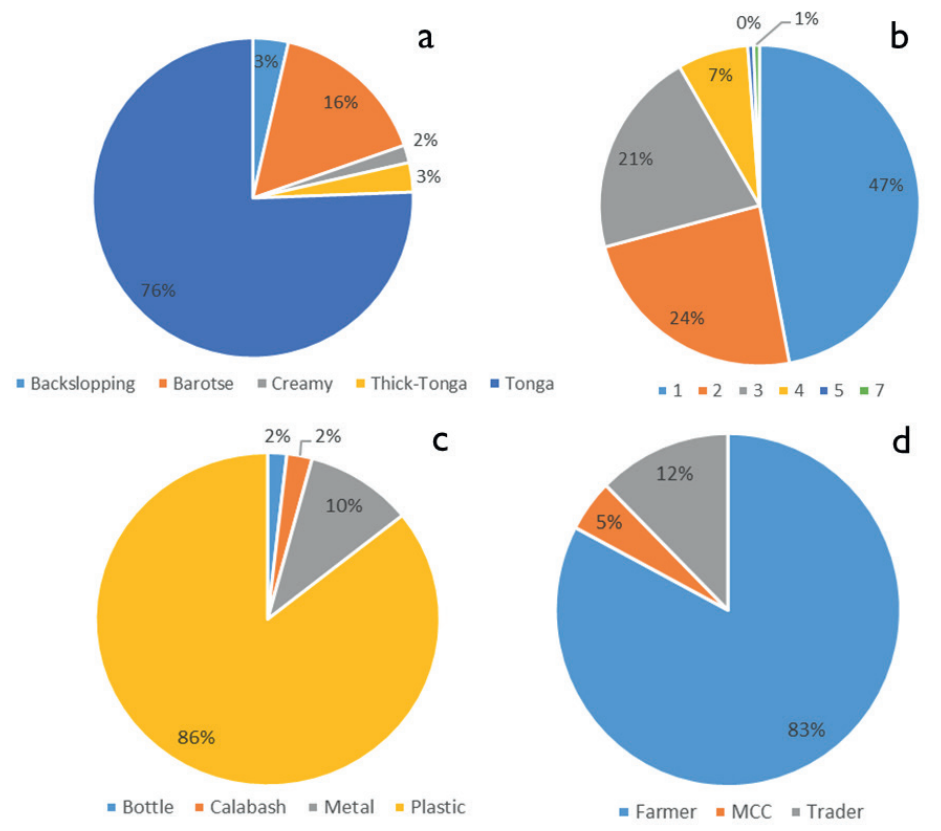

Fig. 2. Frequency data of the production parameters: a) production method of mabisi, b) fermentation time in days (age), c) type of fermentation container and d) type of producer

\subsection{Physicochemical properties}

Mabisi samples collected from Eastern province had the highest mean $\mathrm{pH}$ while those from Western province had the lowest, but both were significantly different from the rest of the other provinces (Fig. 3A). In terms of the types of mabisi, barotse mabisi had a significantly lower mean $\mathrm{pH}$ than the 
rest. Backslopping mabisi also had a lower $\mathrm{pH}$ than tonga, creamy and thick-tonga mabisi but the difference was not significant (Fig. 3B). The traders produced mabisi with lower mean $\mathrm{pH}$ compared to mabisi produced by the farmers or milk collection centres (MCCs), while mabisi fermented in the calabashes had the lowest mean $\mathrm{pH}$ compared to mabisi fermented in either plastic or metal containers (Figs. $3 \mathrm{D} \& \mathrm{E}$ ). The mean $\mathrm{pH}$ of mabisi samples fermented for one day was the highest and the lowest $\mathrm{pH}$ values were observed in mabisi samples fermented for four days (Fig. $3 \mathrm{C}$ ).

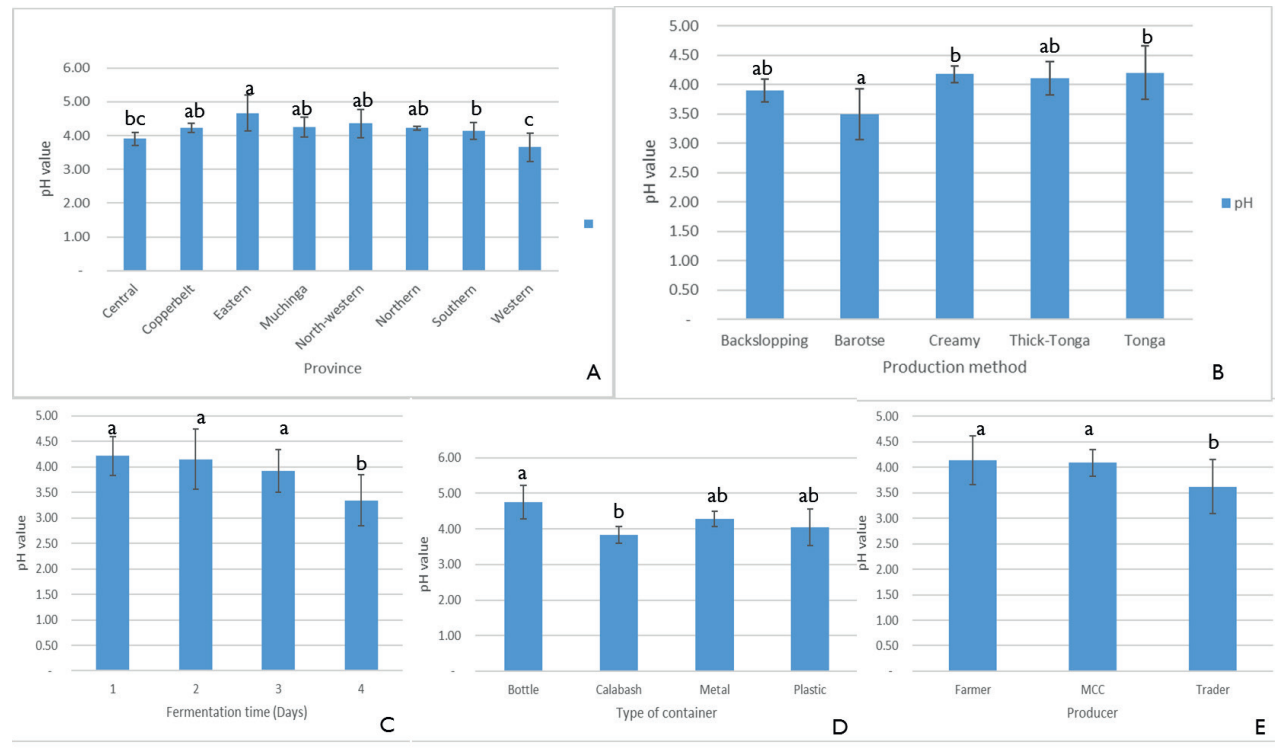

Fig. 3. Mean $\mathrm{pH}$ of mabisi samples. $\mathrm{pH}$ of mabisi from different: A. provinces, B. production methods, C. fermentation time, D. fermentation container and E. producers. The bars with different letters for each mean $\mathrm{pH}$ value indicate statistically significant differences $(p<0.05)$.

\subsection{Bacterial community composition}

The bacterial community composition of mabisi was dominated by species belonging to the phyla, Firmicutes and Proteobacteria (Fig. 4a). The other phyla that made up the top 10 most abundant bacteria include Acidobacteria, Actinobacteria, Bacteriodetes, Cyanobacteria, Fusobacteria, Patescibacteria, Deinococcus-thermus and Gemmatimonadetes. 

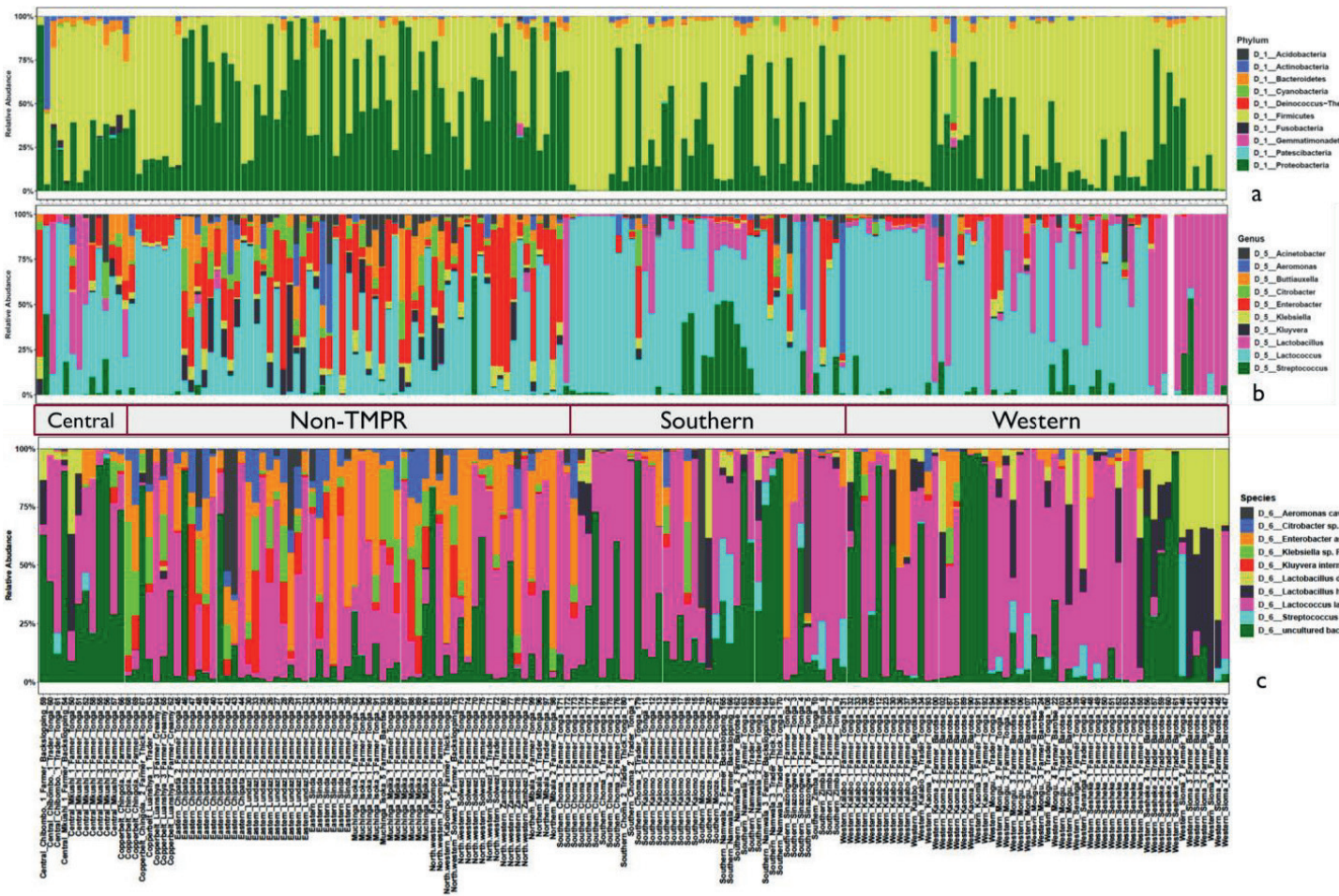

Fig. 4. Bacterial community composition of the top 10 relative abundant bacteria in mabisi at the level of: a. phylum, b. genus \& c. species. Each bar represents an individual sample. Two main regions are shown the traditional mabisi production region (TMPR) represented by Western, Southern and Central provinces, and the non-TMPR.

When the data of all sampled mabisi are combined, Lactococcus is the genus with the highest relative abundance. The other genera that make up the top 10 of most abundant genera include Lactobacillus, Streptococcus, Kluyvera, Klebsiella, Enterobacter, Citrobacter, Buttiauxella, Aeromonas, and Acinetobacter (Fig. 4b). Mabisi is traditionally produced in Western, Southern and parts of Central province, which in this study can be collectively referred to as 'Traditional mabisi production regions (TMPRs)'. The bacterial community composition of mabisi from this region, was dominated by lactic acid bacteria (LAB) of the genera Lactococcus, Lactobacillus and Streptococcus. Within the TMPR, mabisi from Western province had a larger proportion of Lactobacillus than the rest as was the case with Southern Province mabisi for Streptococcus. Mabisi samples from the non-TMPR of Eastern, North-western, Muchinga and Northern provinces had a more complex bacterial community composition collectively dominated by non-LAB, although Lactococcus was present in all samples and was the main driver of the fermentation process. From the non-TMPR, only mabisi samples from Copperbelt province were dominated by Lactococcus but still had a high proportion of Enterobacter.

The top 10 most abundant species found in mabisi included Lactococcus lactis, Streptococcus salivarius, Lactobacillus helveticus, Lactobacillus delbrueckii, Kluyvera intermedia, Klebsiella sp. Enterobacter asburiae, Citrobacter sp. and Aeromonas caviae (Fig. 4c). The top 20 and 30 most abundant species (Fig. S1) include some of LAB species reported by Schoustra, Kasase [24] that are absent in the top 10 most abundant species. 


\subsection{Bacterial diversity}

The alpha diversity (i.e. the mean species diversity) of the mabisi bacteria community was analysed by richness and Shannon index (Fig. $5 \& 6$ ). The results show that tonga mabisi was richer and more diverse in bacterial community composition than the other types of mabisi (Fig. 5a\&b). In addition, when we consider all tonga mabisi samples from all sampling sites (provinces), we observe that samples from the non-TMPR of Eastern, Muchinga, Northern, Copperbelt provinces were richer and more diverse than the TMPR of Western and Southern provinces (Figs. 5a\&b). Creamy mabisi was richer than backslopping, barotse and thick-tonga mabisi but backslopping mabisi had a more diverse bacterial community composition than the other three (Figs. 5a\&b).
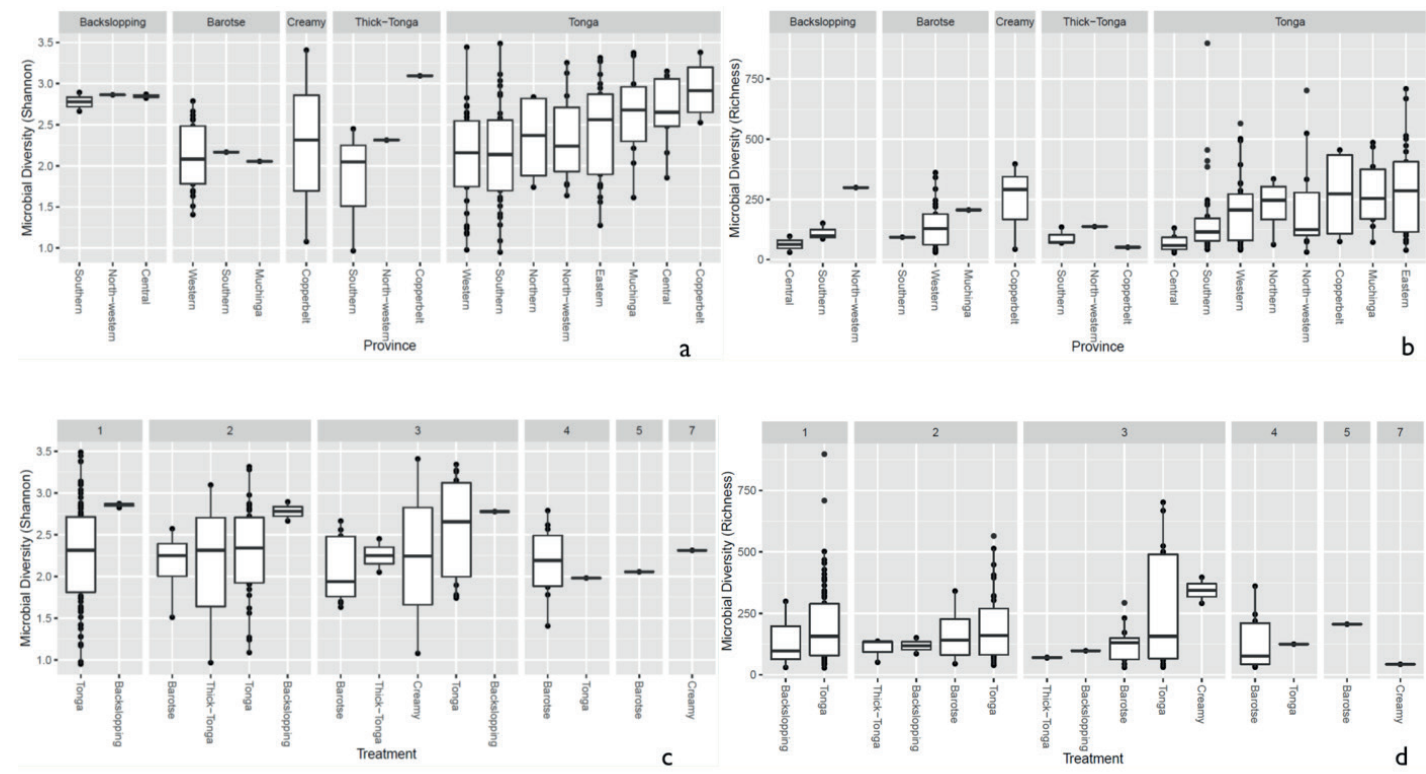

Fig. 5. Bacterial alpha diversity of mabisi according to production method (a. shannon index \& b. speices richness) and fermentation period (c. shannon index $\&$ d. speicies richness).

Tonga mabisi was richer in terms of diversity (no. of species) for samples that were fermented for 1,2 and 3 days (Fig. 5d) compared to those fermented for longer periods of time. Those fermented for 1 day showed more diversity than those fermented for $2 \& 3$ days (Fig. 5c). Furthermore, tonga mabisi samples fermented for 1,2 and 3 days were more diverse than the other types of mabisi.

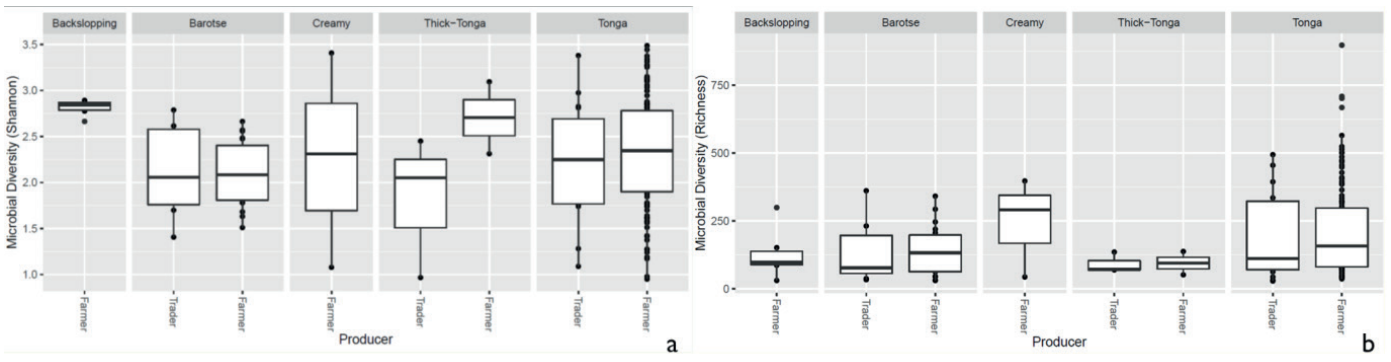




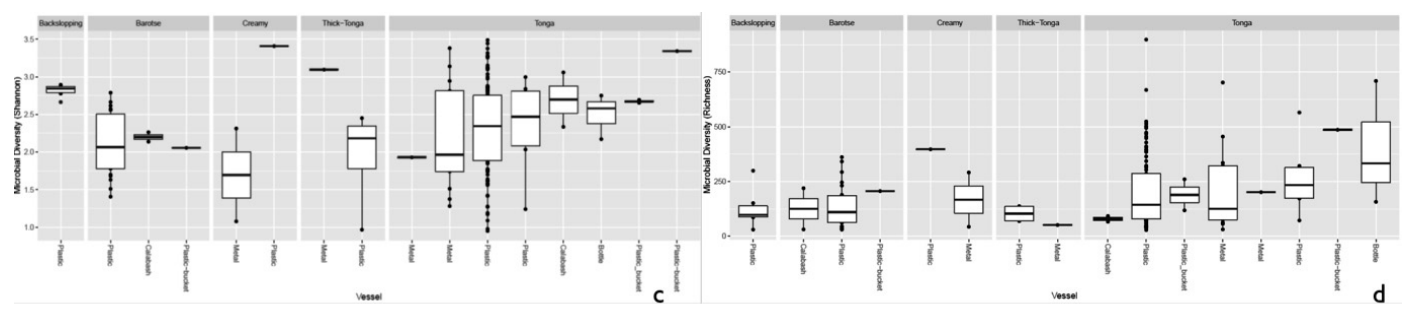

Fig. 6. Bacteria diversity of mabisi in terms of producer (a. shannon index \& b. speices richness) and type of container (c. shannon index \& d. speicies richness).

The tonga mabisi samples were richer in bacterial community diversity than the other types of mabisi but there were no large differences in bacterial community diversity between samples produced by the farmers and the traders who sale their products in the local markets (Fig. 6b). Tonga mabisi had more samples with higher diversity than the other types of mabisi but only thick-tonga mabisi showed significant differences between the producers: the farmers produced mabisi with a higher diversity compared to the traders (Fig. 6a). Tonga mabisi samples fermented in a glass bottle were richer in terms of bacterial community diversity than those fermented in plastic, metal and calabashes containers (Fig.6d). Both the bottle and the calabash fermented tonga mabisi samples had a slightly higher diversity as indicated by the shannon index than those fermented in metal and palstic containers (Fig.6c).

\subsection{Relationship between bacterial community diversity, location and mabisi production method}

The mabisi samples were analysed by non-metric multidimensional scaling (NMDS) to determine the association between type of mabisi/location and taxa. Fig. 7a shows two main clusters of the phyla Firmicutes and Proteobacteria as well as a smaller one of Actinobacteria. The Firmicutes cluster is dominated by mabisi samples from Western and Southern provinces as well as the barotse and tonga types of mabisi whereas the Proteobacteria cluster is dominated by samples from the non-TMPRs and mostly, tonga type mabisi. 


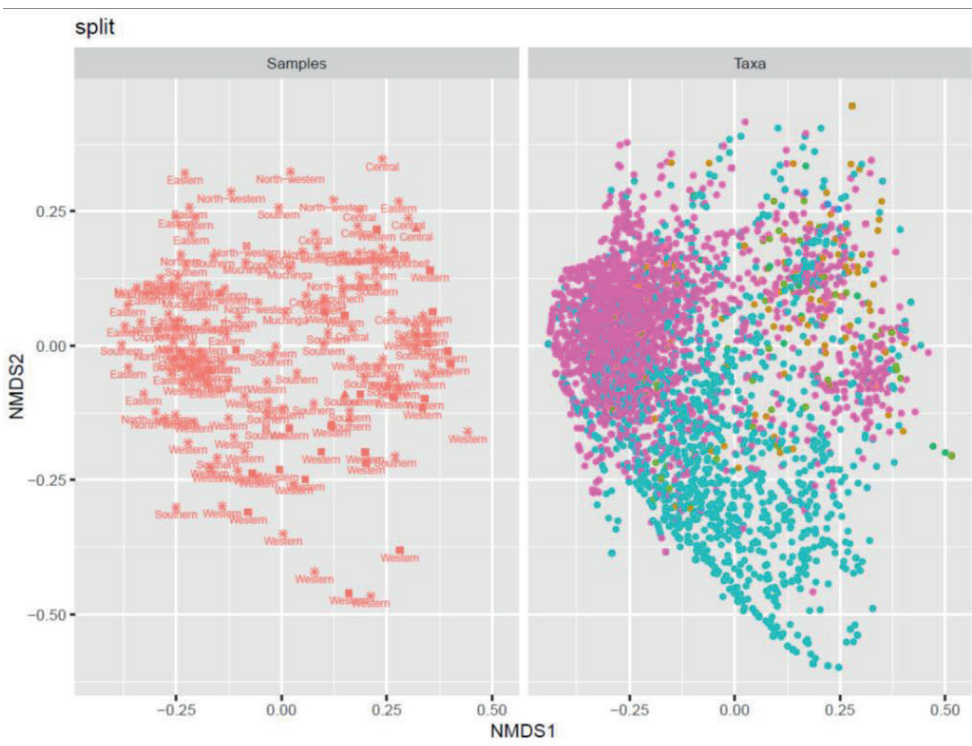

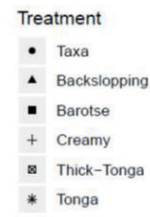

\section{Phylum}

- Samples

- D_1_Actinobacteria

- D_1_Bacteroidetes

- D_1_Cyanobacteria

- D_1_Firmicutes

- D_1_Fusobacteria

- D_1_Gemmatimonadetes

- D_1_Proteobacteria

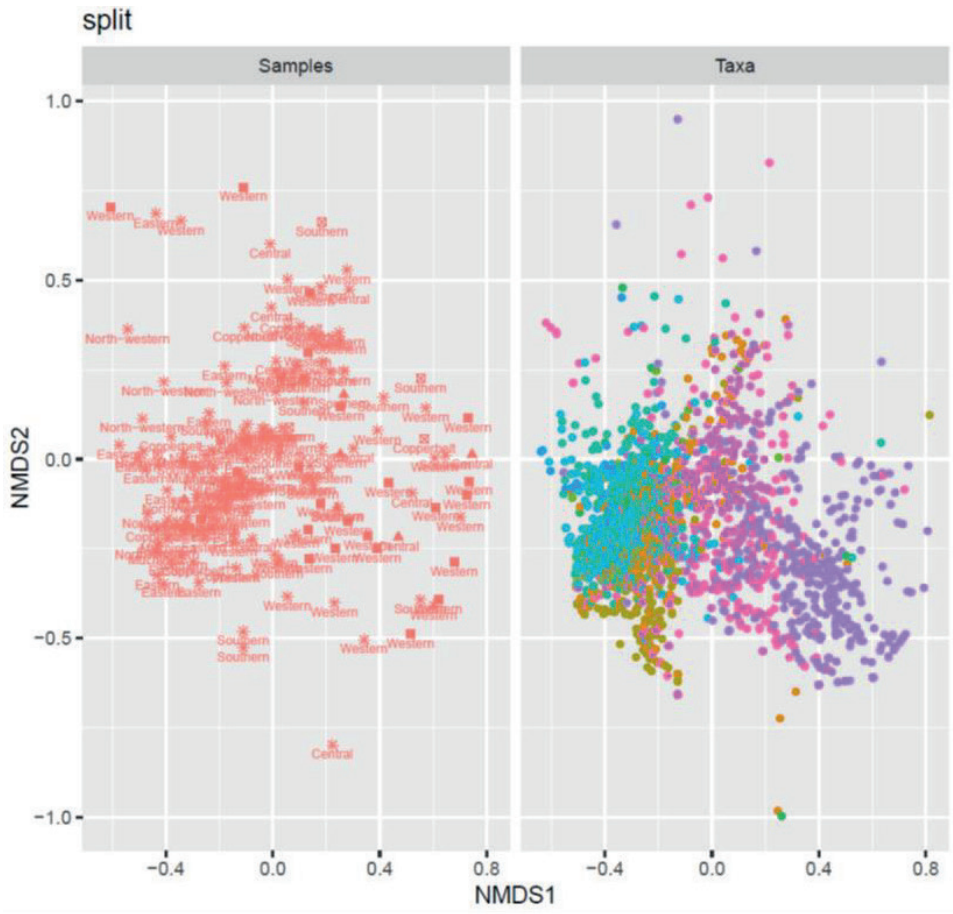

Genus

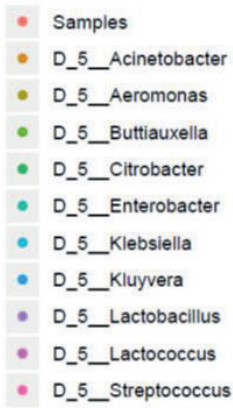

Treatment

- Taxa

- Backslopping

- Barotse

+ Creamy

a Thick-Tonga

* Tonga

Fig. 7. Non-metric multidimensional scaling (NMDS) plot of the relationship between taxa and a. location \& b. production method. 
At genus level (Fig. 7b), we were able to discriminate four big clusters dominated by Lactobacillus, Lactococcus, Enterobacter and Aeromonas, and two smaller clusters dominated by Streptococcus and Klebsiella. The Lactobacillus cluster was associated with the barotse mabisi and samples mostly from Western with a few from Southern and Central provinces. Lactococcus had the largest cluster which included all the types of mabisi and provinces but was most prominent in the TMPR. The smaller Streptococcus cluster was associated with tonga, backslopping and barotse types of mabisi from the TMPR. The clusters of the non-LAB genera of Aeromonas, Enterobacter and Klebsiella were mainly associated with tonga mabisi produced in the non-TMPR, however, other types of mabisi from the TMPR also had some samples with these bacteria at lower levels of abundance.

A hierarchical cluster analysis of the bacterial communities in all mabisi samples was carried out and this resulted in three main clusters: A, B and C (Fig. 8). Cluster A was dominated by samples from TMPR $(65 \%)$ while clusters $B$ and $C$ were populated mostly by samples from non-TMPR $(>75 \%)$ and TMPR $(>80 \%)$, respectively. In terms of types of mabisi, cluster A had tonga, barotse and creamy mabisi, cluster B had mostly tonga mabisi and cluster $\mathrm{C}$ had all types: tonga, barotse, thick-tonga, creamy and backslopping mabisi.

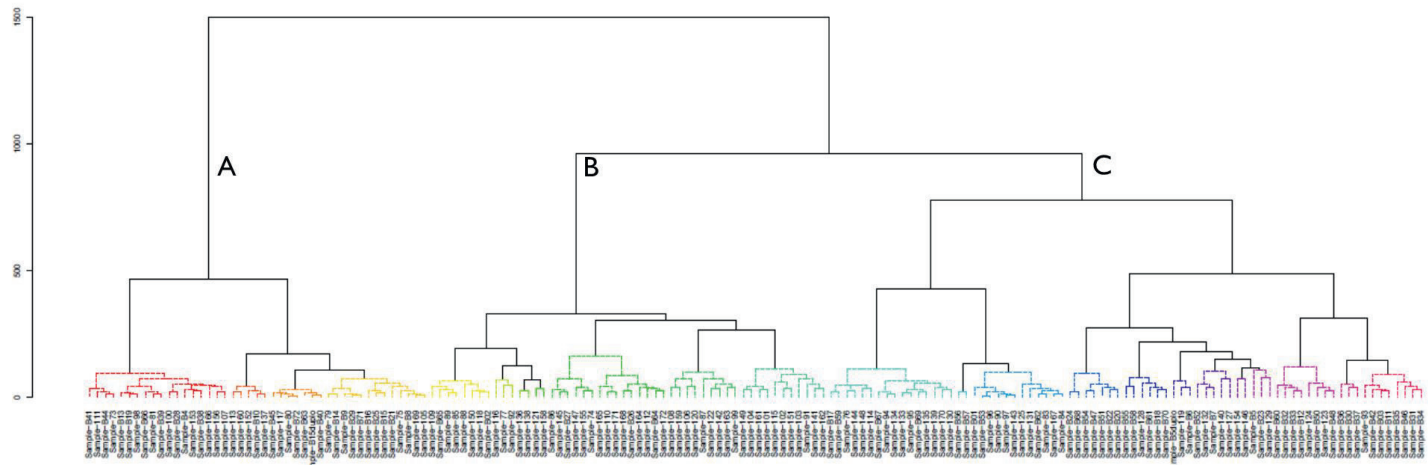

Fig. 8. Cluster analysis of bacterial communities of all mabisi samples. The letters, A, B and C indicate the three main clusters.

\section{Discussion}

The objective of this study was to determine the bacterial community composition of mabisi, its species diversity and the factors that influence community composition. The results show that mabisi is composed of bacteria from mainly two phyla (Firmicutes and Proteobacteria) with the most dominant LAB genera being Lactococcus, Lactobacillus and Streptococcus and the non-LAB dominated by Enterobacter, Aeromonas and Klebsiella (Fig. 4). The LAB genera found in this study have also been reported by Schoustra, Kasase [24] for fewer mabisi samples collected from two provinces only, Southern and Central provinces, which are both part of TMPR. These LAB species dominate the entire TMPR, which also includes the Western province. However, our findings also reveal some non-LAB genera (mostly Gram-negative species), which dominate the non-TMPR and some of them have been reported in other African traditional fermented milk [38]. The TMPR are the regions (Table 1 ) with more cattle and milk production [27, 33, 53], and thus, the production of mabisi has a longer history and is carried out at a larger scale in these regions. In contrast, the nonTMPR are those regions with fewer cattle and low milk production, although Eastern province within this region has high cattle population but low milk production and consequently, low mabisi 
production as well. Moreover, mabisi consumption for some ethnic groups in this province is not common.

Interestingly, Lactococcus was the most dominant genus present in all mabisi samples and can be assumed to be driving the fermentation process. Lactobacillus was region and product specific, mostly found in the TMPR particularly, in barotse and backslopping mabisi, which were mainly produced by traders. Lactobacillus was more dominant in mabisi samples with low $\mathrm{pH}(\mathrm{pH}<4)$, which explains its dominance in mabisi samples from Western province as well as barotse and backslopping mabisi samples (Fig. 3). This is mainly because Lactobacillus sp. are in general more acid tolerant than Lactococcus species [64]. Streptococcus sp. were also found in the TMPR but had a high relative abundance in samples collected from Southern province particularly, from one district.

The top 10 species is made up of four LAB and five non-LAB (Fig. 4). The most abundant species is Lactococcus lactis which is found in all mabisi samples. This species seems necessary for the fermentation to take place for all types of mabisi. It is a well-known homofermentative lactic acid bacterium used in many fermented dairy products like cheese and quark $[65,66]$. However, the different types of mabisi have different bacteria that are responsible for fermentation. For instance, tonga mabisi always has Lactococcus sp. Especially for tonga mabisi from non-TMPR but the one from TMPR will in addition to Lactococcus species also have Streptococcus salivarius and in a few cases Lactobacillus delbrueckii and Lactobacillus helveticus which is also the case for thick-tonga mabisi. However, barotse and backslopping mabisi have all three genera present with Lactobacillus having a higher relative abundance than in the other types of mabisi. This suggests that for a welldesigned mabisi starter culture, we should choose the right combination of lactic acid bacteria as well as take into account the specific production practices that may influence these bacteria in order to produce a product with desirable organoleptic properties. Microbes are known to have specific effects on organoleptic properties of dairy products $[9,10,67]$. Therefore, the effect of the different bacterial community composition on the organoleptic properties of mabisi requires further investigation.

In terms of bacterial community diversity, the mabisi produced in the TMPR was less diverse and was mostly dominated by the LAB genera compared to the ones produced in the non-TMPRs, which had a more complex and diverse composition. There was a relationship between the final $\mathrm{pH}$ and microbial diversity: the lower the $\mathrm{pH}$, the lower the diversity of the bacterial community. This was particularly observed in samples from Western province, which were dominated by Lactococcus species and Lactobacillus species. Conversely, samples with a high $\mathrm{pH}$ exhibited a higher diversity as evidenced with samples from Eastern province. The latter province had mabisi with the highest mean $\mathrm{pH}$ probably because most of the farmers that supplied the samples rarely made mabisi due to the low amounts of milk produced during the dry season which was often consumed fresh. Moreover, it is not cultural for some ethnic groups in this province to make mabisi.

The bacterial community composition results, also show a clear signature of the type of selection pressure acting on the fermenting milk. In this case, we consider mabisi as the ecosystem which is being subjected to selection pressures in the form of production practices, geographical location, use of specific fermentation containers, influence of handling by producers and fermentation duration. This study has demonstrated that geographical location has an effect on the bacterial community composition as shown by the difference in bacterial community structure for the two main regions that have been identified: TMPR and non-TMPR. Non-TMPR samples exhibited a more complex community probably due to low scale and frequency of production, mainly limited to one production method whereas the communities in mabisi samples from TMPRs were less complex and mainly dominated by LAB. This may be due to more production methods used, more frequent and larger scale of production of mabisi in this region, may have led to prolonged co-culturing of $L A B$ that has resulted in this particular outcome.

The production practices may have also contributed to shifts in bacterial communities composition, tonga type production method is a batch production of one to three days and the product is usually 
consumed within that period. The barotse type method involves the alternate removal of whey and addition of raw milk, and takes four to seven days to produce [53]. On the other hand, backslopping type method involves using a portion of a batch of mabisi as starter for the next one and this backslopping process can go on for several cycles. The results obtained in this study show that there are differences in the microbial community composition of these products (Fig 7b). Tonga mabisi is dominated by Lactococcus species and other non-LAB genera while barotse mabisi is dominated by more LAB genera, particularly, Lactococcus species and Lactobacillus species, and backslopping mabisi in addition has Streptococcus species. Thick-tonga and creamy mabisi were similar to tonga mabisi from TMPRs in bacterial community composition. Unfortunately, there were fewer samples for some types of mabisi and thus, leading to lack of statistical power to formally show significant differences but it is clear that each production method exerts a certain selection pressure on the microbial communities of mabisi, which results in different community composition.

The impact of the origin of the mabisi samples, being either directly from producers (farmers) or from traders, on the bacterial community composition was observed in the slightly higher richness and diversity of the bacterial community in samples collected from farmers compared to those collected from traders (Fig. 6a\&b). A comparison of the diversity scores of mabisi produced in different fermentation containers also suggest a certain effect but unfortunately, the sampling did not give equal numbers of samples for each product type, producer, location, container or fermentation duration. This means that to be able to interrogate this further, specific experiments with controls need to be carried out to give more substantive results on each factor. It should also be noted that the samples that were collected were endpoint samples of mabisi fermentation at different stages, which were interpreted based on information provided by the producers on their respective samples.

In conclusion, the mabisi bacterial community is dominated by three LAB and seven non-LAB genera. The bacterial composition is more diverse for mabisi samples collected in non-TMPR than TMPR with longer production history and wider variety of the types of mabisi produced. The non-TMPR primarily produced tonga mabisi dominated with Lactococcus and non-LAB species whereas the TMPR were dominated by Lactococcus, Lactobacillus and Streptococcus with a much smaller proportion of nonLAB species. Therefore, the development of any mabisi starter culture would require selection of strains from these LAB species for specific types of mabisi products.

The geographical location, production method, producer and $\mathrm{pH}$ exerted significant selection pressures on the microbes in mabisi that shaped the outcome of the microbial community structure.

However, it is imperative to carry out experiments to ascertain the effect of each of these factors and determine the optimal production process conditions since this product is already on the market and as more MCCs are being established, standardised production protocols will ensure the production of consistent and good quality mabisi that meet the consumer needs. 


\section{Supplimentary material}

Fig. S1. The top 20 (a) and 30 (b) most abundant bacterial community species

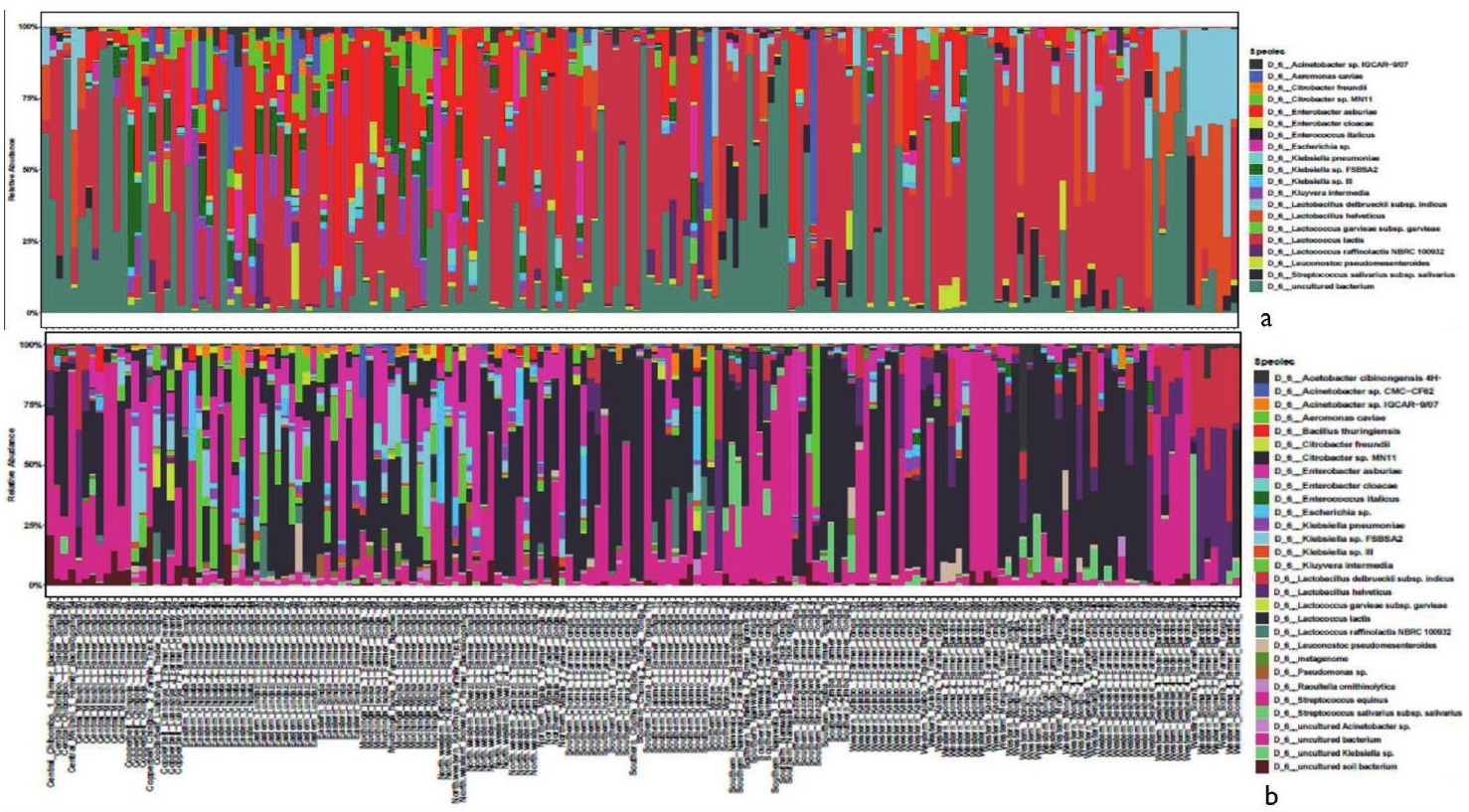





\section{Chapter 4}

\section{Influence of fermentation temperature on microbial community composition and physicochemical properties of mabisi, a traditionally fermented milk.}

Himoonga Bernard Moonga 1,2,3,4, Sijmen E. Schoustra ${ }^{3,4}$, Anita R. Linnemann², Joost van der Heuve/3, John Shindano ${ }^{4}$ and Eddy J. Smid ${ }^{1}$

Affiliation:

1. Laboratory of Food Microbiology, Wageningen University and Research, Wageningen, The Netherlands

2. Food Quality and Design, Wageningen University and Research, Wageningen, The Netherlands

3. Laboratory of Genetics, Wageningen University and Research, Wageningen, The Netherlands

4. Department of Food Science \& Nutrition, School of Agricultural Sciences, University of Zambia, Lusaka, Zambia 


\section{Abstract}

Fermentation temperature is a crucial factor in the production of fermented dairy products such as yoghurt and cheese. Not only does fermentation temperature affect organoleptic properties of the product, which are related to its sensorial quality and acceptability by consumers, it also affects the microbial community composition that underlies the fermentation process. This study investigated the influence of fermentation temperature on physiochemical properties and the composition of the microbial communities of two types of mabisi. Mabisi is a traditionally fermented milk product made in Zambia by spontaneous fermentation of raw milk at ambient temperature. Two types of mabisi, namely tonga and barotse mabisi, were produced with tonga mabisi fermented at 20, 22, 25 and $30^{\circ} \mathrm{C}$, and barotse mabisi at 25 and $30^{\circ} \mathrm{C}$. The $\mathrm{pH}$, titratable acidity, syneresis, consistency, microbial community composition and composition of aroma compounds were determined for the products. We found that fermentation at 20 and $22^{\circ} \mathrm{C}$ was slower than at $25^{\circ} \mathrm{C}$. At all temperatures a product was obtained with medium acidity ( $\mathrm{pH} \mathrm{4.2)}$ ) and 'medium' consistency within $48 \mathrm{~h}$ for tonga mabisi. Fermentation was most rapid at $30^{\circ} \mathrm{C}$ but resulted in a product with a 'thin' consistency due to a high degree of syneresis. Fermentation temperature did not affect the microbial community composition of tonga mabisi, which remained diverse and complex with Lactococcus (25\%) as the dominant fermenting genus for all treatments. Fermentation temperature did affect the characteristics of barotse mabisi. At $25^{\circ} \mathrm{C}$, a product with medium acidity and 'thick' consistency was formed and the microbial community was dominated by Lactococcus $(80 \%)$. At $30^{\circ} \mathrm{C}$ a 'very thick' consistency product was formed with Lactobacillus (80\%) dominating. Fermentation at $30^{\circ} \mathrm{C}$ also produced more aroma compounds in barotse mabisi. Follow-up consumer research is needed to assess the preferred acidity, consistency and aroma of mabisi. 


\section{Introduction}

Dairy fermentations require the activity of microbes. Many of the commercially produced fermented dairy products use specific starter cultures, which have been carefully selected to deliver desirable organoleptic and quality attributes to the product. The most common microbes used in dairy fermentations belong to the group of lactic acid bacteria (LAB) but yeast and moulds can also be used for certain products such as kefir and surface ripened cheese, respectively Gripon [68], [69, 70]. The primary role of LAB is the production of lactic acid which reduces the $\mathrm{pH}$ of milk to values below the iso-electric point of caseins (i.e. $\mathrm{pH} 4.6$ ) and thereby induces coagulation of the milk [35]. The different species of lactic acid bacteria grow at different temperatures.

To ensure that only the desirable bacteria grow and impart the desired quality attributes on the specific product, the optimum fermentation conditions should be put in place. Amongst these, temperature is critical because using wrong temperature may promote the growth of undesirable and harmful bacteria, which can cause spoilage and foodborne infections. A good example of a fermentation process that is strictly controlled by temperature is yoghurt production. The starter culture is inoculated into heat treated milk at the moment when the milk has been cooled to $45^{\circ} \mathrm{C}$, which is the optimum temperature for starter growth. The species used are Streptococcus thermophilus and Lactobacillus delbrueckii subsp. bulgaricus which are both classified as thermophilic lactic acid bacteria ( $L A B$ ) suited to grow at relatively high temperature [36]. These microbes will coagulate the milk to the desired consistency/texture and deliver the characteristic aroma and flavour. For cheese production, usually mesophilic LAB such as Lactococcus lactis and Leuconostoc mesenteroides are used, which thrive at slightly lower temperatures $\left(20-39^{\circ} \mathrm{C}\right)$ [71] compared to the thermophilic LAB. These examples show the importance of establishing the appropriate process conditions for the production of a fermented dairy product. This type of information is especially important for the development and optimisation of artisanal or traditional products such as mabisi.

Mabisi is a traditionally fermented milk product from Zambia, which is made by spontaneous fermentation of raw bovine milk in a calabash or gourd at ambient temperature for up to $48 \mathrm{~h}$ after which it is stirred and ready for consumption [24,53]. No defined starter culture is used in this traditional fermentation. Previous work has shown that the microbial community is dominated by around six to up to eight different species of lactic acid bacteria [24] including both mesophilic and thermophilic bacteria. Mabisi is a popular and versatile product with several uses in the diet as it can be consumed with the main meal, as a dessert, snack or a beverage by both children and adults. Its consumption is wide spread throughout the country but the production is not formally regulated due to lack of information on product characteristics and optimum production process conditions. A recent study on mabisi identified seven different production methods [53]. Some of the critical processing parameters include fermentation temperature and duration which have been associated with increased whey content in the product (watery mabisi) by consumers [53].

The importance of incubation temperature is highlighted by the producers' choice of fermentation location. Most mabisi fermentations are carried out in a cool place in the house but production can be accelerated by placing the container outside directly in the sun especially during the cold months or slowed down by putting it in a water-bath to buffer the effect of high temperatures during the hotter months. Producers also reported that fermentation takes longer in a new container than an old one that was repeatedly used for mabisi production [53]. With the establishment of more milk collection centres (MCC) and promotion of value addition within value chains of local products in the country, there is need to establish standard processing conditions and document product characteristics for mabisi.

The ambient temperatures in Zambia vary from one season to another, leading to the following division: Hot dry (Sept-Nov.), hot wet (Dec.-April) and cold (May-July). These will have the following temperature ranges $18-35^{\circ} \mathrm{C}, 16-32^{\circ} \mathrm{C}, \& 8-28^{\circ} \mathrm{C}$, respectively [72]. This implies that fermentation temperatures differ throughout the year and given the fact that the microbial community responsible for fermentation of mabisi consists of both mesophilic and thermophilic bacteria, variations in temperature could have an impact on their relative abundance. This in turn, may lead to variation in the quality of the product. Therefore, the aim of this study was three-fold: (i) The first aim was to investigate the influence of fermentation temperature on quality parameters and microbial community composition changes in mabisi by examining the production of mabisi in a single batch as well as multiple batches at different temperatures that mimic the seasonal variations and producer 
practices. (ii) The second aim was to assess the effect of using a new fermentation container as opposed to one previously used and (iii) also compared two different production methods: tonga and barotse mabisi. This study provides insights on how the differences in microbial composition as related to fermentation temperature fluctuations impacts the quality of mabisi.

\section{Material and methods}

\subsection{Mabisi preparation and experimental layout}

Two methods of mabisi production were used in this study to produce tonga and barotse mabisi. Their respective production flow diagrams are shown in Fig. 1.

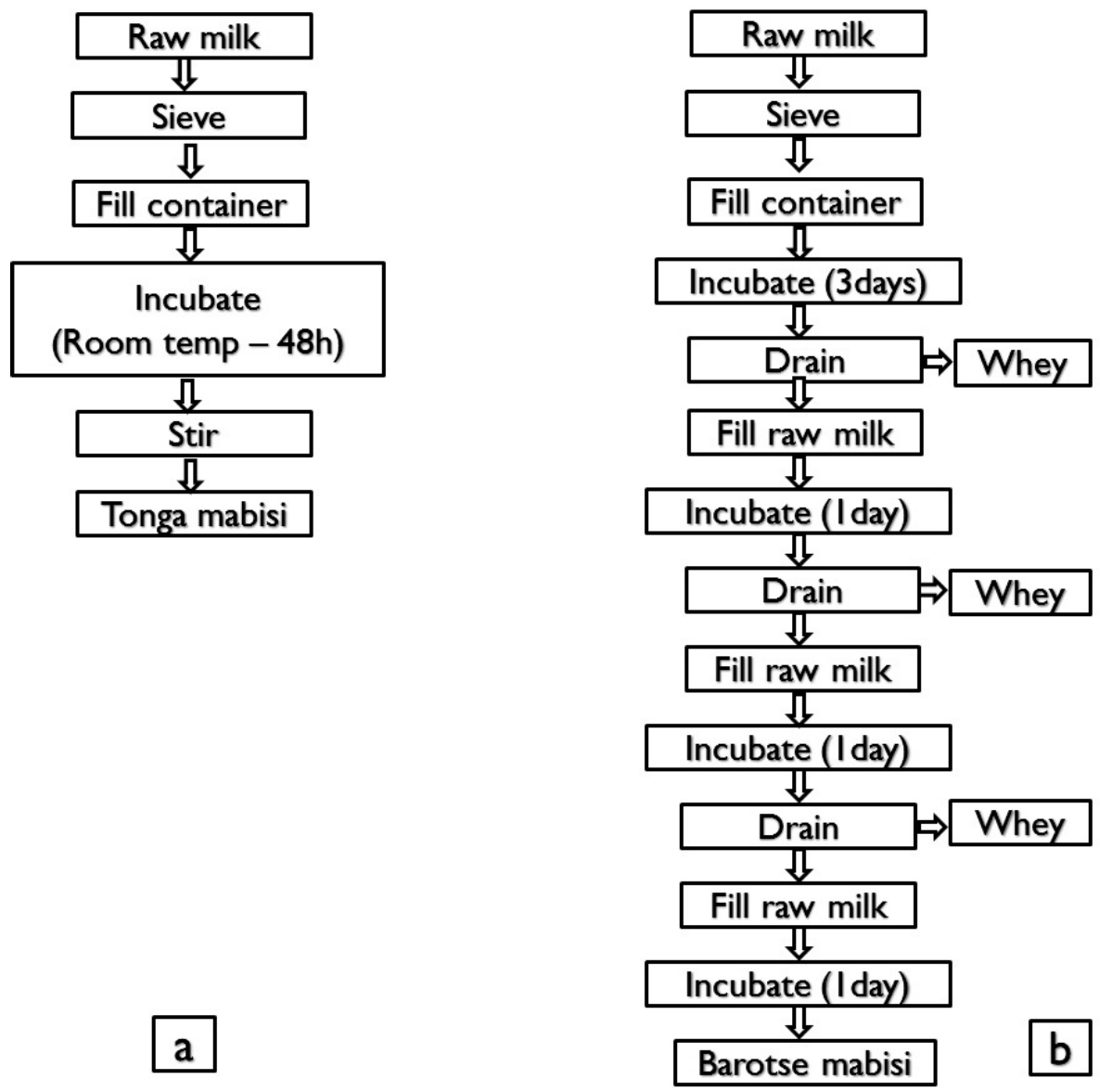

Fig. 1. Production flow diagram of tonga (a) and barotse (b) mabisi

The study was divided into four experiments. Tonga mabisi was used to study the effect of temperature using four different fermentation temperature regimes i.e. water temperature $\left(20^{\circ} \mathrm{C}\right.$ (WT)), room temperature $\left(22^{\circ} \mathrm{C}(\mathrm{RT})\right), 25^{\circ} \mathrm{C}$ and $30^{\circ} \mathrm{C}$, which cover the range of seasonal temperature variations. The experimental set-up is shown in Fig. 2. Water temperature means that the fermentation container was placed in a water bath filled with tap water with a temperature of approximately $20^{\circ} \mathrm{C}$. 


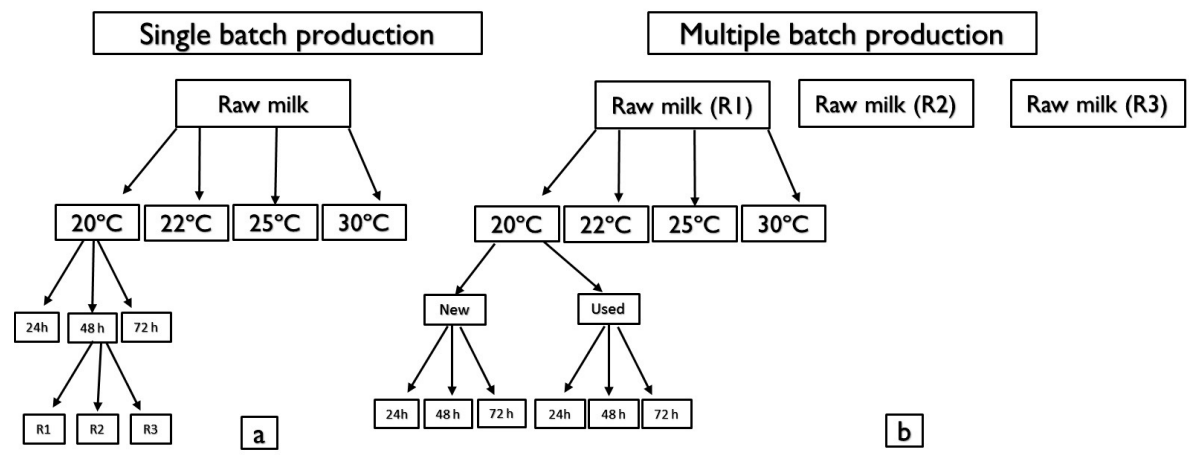

Fig. 2. Experimental layout of single batch (a) and multiple batch (b) production of tonga mabisi. R1-3 are biological replicates, sampling time (24, 48 \& 72h), fermentation temperature $\left(20,22,25 \& 30^{\circ} \mathrm{C}\right.$ ) and type of fermentation container (new plastic container and used plastic container (previously used for mabisi production))

\subsubsection{Single batch production of tonga mabisi}

The first experiment involved the production of mabisi from a single batch of raw bovine milk split into triplicate and fermented under four different fermentation conditions with three sampling time points (Fig 2a). The fresh raw milk was obtained from the University of Zambia (UNZA), School of Agricultural Sciences Field Station in a new clean (sterile) 5-litre plastic container. Out of this, $400 \mathrm{ml}$ was then poured into each clean pre-washed $500 \mathrm{ml}$ plastic bottle, closed with a lid and left to ferment for up to 72 $\mathrm{h}$ according to the production flow diagram (Fig 1a). Each given temperature was allocated nine bottles, three for each time point of sampling indicted as R1, R2 \& R3 (Fig 2a) which, were the biological replicates.

\subsubsection{Multiple batch production of tonga mabisi}

The set up was similar to the single batch production in terms of fermentation temperature and sampling times but the difference was that three independent batches of raw milk were used to produce mabisi on 3-day intervals per batch. These repeated production batches are the biological replicates, which were all fermented in new containers (Fig 2b).

\subsubsection{Fermentation in a used container}

The batch to batch production in new containers was simultaneously executed in previously used containers at the same temperature and same time series of sampling points. The $500 \mathrm{ml}$ bottles previously used for mabisi fermentation were washed with hot water prior to filling with raw milk. Three batches of production were made on the same days as those in section 2.1.2 using the same raw milk for each batch as shown in the layout (Fig 2b).

\subsubsection{Barotse mabisi}

The barotse mabisi was fermented at only two temperatures, $25^{\circ} \mathrm{C}$ and $30^{\circ} \mathrm{C}$ with four time points for sampling. The raw milk was also obtained from the UNZA Field Station from one batch with $400 \mathrm{ml}$ filled in each of the new clean and pre-washed $500 \mathrm{ml}$ plastic bottles. The layout was similar to the single batch production shown in Fig. $2 a$ but only at two temperatures and the production flow was as shown in Fig. 1b. Three (3) bottles were incubated at each temperature (as replicates) for three days after which the whey was removed and fresh raw milk added up to $400 \mathrm{ml}$. They were allowed to ferment for another day (fourth day) at their respective temperature and again the whey was removed followed by addition of raw milk. This was repeated for one more day (fifth day) and the final product was obtained on the sixth day. The samples of whey removed and final product were retained for physiochemical and 
microbial analysis. The volume of whey removed was also measured and used to determine product yield using the following formula:

Product Yield $(\%)=($ Final volume of end product/Total volume of raw milk used $) * 100$

\subsection{Physiochemical analysis}

The mabisi samples were analysed for $\mathrm{pH}$, titratable acidity (TTA), syneresis and consistency. $\mathrm{pH}$ was analysed by a digital $\mathrm{pH}$ meter and the acidity was analysed according to the AOAC official methods [73]. Syneresis was analysed by measuring the volume of whey separated from the curd and calculating its percentage of the initial volume of raw milk. Consistency was analysed using the Adam's consistometer, which measures the diameter of spread of a semi-liquid product after 30s [74, 75].

\subsection{Microbial composition}

The mabisi samples were analysed by a culture independent method. The DNA was extracted and purified as described by Schoustra, Kasase [24] as well as in chapter 3. The DNA extracted were subsequently, sent for bacterial 16S rRNA gene amplicon paired-end sequencing of the V4 hypervariable region (341F-785R) on the MiSeq Illumina platform performed by LGC genomics (Berlin, Germany).

For further data processing and statistics the QIIME pipeline [57], modified by Bik, Costello [58] was used. Paired-end reads were joined using join_paired_ends.py (with minimum overlap 10 basepairs) after which sequences were trimmed and filtered using cutadapt (v1.11 -q 20, -m 400, [59]) using the known primer sequences CCTACGGGNGGCWGCAG and

GACTACHVGGGTATCTAAKCC to trim both sides of the sequence. These trimmed sequences were then checked for chimera's, using uchime (v4.2.20, gold database, [60]), with sequences with a lower chimera scored than 0.28 were retained. After trimming, filtering and a quality check using pick_open_reference_otus.py (-s 0.1, -enable_rev_strand_match TRUE, -align_seqs_min_length 75, -pick_OTU_similatiry 0.95), the sequences were clustered into operational taxonomic units (OTUs). Taxonomy of the resulting OTUs was assigned to representative sequences using the Greengenes (v13.5) rRNA database. This algorithm gives a representative sequence for an OTU, which is subsequently used to perform a local blast using the gold database from uchime. The taxonomy from the top ranking BLAST hit was used for further data processing.

\subsection{Aroma compounds}

Volatile organic compounds (VOC's) in the mabisi samples were measured using HeadspaceSolid Phase Microextraction Gas Chromatography-Mass Spectrometry (HS-SPME GC-MS) with a Trace 1300 Gas Chromatograph (Thermo Fisher) coupled to a TriPlus RSH autosampler (Thermo Fisher) and an ISQ QD mass spectrometer (Thermo Fisher). Frozen samples were incubated at $60^{\circ} \mathrm{C}$ for $20 \mathrm{~min}$. Volatile compounds were extracted for $20 \mathrm{~min}$ at $60^{\circ} \mathrm{C}$ using an SPME fiber (Car/DVB/PDMS, Supelco). The compounds were desorbed from the fiber for 2 min onto a Stabilwax®-DA column (30 m length, $0.25 \mathrm{~mm}$ ID, $0.5 \mu \mathrm{m} \mathrm{df}$, Restek). The PTV was heated to $250^{\circ} \mathrm{C}$ and operated in split mode at a ratio of $1: 25$. The GC oven temperature was kept at $40^{\circ} \mathrm{C}$ for $2 \mathrm{~min}$, raised to $240^{\circ} \mathrm{C}$ with a slope of $10^{\circ} \mathrm{C} / \mathrm{min}$ and kept at $240^{\circ} \mathrm{C}$ for $5 \mathrm{~min}$. Helium was used as carrier gas at a constant flow rate of $1.2 \mathrm{ml} / \mathrm{min}$. Mass spectral data were collected over a range of $\mathrm{m} / \mathrm{z} 33-250$ in full-scan mode with 3.0030 scans/second. Data were analysed using Chromeleon $® 7$ 7.2. The ICIS algorithm was used for peak integration and the NIST main library to match the mass spectral profiles with the profiles of NIST. Peak areas were calculated using the MS quantification peak (highest $\mathrm{m} / \mathrm{z}$ peak per compound). The peak area data were normalised and used construction heat maps using multiple experiment viewer (Mev) version 4.9.0 software. We carried out a hierarchical clustering on all mabisi sample data.

\subsection{Statistical analysis}

The data was analysed using analysis of variance (ANOVA) at 95\% significance level and mean comparisons were performed by Tukey test at 95\% significance level using SPSS version 22 . 


\section{Results and discussion}

The main objective of this study was to determine the influence of fermentation temperature on microbial communities and quality of mabisi by using single or multiple production, new or used containers and comparing two production methods. The results are presented in four sections.

\subsection{Effect of temperature on single batch mabisi production \\ 3.1.1 Physicochemical properties}

We have studied the changes in the physicochemical properties of mabisi fermented at four different temperatures determined in triplicate from a single batch milk production using new plastic containers (Fig. 3).

Mabisi is made from raw milk, which has a $\mathrm{pH}$ ranging from 6.6 to 6.8 . The $\mathrm{pH}$ and titratable acidity (TTA) change during fermentation of tonga mabisi are shown in Fig. 3. Only samples fermented at $30^{\circ} \mathrm{C}$ coagulated after $24 \mathrm{~h}$ reaching $\mathrm{pH} 4.6-4.8$ while those incubated at $25^{\circ} \mathrm{C}$ coagulated after $36 \mathrm{~h}$ and those at $20^{\circ} \mathrm{C}$ (water temperature (WT)) and $22^{\circ} \mathrm{C}$ (room temperature (RT)) both showed coagulation after $48 \mathrm{~h}$ of incubation reaching $\mathrm{pH} 4.5$. After $72 \mathrm{~h}$, the lowest $\mathrm{pH}$ of 4.1 was attained by samples incubated at $25^{\circ} \mathrm{C}$ and the highest $\left(\mathrm{pH} \mathrm{4.4)}\right.$ by samples incubated at $20^{\circ} \mathrm{C}$. There were no significant differences in $\mathrm{pH}$ at different temperatures after 48 and $72 \mathrm{~h}(\mathrm{p}>0.05)$.

This range of $\mathrm{pH}$ values obtained after $48 \mathrm{~h}$ confirms what has previously been reported for mabisi by Schoustra, Kasase [24]. Moreover, similar pH ranges were reported for other traditional fermented dairy products from across Africa such as nunu [12], amasi [21, 76, 77] and kivuguto [13].

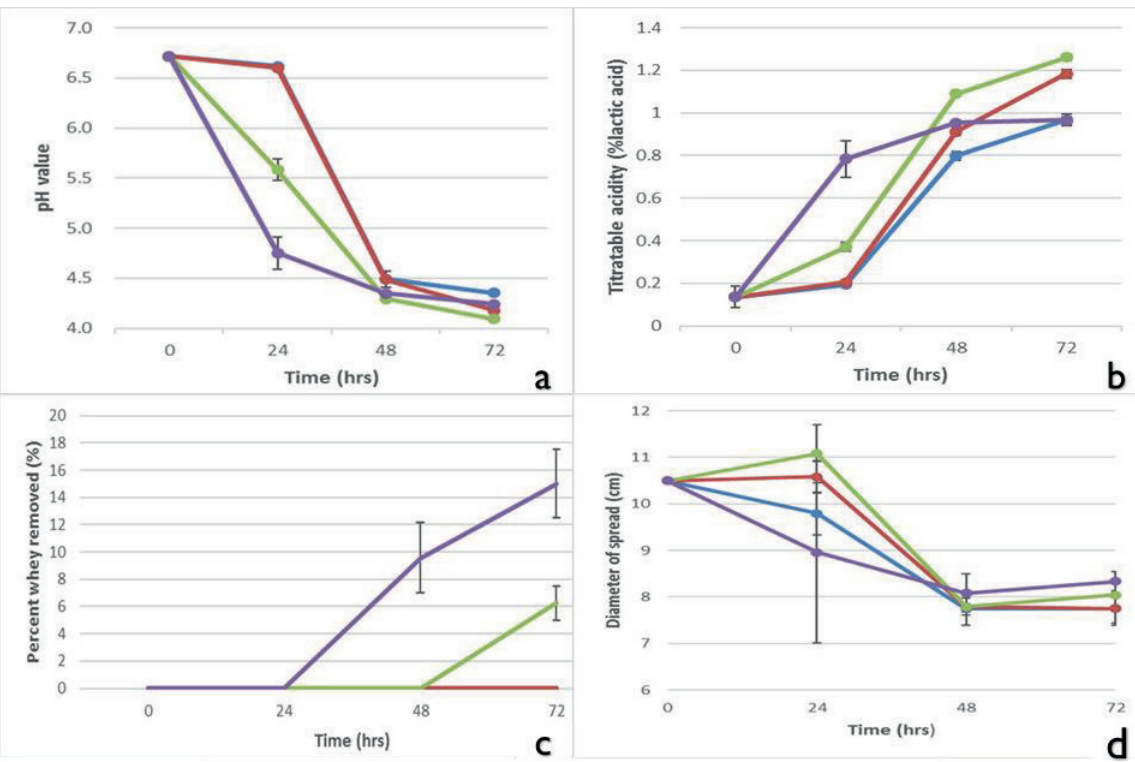

Fig 3. Effect of temperature on physicochemical properties of tonga mabisi during a single batch production. The Fig. shows changes of: a. $\mathrm{pH}, \mathrm{b}$. TTA, c. degree of syneresis and d. consistency with fermentation time in hours. The colour blue denotes the temperature $20^{\circ} \mathrm{C}$, red for $22^{\circ} \mathrm{C}$, green for $25^{\circ} \mathrm{C}$ and purple for $30^{\circ} \mathrm{C}$.

Syneresis is the separation of whey from the curd after coagulation and this can affect the quality of mabisi especially in terms of consistency and viscosity. Syneresis is desirable in products such as cheese where whey is a by-product but not in products like yoghurt and mabisi. No syneresis was observed in the single batch production of tonga mabisi after $24 \mathrm{~h}$ for each of the different temperatures (Fig 3c). However, the whey separation started soon after and reached $10 \%$ after $48 \mathrm{~h}$ for the samples incubated at $30^{\circ} \mathrm{C}$. This continued to increase until $15 \%$ at $72 \mathrm{~h}$. For samples incubated at $25^{\circ} \mathrm{C}$, the whey separation started after $48 \mathrm{~h}$ and reached a final value of $6 \%$ at $72 \mathrm{~h}$. Little or no syneresis was observed for samples incubated at $20^{\circ} \mathrm{C}$ and $22^{\circ} \mathrm{C}$ (Fig S1). This shows 
that a higher incubation temperature correlates with a higher degree of syneresis. A similar correlation has been reported for cheese making during curd processing [78]. Syneresis in the range between 14 and 19\% has been reported in a Namibian fermented buttermilk, Omashikwa [19] but it should be pointed out that such observations have not been reported often for traditional fermented milk products found in Africa.

Next, the effect of fermentation temperature on consistency (thickness) of mabisi was determined using the Adam's consistometer. For this a classification system with 4 classes was developed (Table 1 ) based on the observation of diameter of spread of the product in centimetre $(\mathrm{cm})$.

Table 1: Classification of mabisi consistency

\begin{tabular}{|l|l|l|l|l|l|}
\hline Class & 1 & 2 & 3 & 4 \\
\hline Consistency & Very thick & Thick & Medium & Thin \\
\hline $\begin{array}{l}\text { Diameter of } \\
\text { spread (cm) }\end{array}$ & $<6$ & $6-7$ & $7.1-8$ & $8.1-9$ \\
\hline Visual & \multicolumn{1}{|c|}{} & & & \\
& & & & & \\
& & & & & \\
\hline
\end{tabular}

Mabisi production begins with raw milk that has a very thin consistency of over $10.5 \mathrm{~cm}$ in diameter of spread. This diameter reduces over the course of fermentation bringing about "medium" to "thick" $(6-8 \mathrm{~cm})$ consistency once the milk has coagulated and this can be observed between $24-48 \mathrm{~h}$ of fermentation (Fig. 3d). This reduction in diameter of spread is essentially an increase in consistency from thin to thick, which can also be expressed in terms of classes 1-4 as indicated in Table 1 . The fermentation temperature, which shows a change in consistency at $24 \mathrm{~h}$ is $30^{\circ} \mathrm{C}$, where a "thin" or class 4 consistency $(9 \mathrm{~cm})$ was attained for samples fermented at this temperature. These samples went on to reach their peak consistency of nearly "medium" or class $3(8.1 \mathrm{~cm})$ at $48 \mathrm{~h}$ but thereafter, became thin again as a result of the high degree of syneresis $(15 \%)$ after $72 \mathrm{~h}(8.3 \mathrm{~cm})$. The consistency of the products fermented at $25^{\circ} \mathrm{C}, 20^{\circ} \mathrm{C}$ and $22^{\circ} \mathrm{C}$ all reached class $3(7.8-7.9 \mathrm{~cm})$ at $48 \mathrm{~h}$ with those fermented at $20^{\circ} \mathrm{C}$ and $22^{\circ} \mathrm{C}$ retaining this consistency at $72 \mathrm{~h}$ but the one at $25^{\circ} \mathrm{C}$ became slightly thinner at $72 \mathrm{~h}(8.0 \mathrm{~cm})$ due to syneresis (Fig. $\mathrm{S} 1$ ).

Few studies have analysed the consistency of traditional fermented milk products. A study on amasi from Zimbabwe by Mutukumira [21] only assessed consistency using a sensory panel to score samples on a 5-point hedonic scale, which was also done by Bille, Buys [19] on omashikwa of Namibia though they went further to analyse the viscosity of the fermented product. Other studies analysed the viscosity of commercial sour milk (amasi variants) from South Africa [79] and the Rwandan kivuguto variants during starter culture development [80] but there is no classification in place for such products. Hence, this study proposes the use of this classification system for such products in future studies or for product differentiation as is the case for stirred and set yoghurt [67].

\subsubsection{Microbial composition and aroma compounds}

The composition of the microbial community of tonga mabisi fermented at two temperatures $\left(25^{\circ} \mathrm{C}\right.$ and $30^{\circ} \mathrm{C}$ ) was determined using high throughput amplicon sequencing of DNA encoding $16 \mathrm{~S}$ rRNA gene fragments (Fig. 2a). A diverse composition of the microbial community was found in all mabisi samples regardless of the fermentation temperature applied. The most dominant genus responsible for the fermentation was found to be Lactococcus, which was present in all the samples analysed with relative abundances ranging from $13 \%$ to $42 \%$. The other major genera present include Acinetobacter, Aeromonas, Citrobacter, Enterobacter, Escherichia, Klebsiella, and Serratia. The same genera were reported by Schoustra, Kasase [24] in an earlier study on mabisi except for Aeromonas, Enterobacter, Escherichia and Serratia. The latter four genera were however found in a South African fermented milk, amasi [38]. Schoustra, Kasase [24] also reported the presence of Lactobacillus, Streptococcus and 
Leuconostoc but these genera were present in very low relative abundances $(<1 \%)$ in the tonga mabisi studied here.
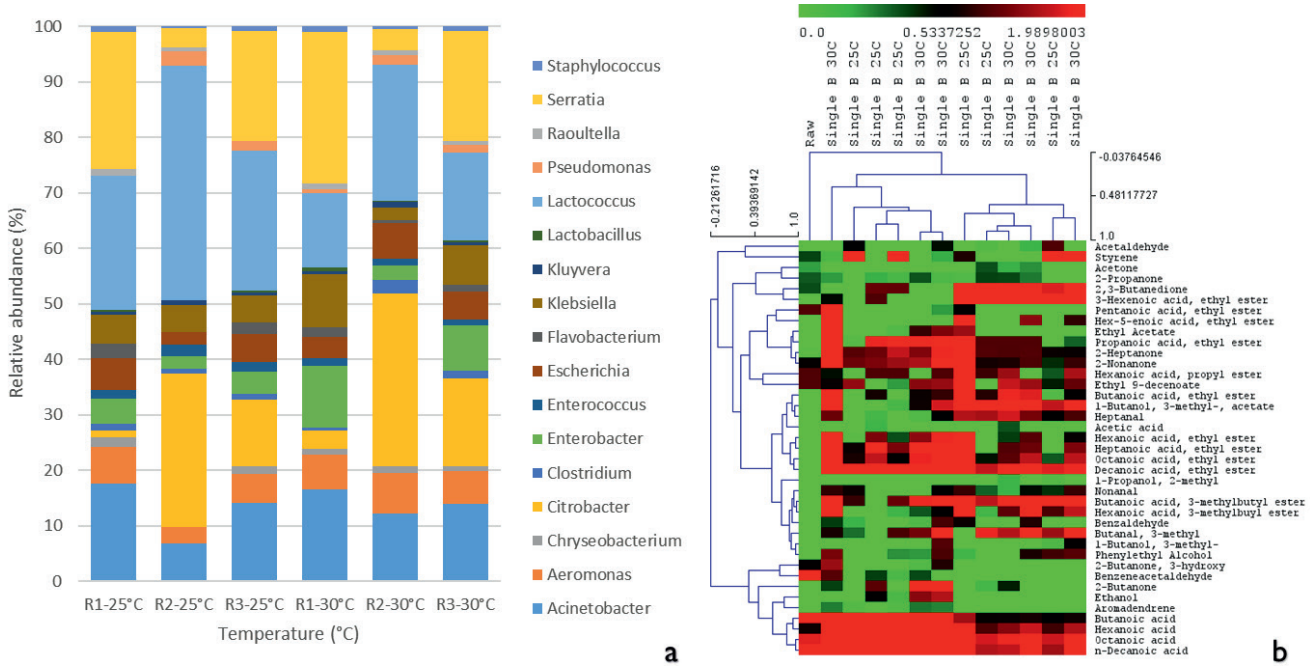

Fig 4. Microbial composition and aroma compounds of tonga mabisi produced from a single batch production. The figure shows: a. the relative abundance (\%) of the top 20 microbes at genus level ( $y-$ axis) in mabisi fermented at two temperatures, $25^{\circ} \& 30^{\circ} \mathrm{C}$ (x-axis) with $\mathrm{R} 1-3$ as replicates and $\mathrm{b}$. a heat map of volatile compounds from the same product with the colour green to red showing low to high levels of volatile compounds.

The volatile compounds detected in tonga mabisi were analysed and the results are shown in a heat map (Fig. 4b). A complex mixture of 15 esters, 7 ketones, 6 aldehydes, 3 alcohols, 2 terpenes and 6 fatty acids was found in the collective fermented product compared to mainly fatty acids in raw milk. Individual compounds are fully listed in Table S1 (Supplementary material 1). Temperature does not have a clear differentiating effect on the aroma profile of tonga mabisi produced in a single batch production. In similar products like amasi, 4 alcohols, 4 aldehyde, 4 ketones and 2 esters were reported $[22,81]$ while fermented buttermilk from Ethiopia reported 5 alcohols, 4 aldehydes, 5 ketones and 1 ester [32] and kivuguto variants reported fewer compounds [80].

\subsection{Effect of temperature on multiple batch mabisi production}

\subsubsection{Physicochemical properties}

To assess the degree of variation from one batch to another, three different batches of milk were used to produce mabisi on different days as biological replicates of tonga mabisi fermented at four different temperatures using new plastic containers. The $\mathrm{pH}$ values found (Fig. 5a) were similar to those observed in the single batch production in section 3.1.1 but there was a larger reduction in $\mathrm{pH}$ for samples incubated at $20^{\circ} \mathrm{C}(\mathrm{WT}) \& 22^{\circ} \mathrm{C}$ (RT) after $24 \mathrm{~h}$ to 6.1 . However, this trend slowed down at $48 \mathrm{~h}$ only reaching $\mathrm{pH} 4.9$ and 4.7 , respectively and finally, ending with $\mathrm{pH} 4.5$ after $72 \mathrm{~h}$. This could be the result of ambient temperature fluctuations since these fermentations were conducted on different days and could have had a slight bearing on the room and water temperatures under which they were incubated. On the other hand, the lowest $\mathrm{pH}$ attained after $72 \mathrm{~h}$ of fermentation at $25^{\circ} \mathrm{C}$ and $30^{\circ} \mathrm{C}$ was 4.4 . This $\mathrm{pH}$ was higher than that observed in section 3.1 but the fermentation trends were similar and reproducible. The latter temperatures were not affected by ambient temperature fluctuations, since they were kept constant throughout the fermentation in respective incubators. In general, multiple batch mabisi production showed larger standard deviation than the single batch, indicating considerable variation from 
one batch to another probably due to differences in raw milk quality and the differences in the composition of the initial microbial community present at the onset of each fermentation.

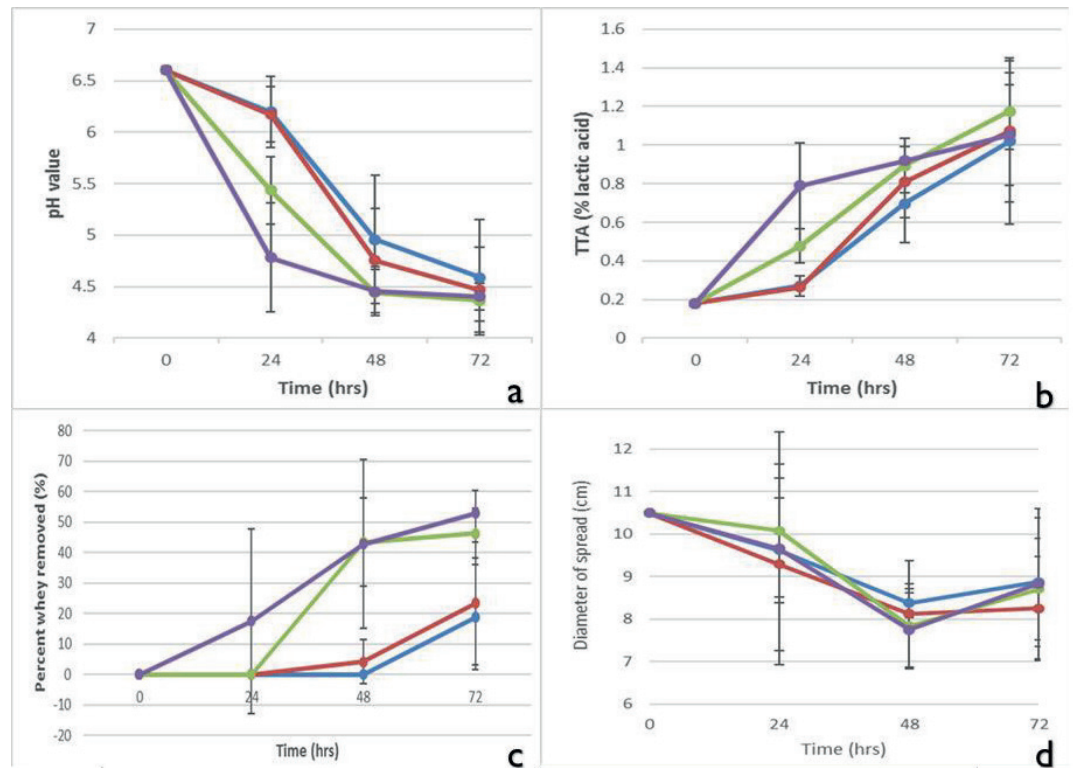

Fig 5. Effect of temperature on physicochemical properties of tonga mabisi produced from batch to batch. The figure shows changes in: a. $\mathrm{pH}, \mathrm{b}$. TTA, c. degree of syneresis and d. consistency with fermentation time (hours). The colour blue denotes the temperature $20^{\circ} \mathrm{C}$, red for $22^{\circ} \mathrm{C}$ green for $25^{\circ} \mathrm{C}$ and purple for $30^{\circ} \mathrm{C}$.

Early onset of syneresis was observed in samples fermented at $30^{\circ} \mathrm{C}$ with time point $24 \mathrm{~h}$ reaching $18 \%$, which continued to increase to $43 \%$ after $48 \mathrm{~h}$ and ending at $53 \%$ after $72 \mathrm{~h}$ (Fig. $5 \mathrm{c}$ ). For those batches of mabisi fermented at $25^{\circ} \mathrm{C}$, syneresis started after $24 \mathrm{~h}$ rising to $45 \%$ at $48 \mathrm{~h}$ then reaching a maximum of $48 \%$ after $72 \mathrm{~h}$. Syneresis for the samples fermented at $20^{\circ} \mathrm{C}$ only started after $48 \mathrm{~h}$ rising to $19 \%$ after $72 \mathrm{~h}$ whereas for those fermented at $22^{\circ} \mathrm{C}$, it was $5 \%$ at $48 \mathrm{~h}$ and then further increased to $23 \%$ after $72 \mathrm{~h}$. There was generally more syneresis in this experiment at all temperatures than in the single batch production experiment in section 3.1 .

The consistency (thickness) trends for samples fermented at $25^{\circ} \mathrm{C}$ and $30^{\circ} \mathrm{C}$ were similar to those observed in the single batch production but a slightly thicker consistency (class $3 ; 7.8 \mathrm{~cm}$ ) was attained at $48 \mathrm{~h}$ (Fig. $5 \mathrm{~d}$ ). A lower consistency (class $4 ; 9 \mathrm{~cm}$ ) was observed after $72 \mathrm{~h}$ due to a higher degree of syneresis. The consistencies of samples from batches fermented at $20^{\circ} \mathrm{C}$ and $22^{\circ} \mathrm{C}$ were also lower than those in the single batch production both at $48 \mathrm{~h}$ and $72 \mathrm{~h}$ (class 3 ) as they both fell in class 4.

\subsubsection{Microbial composition and aroma compounds}

The multiple batch variation in the composition of the microbial communities was determined (Fig. 6a). In this experiment, results for all four temperatures are presented. The mabisi samples were also dominated by Lactococcus sp. (21-24\%) but Lactobacillus sp. were also observed in samples incubated at $30^{\circ} \mathrm{C}$ with a higher relative abundance $(3 \%)$ than the single batch production $(<1 \%)$. The other differentiating aspect was the much lower proportion of the genus Serratia and higher presence of Pseudomonas. Apart from that, the overall microbial compositions found in the two experiments were similar. 

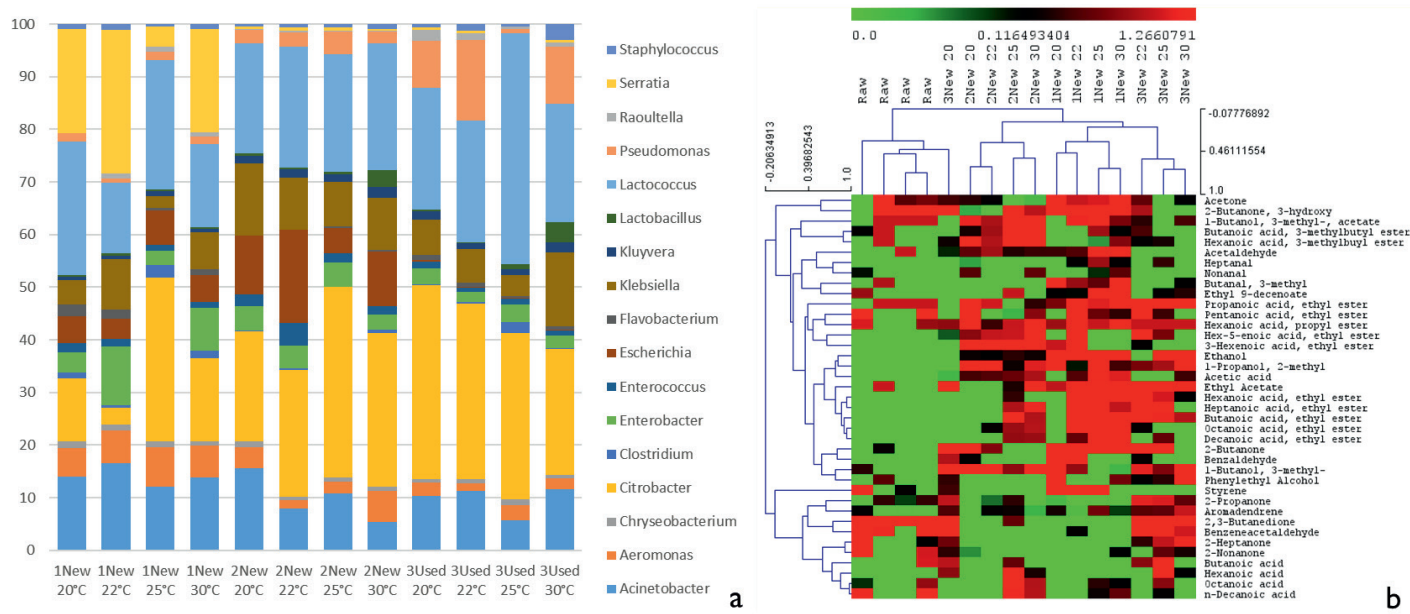

Fig 6. Microbial composition and aroma compounds of multiple batch mabisi production in new containers. Panel a. the relative abundance (\%) of the top 20 microbes at genus level in mabisi fermented at four temperatures, $20^{\circ}, 22^{\circ}, 25^{\circ} \& 30^{\circ} \mathrm{C}$ and b. a heat map of volatile compounds from the same products with the colour green to red showing low to high levels of volatile compounds, respectively. Hierarchical clustering of the samples is also shown in the heat map. The batch number is indicated as $1,2, \& 3$ on each bars.

The aroma compounds were similar to those found in the single batch production even at lower temperatures of $20^{\circ} \mathrm{C}$ and $22^{\circ} \mathrm{C}$ which were not analysed in that experiment. The only exception is that there was a lower relative abundance of fatty acids observed in this experiment than in the single batch production as shown in Fig. $6 \mathrm{~b}$. The cluster analysis reveals two main clusters: raw milk on the left with fewer compounds than mabisi on the right, which also has three sub-clusters for each batch apart one sample from batch 3 fermented at $20^{\circ} \mathrm{C}$. These sub-clusters show slight variation of aroma compounds from one batch to another, which might be linked to differences in microbial composition at species level.

\subsection{Effect of fermentation container type}

\subsubsection{Physicochemical properties}

Three different batches of milk were simultaneously fermented at different temperatures in washed containers which were previously used for tonga mabisi production with the objective to assess the effect of container type (used versus new). A much sharper decrease in $\mathrm{pH}$ was observed after $24 \mathrm{~h}$ in all samples fermented in used containers as compared to mabisi productions in which new containers were used (see section 3.1 and section 3.2 and Fig. S1, supplementary material 3). To elaborate this, we selected the results of samples fermented at two temperatures: a low temperature of $20^{\circ} \mathrm{C}$ (WT) and a high one of $25^{\circ} \mathrm{C}$ (Fig. 7). Figs. $7 \mathrm{a}$ and $7 \mathrm{~d}$ show that the $\mathrm{pH}$ of the used container was lower than the new one throughout the fermentation at both temperatures. However, the differences between the used and new container were not significant $(p>0.05)$. The rapid decrease in $\mathrm{pH}$ for samples fermented in used containers can be attributed to the formation of biofilms on the walls of the container during the previous fermentation, since the containers were only washed with hot water as practiced by the producers. These biofilms potentially act as a starter culture and in turn accelerate the fermentation in the initial stages.

A lower degree of syneresis was found for the used container as compared to the new one at both temperatures (Fig. 7c \& 7f). The low degree of syneresis produced mabisi with thicker consistencies after $72 \mathrm{~h}$ of class $2(7 \mathrm{~cm})$ and class 3 at $20^{\circ} \mathrm{C}$ and $25^{\circ} \mathrm{C}$, respectively compared to class 4 for both temperatures in the new container (Fig. 7c \& 7f). 

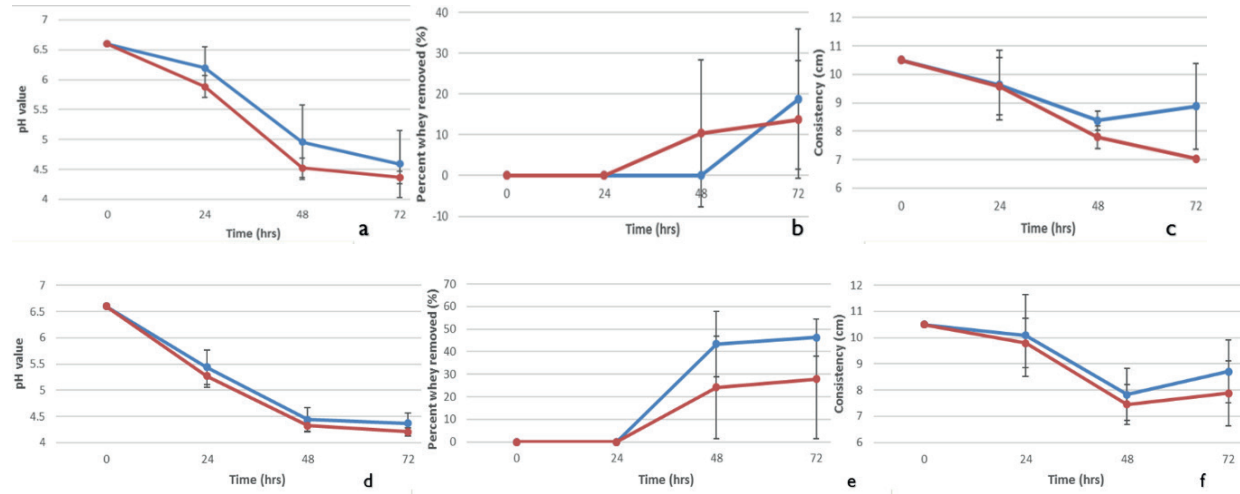

Fig 7. Effect of temperature on physicochemical properties of tonga mabisi produced in new and used containers. The figure shows changes in: $\mathrm{pH}(\mathrm{a} \& \mathrm{~d})$, degree of syneresis (b \& e) and consistency with fermentation time (c \& f) at temperatures of $20^{\circ} \mathrm{C}$ and $25^{\circ} \mathrm{C}$, respectively. The colour blue is for a new container and red for a used container.

Generally, the results show that syneresis and consistency have a reverse correlation in mabisi, since a higher degree of syneresis leads to lower consistency. This was observed particularly for products with high syneresis of $48-52 \%$ which resulted in mabisi with class 4 consistency (Table 1 ) of around $9 \mathrm{~cm}$ diameter of spread or more mainly for samples fermented at $25^{\circ} \mathrm{C}$ and $30^{\circ} \mathrm{C}$ after $72 \mathrm{~h}$ in the assessment of batch variation mabisi production using both new and used containers (Fig 3d \& S1). The relationship between syneresis and consistency has also been observed by Bille, Buys [19] in omasikwa. In addition, to improve the consistency of another traditional product amasi, $40-50 \%$ of whey was removed [21]. The removal of whey is also practiced in the so-called "thick-tonga mabisi" [53] though the proportion removed is unknown. Therefore, this study has established that syneresis levels of not more than $30 \%$ produce mabisi with a desirable consistency of class 3 (see Fig. 7e and 7f).

\subsubsection{Microbial composition and aroma compounds}

The composition of microbial communities of tonga mabisi produced in the used containers was also diverse (Fig. 8a) and dominated by species of the genus Lactococcus (22-44\%) as well. Lactobacillus $\mathrm{sp}$. were only observed in samples fermented at $30^{\circ} \mathrm{C}$ with a relative abundance of $4 \%$. The only difference between the mabisi produced in new and used containers was the higher proportions of members of the genera Escherichia and Pseudomonas in the former and latter containers, respectively. In general, tonga mabisi can be described as having a diverse microbial community composition regardless of fermentation temperature, different batches of production and use of new or used container over a three day fermentation period. Thus, the selected treatments did not affect the outcome of the fermentation in terms of microbial community composition. 

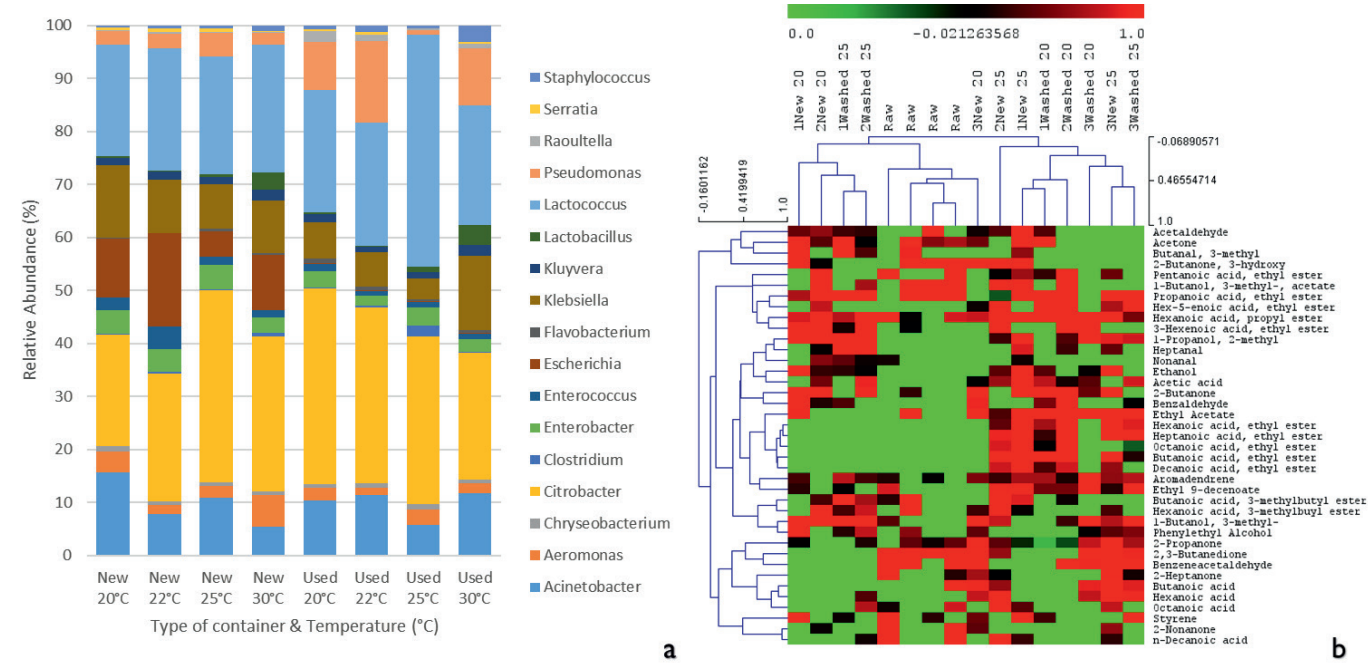

Fig. 8. Microbial composition and aroma compounds of mabisi production in new and used containers. The Fig. shows: a. the relative abundance (\%) of the top 20 microbes at genus level in mabisi fermented at four temperatures, $20^{\circ}, 22^{\circ}, 25^{\circ} \& 30^{\circ} \mathrm{C}$ and b. a heat map of volatile compounds from the same products with the colour green to red showing low to high levels of volatile compounds, respectively. Hierarchical clustering of the samples is also shown in the heat map.

The heat map shows that all raw milk samples were grouped in one sub-cluster with different and fewer aroma compounds than those found in mabisi (Fig. 8b). However, there is no clear distinction in the profile of aroma compounds found in mabisi produced in the new and used containers at 4 different temperatures.

\subsection{Effect of production method}

\subsubsection{Physicochemical properties}

Based on the observations of the effect of temperature on tonga mabisi, barotse mabisi was only incubated at two temperatures: $25^{\circ}$ and $30^{\circ} \mathrm{C}$. As compared to the lower temperatures $\left(20^{\circ} \mathrm{C}\right.$ and $22^{\circ} \mathrm{C}$ ), these temperatures produced a higher degree of syneresis in tonga mabisi $(20-50 \%)$, which is important for the barotse mabisi production method as it involves the sequential removal of whey followed by re-addition of raw milk (Fig.1b). Raw milk had a pH of 6.7, which dropped to pH 4.1 for samples incubated at $25^{\circ}$ and pH 4.3 for those incubated at $30^{\circ} \mathrm{C}$ after 3 days of fermentation (Fig. 9a). Thereafter, the $\mathrm{pH}$ for the samples incubated at $25^{\circ} \mathrm{C}$ rose slightly (to $\mathrm{pH} 4.3$ ) and the fermentation ended with the same $\mathrm{pH}$ value after a further three days of fermentation. However, for samples incubated at $30^{\circ} \mathrm{C}$, the $\mathrm{pH}$ dropped to 3.3 on the fifth day of fermentation and reached a final $\mathrm{pH}$ of 3.2 on the last day. The difference in the $\mathrm{pH}$ values for the final products was significant $(p<0.05)$ with the barotse mabisi incubated at $30^{\circ} \mathrm{C}$ producing a more acidic mabisi than the former. This $\mathrm{pH}$ was also much lower than in both the single batch and multiple batch production of tonga mabisi, which had similar $\mathrm{pH}$ to barotse mabisi fermented at $25^{\circ} \mathrm{C}$.
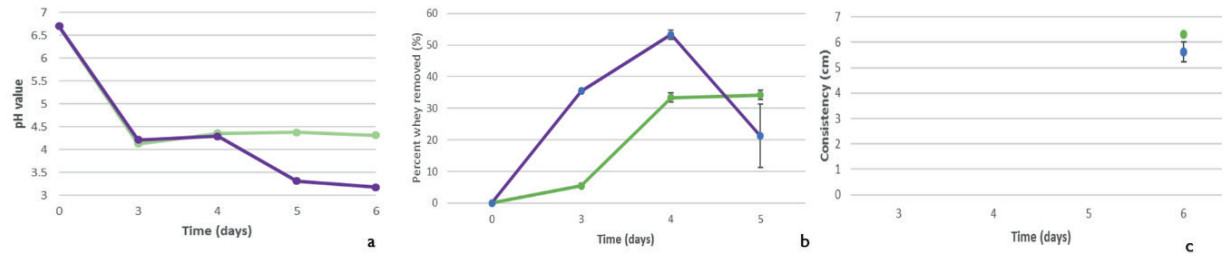
Fig 9. Effect of temperature on physicochemical properties of barotse mabisi fermented at two temperatures. The fig. shows changes in: a. $\mathrm{pH}$, b. degree of syneresis and c. consistency with fermentation time (hours). The colour green shows barotse mabisi incubated at $25^{\circ} \mathrm{C}$ and purple those at $30^{\circ} \mathrm{C}$. The fermentation at each was done in triplicate.

Syneresis was observed after three days of fermentation and samples incubated at $30^{\circ} \mathrm{C}$ had up to $35 \%$ in whey content at this stage, which further increased to a peak of $52 \%$ a day later and declined to $20 \%$ on the fifth day (Fig. 9b). On the other hand, samples fermented at $25^{\circ} \mathrm{C}$ had low whey separation after three days with only $5 \%$ syneresis, which later increased sharply to $35 \%$ the following day and remained the same on the fifth day. Cumulatively, more whey was produced in the barotse mabisi fermented at $30^{\circ} \mathrm{C}$ than at $25^{\circ} \mathrm{C}$, which implies that the product yield in volume terms was less for the production at $30^{\circ} \mathrm{C}(48 \%)$ compared to $25^{\circ} \mathrm{C}(58 \%)$. The degree of syneresis in barotse mabisi was comparable to the multiple batch production of tonga mabisi both in new and used containers (Figs. $5 c \& 7 e$ ).

Consistency was only measured at the end of fermentation (Fig. 9c). The barotse mabisi fermented at $25^{\circ} \mathrm{C}$ had a class 2 consistency $(6.3 \mathrm{~cm})$ whereas the one fermented at $30^{\circ} \mathrm{C}$ was thicker and had a class 1 consistency $(5.6 \mathrm{~cm})$. This is because the latter had a higher degree of syneresis and consequently, more whey was removed (52\%) which was replaced with raw milk leading to an increase in the total solid content and thus, a "very thick" consistency. It must be stated that not all the whey could be removed during the production of barotse mabisi because of the design of the container which retained a certain amount of whey. That generally, resulted in a final product having a slightly lower consistency than would be expected if a container, equipped with a better draining mechanism, was used. This shows that barotse mabisi had a thicker consistency than tonga mabisi (class 3-4).

\subsubsection{Microbial composition and aroma compounds}

The barotse mabisi (Fig. 10a) showed a different composition of the microbial community as compared to tonga mabisi (Fig. 4a). At $25^{\circ} \mathrm{C}$, Lactococcus sp. dominated barotse mabisi while at $30^{\circ} \mathrm{C}$ Lactobacillus sp. were dominant. Lactococcus had a relative abundance ranging from $84-91 \%$ when fermented at $25^{\circ} \mathrm{C}$ and $6-9 \%$ at $30^{\circ} \mathrm{C}$ whereas Lactobacillus had a range of $1-2 \%$ and $84-87 \%$, at each of the two temperatures, respectively. There was a much larger proportion of Lactococcus $(6-9 \%)$ in samples fermented at $30^{\circ} \mathrm{C}$ than Lactobacillus $(1 \%)$ in samples fermented at $25^{\circ} \mathrm{C}$. This suggests that during fermentation at $30^{\circ} \mathrm{C}$, Lactococcus was initially dominant as was the case in tonga mabisi but as the fermentation progressed, there was a shift towards Lactobacillus domination. This could be as a result of elevated temperature and low $\mathrm{pH}$ favouring the growth or survival of Lactobacillus. These results clearly show a significant effect of fermentation temperature on microbial community composition between two production methods and probably fermentation duration. The relative abundance of other microbes (non-LAB) in barotse mabisi was less than $10 \%$ whereas in tonga mabisi they accounted for $74 \%$ on average. 

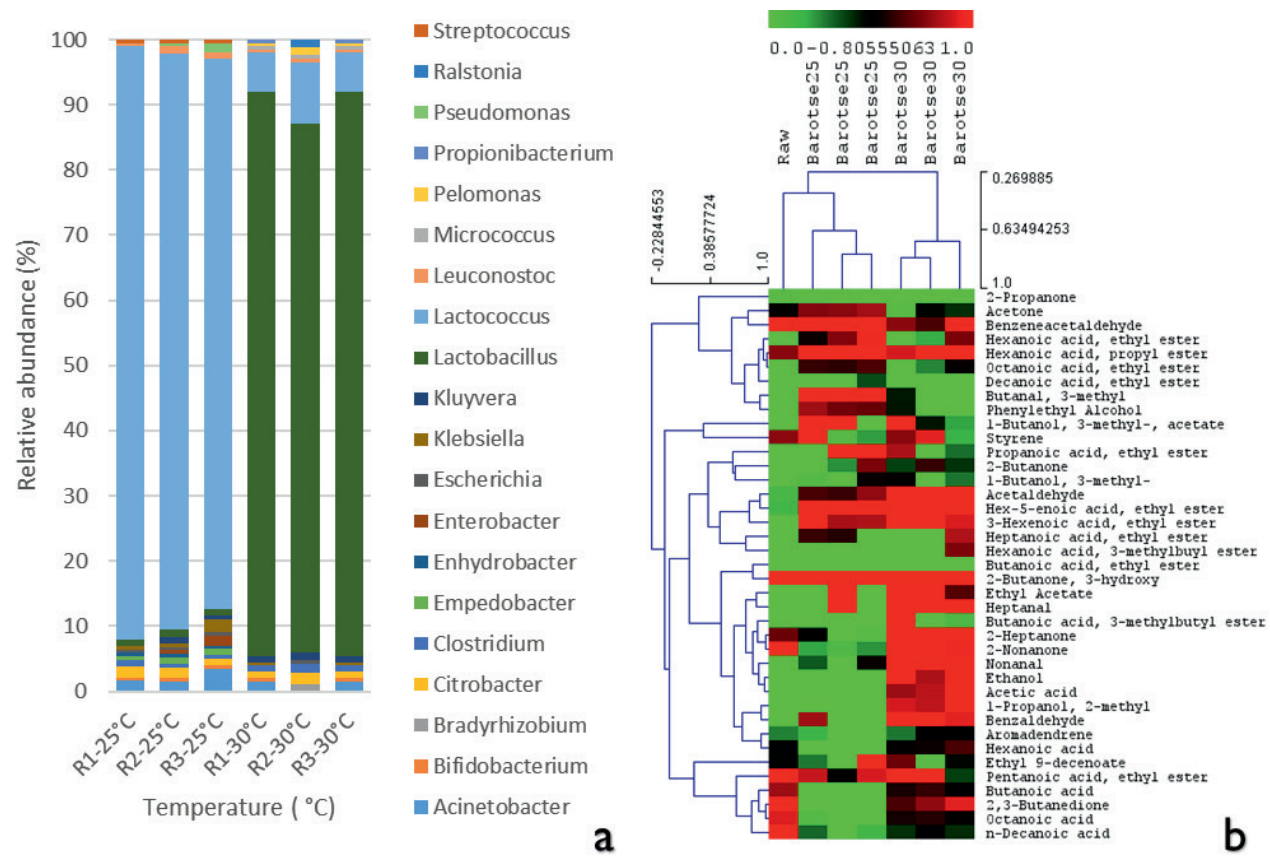

Fig 10. Microbial composition and aroma compounds of barotse mabisi fermented at two temperatures. The Fig. shows: a. the relative abundance (\%) of the top 20 microbes at genus level in mabisi fermented at two temperatures, $25^{\circ} \& 30^{\circ} \mathrm{C}$ and $\mathrm{b}$. a heat map of volatile compounds from the same product with the colour green to red showing low to high levels of volatile compounds, respectively. Hierarchical clustering of the samples is also shown in the heat map.

Fermentation temperature was found to have a pronounced effect on the composition of aroma compounds in barotse mabisi with two clusters clearly separated on basis of fermentation temperature (see heat map Fig. 10b). The samples fermented at $30^{\circ} \mathrm{C}$ produced more compounds than those fermented at $25^{\circ} \mathrm{C}$ which include 12 esters, 2 alcohols, 2 fatty acids, 1 terpene, 6 ketones, and 5 aldehydes that were in low relative abundance in samples fermented at $25^{\circ} \mathrm{C}$. This difference is most likely is caused by the differences in the composition of the microbial community occurring at the two incubation temperatures.

\section{Conclusion}

Fermentation temperature did not show a clear effect on the composition of microbial communities of tonga mabisi, which retained a diverse and stable microbial community regardless whether the production was done in replicates from a single batch or multiple batches of raw milk. Also use of new containers or previously used containers did not lead to clear differences in the complex composition of the microbial community. In tonga mabisi, Lactococcus was the dominant genus. Interestingly, temperature had a clear effect on microbial community composition in barotse mabisi with the mesophilic Lactococcus dominating the fermentation at $25^{\circ} \mathrm{C}$ and the thermophilic Lactobacillus dominating at $30^{\circ} \mathrm{C}$. Furthermore, more aroma compounds were produced at $30^{\circ} \mathrm{C}$ in barotse mabisi than at $25^{\circ} \mathrm{C}$ whereas tonga mabisi retained a similar aroma profiles regardless of temperature or treatment and moreover produced more aroma compounds than similar African traditional fermented products. 
Temperature exerted a profound effect on fermentation time of tonga mabisi. Furthermore, used containers also accelerated fermentation whereas new containers coupled with low ambient temperatures slowed down fermentation up to three days. For this study, a classification system for mabisi consistency was developed. High fermentation temperatures resulted in a higher degree of syneresis, which led to a mabisi with a 'thin' consistency of class 4 after 3 days. On the other hand, lower temperatures produced a thicker product of class 3 or lower in tonga mabisi. However, barotse mabisi produced a much thicker mabisi of class 2 at $25^{\circ} \mathrm{C}$ and class 1 at $30^{\circ} \mathrm{C}$.

The shifts between the mesophilic and thermophilic bacteria in the barotse mabisi showed a clear difference in types of aroma compounds produced at lower and higher temperatures, which may have an implication on the taste of the product at different times of the year depending the prevailing temperature or season or production location. There is need to carry out a sensory evaluation in order to establish the preferred taste and to validate the developed consistency classification system using a trained tasting panel as well as consumers. In addition, the established process conditions can be used to scale up mabisi production. 


\section{Supplementary material}

Table S1. List of aroma compounds found in tonga \& barotse mabisi

\begin{tabular}{|c|c|c|c|c|c|}
\hline Alcohols & Ketones & Aldehydes & Terpenes & Esters & $\begin{array}{l}\text { Carboxylic } \\
\text { acids }\end{array}$ \\
\hline Ethanol & Acetone & Acetaldehyde & Styrene & Ethyl Acetate & Acetic acid \\
\hline $\begin{array}{l}\text { 2-methyl-1- } \\
\text { Propanol }\end{array}$ & 2-Butanone & 3-methylbutanal, & $\begin{array}{l}\text { Aromadendr } \\
\text { ene }\end{array}$ & Propanoic acid, ethyl ester & Butanoic acid \\
\hline \multirow{13}{*}{$\begin{array}{l}\text { 3-methyl-1- } \\
\text { Butanol }\end{array}$} & 2,3-Butanedione & Heptanal & & Butanoic acid, ethyl ester & Hexanoic acid \\
\hline & 2-Propanone & Nonanal & & $\begin{array}{l}\text { 1-Butanol, 3-methyl-, } \\
\text { acetate }\end{array}$ & $\begin{array}{l}\text { Phenylethyl } \\
\text { Alcohol }\end{array}$ \\
\hline & 2-Heptanone & Benzaldehyde & & 2-Butenoic acid, ethyl ester & Octanoic acid \\
\hline & $\begin{array}{l}\text { 3-hydroxy2- } \\
\text { Butanone } \\
\text { (Acetoin) }\end{array}$ & $\begin{array}{l}\text { Benzeneacetaldeh } \\
\text { yde }\end{array}$ & & Hexanoic acid, ethyl ester & n-Decanoic acid \\
\hline & 2-Nonanone & & & $\begin{array}{l}\text { Butanoic acid, 3- } \\
\text { methylbutyl ester }\end{array}$ & \\
\hline & & & & $\begin{array}{l}\text { Hex-5-enoic acid, ethyl } \\
\text { ester }\end{array}$ & \\
\hline & & & & Octanoic acid, ethyl ester & \\
\hline & & & & Hexanoic acid, propyl ester & \\
\hline & & & & $\begin{array}{l}\text { 3-Hexenoic acid, ethyl } \\
\text { ester }\end{array}$ & \\
\hline & & & & Heptanoic acid, ethyl ester & \\
\hline & & & & $\begin{array}{l}\text { Hexanoic acid, 3- } \\
\text { methylbuyl ester }\end{array}$ & \\
\hline & & & & Decanoic acid, ethyl ester & \\
\hline & & & & Ethyl 9-decenoate & \\
\hline
\end{tabular}




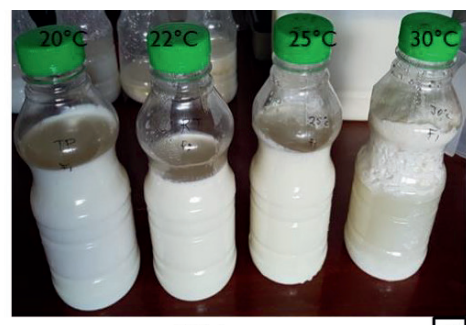

24 hours

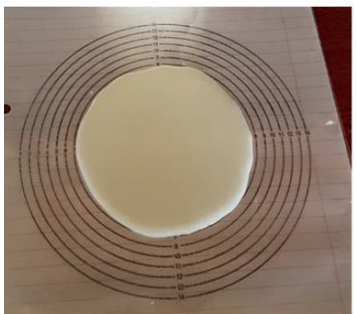

Water temp $\left(20^{\circ} \mathrm{C}\right)$

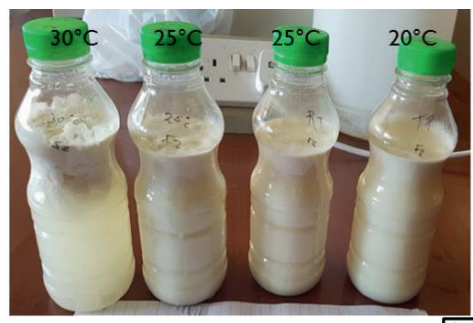

48 hours

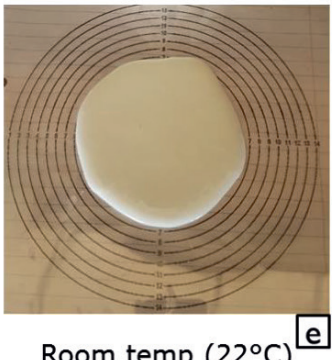

Room temp $\left(22^{\circ} \mathrm{C}\right)$

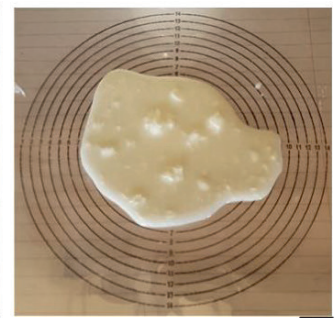

At $25^{\circ} \mathrm{C}$

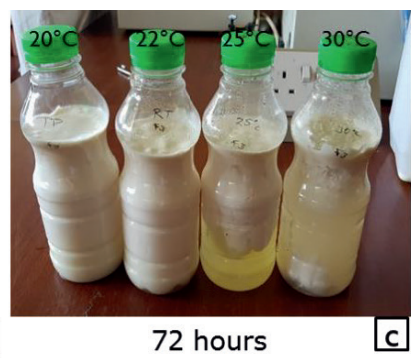

72 hours

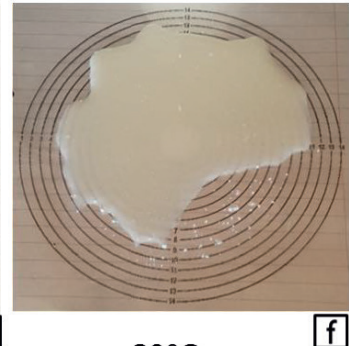

$30^{\circ} \mathrm{C}$

Fig. S1. Visual effect of fermentation temperature on syneresis and consistency. Figs. a-c show syneresis level at 24,48 and $72 \mathrm{~h}$ at four different temperatures: $20,22,25 \& 30^{\circ} \mathrm{C}$. Figs. d-f show the consistency of mabisi at four different temperatures after $72 \mathrm{~h}$ of fermentation. 


\section{Chapter 5}

\section{Microbial community dynamics of three types of mabisi, a traditionally fermented milk.}

Himoonga Bernard Moonga, 1,3,4, Sijmen E. Schoustra ${ }^{3,4}$, Anita R. Linnemann², Joost van der Heuvel ${ }^{3}$, John Shindano ${ }^{4}$ and Eddy J. Smid ${ }^{1}$

Affiliation:

1. Laboratory of Food Microbiology, Wageningen University and Research, Wageningen, The Netherlands

2. Food Quality and Design, Wageningen University and Research, Wageningen, The Netherlands

3. Laboratory of Genetics, Wageningen University and Research, Wageningen, The Netherlands

4. Department of Food Science \& Nutrition, School of Agricultural Sciences, University of Zambia, Lusaka, Zambia 


\section{Abstract}

Spontaneous fermentation can exert selection pressure, which may to lead to changes in microbial community composition of the fermenting microbes. The effect of production method and producer on the microbial community composition was determined for three types of mabisi, a traditionally fermented milk in Zambia made by a spontaneous fermentation process at ambient temperature. A field trial involving our experienced producers was conducted where each of them made 10 production cycles of each type of mabisi, namely; the tonga, illa and backslopping mabisi. Samples were analysed for physicochemical properties including $\mathrm{pH}$, titratable acidity (TTA), consistency and aroma compound profile and for microbial community composition by $16 \mathrm{~S}$ rRNA gene amplicon sequencing. The mean $\mathrm{pH}$ for all three types of mabisi was $4.36 \pm 0.28$ with no significant differences among the processing methods. However, differences did appear among the producers $(p<0.05)$ with one producer having a higher $\mathrm{pH}$ than the others. Tonga mabisi had the thickest consistency followed by the backslopping type and lastly, illa mabisi. The most important aroma compounds were aldehydes, alcohols, esters, ketones and terpenes, which were present at their highest levels in backslopping and illa mabisi from the $10^{\text {th }}$ cycle due to the type of microbes present. Tonga mabisi had a complex diverse bacterial community composition throughout the 10 production cycles that did not change during the production cycles. Backsloppping and illa mabisi started off with a diverse bacterial composition in the $1^{\text {st }}$ cycle, which changed to be dominated by species of the genera Lactococcus and Lactobacillus after the $10^{\text {th }}$ production cycle. This study shows that the production method of mabisi exerts a selection pressure that shapes the microbial community structure, which may impact the sensorial and other physical product characteristics. 


\section{Introduction}

In nature, various eco-systems exist that are dominated by communities of microbes, such as the soil, human gut as well as fermented foods $[52,82,83]$. In these systems, microbial species co-exist and the species diversity in these systems can be described in terms of the number of species present, their relative abundance and the evenness of the species distribution in the community. It has been observed that similar systems harbour similar species diversity and both biotic and abiotic factors are hypothesised to stabilise eco-systems. These factors impose selection pressure that may alter the species diversity in terms of number of species and their relative abundance. This selective process has also been named 'species sorting' [84, 85].

Here, we use traditional fermented foods to study how changes in selective pressure can alter species diversity over multiple cycles of propagation. Many traditional fermented foods harbour a characteristic community of microorganisms present naturally in and on the products that are involved in the spontaneous fermentation that results in a product with a complex microbial community. In our study, we use Mabisi, a traditional fermented milk product from Zambia.

Mabisi is made by spontaneous fermentation of raw milk at ambient temperature in a calabash, metal or plastic container. Previous work has shown that the community of fermenting microbes is comprised of around six to 10 main groups of lactic acid and acetic acid bacteria [24]. Several different processing methods exist, each starting with fresh milk as the raw material for fermentation. A countrywide survey revealed that there are seven types of mabisi: tonga, thicktonga, illa, barotse, backslopping, creamy and cooked type with the tonga type being the most popular [53]. Out of these, illa and backslopping mabisi both involve transfer of product from one batch to another (referred to as backslopping) while illa processing also has an agitation (churning) step. Both products (illa and backslopping mabisi) can be produced continuously for at least 6 months. Tonga-type processing, on the other hand does not involve transfer of product from batch to batch.

As a result of repeated cycles of batch production, the different processing methods impose a different abiotic selection pressure on microbial communities in the products. We hypothesise that after various rounds of propagation, the species diversity in the microbial communities will be altered under the influence of these selection pressures such that different methods of processing lead to distinct microbial communities in terms of their species diversity. To test this idea, we studied the changes in microbial community composition and community dynamics as a function of three types of mabisi processing (i.e. tonga, illa and backslopping) and number of production cycles, respectively. The study involved the production of 10 cycles of batch propagation for each type of mabisi by four different producers using their own raw milk in their respective home settings in rural Zambia. The changes in the microbial communities linked to these production cycles gives an impression of their resilience and stability when subjected to selection pressure over a period of time. We further explored the physiochemical properties of the corresponding products and linked the volatile compounds to the microbial communities. The link between the physicochemical properties and the microbial communities is important for product optimisation and for developing production standards for such traditional products. This information is not only useful for answering fundamental questions about microbial interactions but also for starter culture development. 


\section{Material and methods}

\subsection{Mabisi production}

In this study, we used three types of mabisi processing methods: tonga, illa and backslopping (Fig. 1). Tonga mabisi was produced by sieving raw milk into a 2-litre plastic container (Fig S1) and allowing it to ferment at room temperature for $48 \mathrm{~h}$, after which it was stirred (Fig $1 \mathrm{a}$ ). The process for backslopping mabisi was similar to tonga mabisi but after the first $48 \mathrm{~h}$ of fermentation and stirring, $70 \%$ of the product was removed from the container for consumption and fresh raw milk was added and mixed, then left to ferment for a day. After a day the container was shaken to mix the product and another $70 \%$ of mabisi was removed, which was replaced by fresh raw milk and the production was repeated till 10 cycles were made (Fig. 1b). Illa mabisi followed a similar production process as backslopping except that it had an agitation (churning) step of 10-20 minutes at each time for 3-5 times a day during fermentation (Fig 1c). During the removal of $70 \%$ of mabisi for consumption, butter granules were also removed from the product. For all three types of mabisi processing, 10 production cycles were performed.

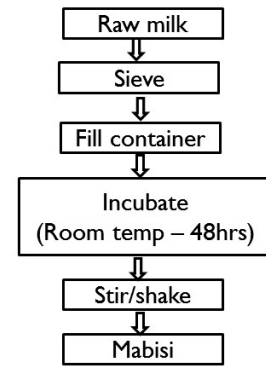

Tonga mabisi

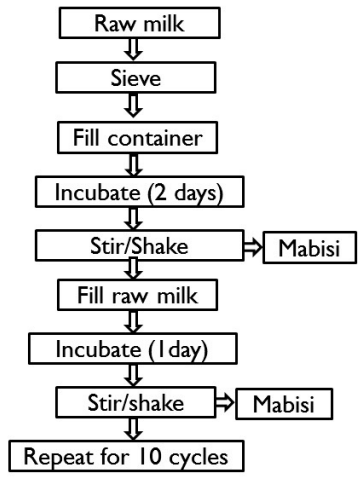

Backslopping mabisi b

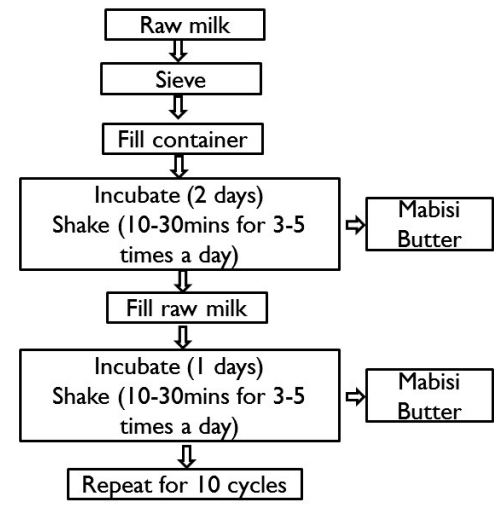

Illa mabisi

Fig. 1. Production flow diagrams of three types of mabisi: (a) tonga, (b) backslopping and (c) illa mabisi.

\subsection{Experimental design}

The three types of mabisi were all produced by four different producers in their respective houses with raw milk coming from their own cows. Each of the producers was given three new sterile 2-litre plastic containers for the production of each type of mabisi. The producers were taken as replicates for the three mabisi processing methods (Fig. 2). The first fermentation took three days for all types of mabisi mainly because of the new container and cool temperature $\left(12-22^{\circ} \mathrm{C}\right)$ as the study was carried during the cold season (July 2017). The samples were collected in sterile plastic bottles and placed in a cool box with ice, then taken for physicochemical analysis. The samples for microbial composition and aroma compounds analysis were frozen at $-20^{\circ} \mathrm{C}$. Samples for backslopping and illa mabisi were collected daily while those for tonga mabisi were collected every two days. 

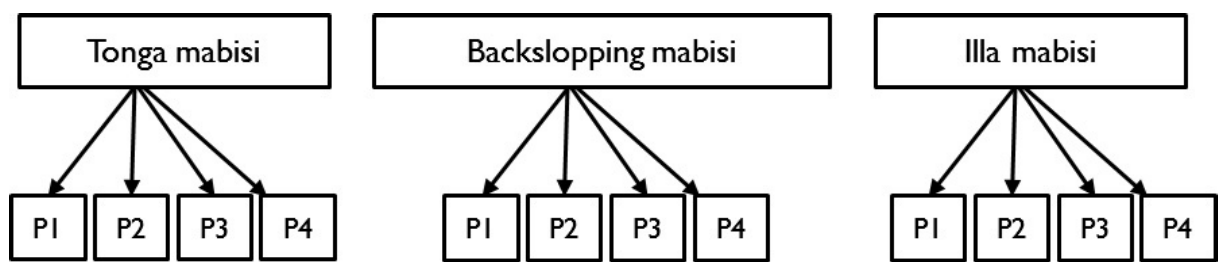

Fig. 2. Experimental layout for three types of mabisi and four producers for each type. Where $P 1$ denotes producer 1, P2 - producer 2, P3 - producer 3 and P4 - producer 4.

\subsection{Physicochemical properties}

The mabisi samples were analysed for $\mathrm{pH}$, titratable acidity (TTA) and consistency. The $\mathrm{pH}$ was analysed using a digital $\mathrm{pH}$ meter and the acidity was analysed according to the AOAC official methods [73]. Consistency was analysed using the Adam's consistometer which measures the diameter of spread of a semi-liquid product after 30 s [74, 75].

\subsection{Microbial composition}

The mabisi samples were analysed by a culture independent method. DNA was extracted from the mabisi samples and purified as described by Schoustra, Kasase [24] and in chapter 3. Next, the purified DNA samples were sent for bacterial 16S rRNA gene amplicon paired-end sequencing of the V4 hypervariable region (341F-785R) on the MiSeq Illumina platform performed by LGC genomics (Berlin, Germany).

For further data processing and statistics the QIIME pipeline [57], modified by Bik, Costello [58] was used. Paired-end reads were joined using join_paired_ends.py (with minimum overlap 10 basepairs) after which sequences were trimmed and filtered using cutadapt (v1.11 -q 20, -m 400, [59]) using the known primer sequences CCTACGGGNGGCWGCAG and GACTACHVGGGTATCTAAKCC to trim both sides of the sequence. These trimmed sequences were then checked for chimera's, using uchime (v4.2.20, gold database, [60]). Sequences with a chimera score lower than 0.28 were retained. After trimming, filtering and a quality check using pick_open_reference_otus.py (-s 0.1, enable_rev_strand_match TRUE, -align_seqs_min_length 75, -pick_OTU_similatiry 0.95), the sequences were clustered into operational taxonomic units (OTUs). Taxonomy of the resulting OTUs was assigned to representative sequences using the Greengenes ( $v 13.5$ ) rRNA database. This algorithm gives a representative sequence for an OTU, which is subsequently used to perform a local blast using the gold database from uchime. The taxonomy from the top ranking BLAST hit was used for further data processing. We carried out a hierarchical clustering on all mabisi sample data.

\subsection{Aroma compounds}

Volatile organic compounds (VOC's) in the mabisi samples were measured using Headspace-Solid Phase Microextraction Gas Chromatography-Mass Spectrometry (HS-SPME GC-MS) with a Trace 1300 Gas Chromatograph (Thermo Fisher) coupled to a TriPlus RSH autosampler (Thermo Fisher) and an ISQ QD mass spectrometer (Thermo Fisher). Frozen samples were incubated at $60^{\circ} \mathrm{C}$ for 20 min. Volatile compounds were extracted for $20 \mathrm{~min}$ at $60^{\circ} \mathrm{C}$ using an SPME fiber (Car/DVB/PDMS, Supelco). The compounds were desorbed from the fiber for 2 min onto a Stabilwax $®$-DA column (30 $\mathrm{m}$ length, $0.25 \mathrm{~mm}$ ID, $0.5 \mu \mathrm{m} \mathrm{df}$, Restek). The PTV was heated to $250^{\circ} \mathrm{C}$ and operated in split mode 
at a ratio of $1: 25$. The GC oven temperature was kept at $40^{\circ} \mathrm{C}$ for 2 min, raised to $240^{\circ} \mathrm{C}$ with a slope of $10^{\circ} \mathrm{C} / \mathrm{min}$ and kept at $240^{\circ} \mathrm{C}$ for $5 \mathrm{~min}$. Helium was used as carrier gas at a constant flow rate of $1.2 \mathrm{ml} / \mathrm{min}$. Mass spectral data were collected over a range of $\mathrm{m} / \mathrm{z} 33-250$ in full-scan mode with 3.0030 scans/second. Data were analysed using Chromeleon ${ }^{\circ} 7.2$. The ICIS algorithm was used for peak integration and the NIST main library to match the mass spectral profiles with the profiles of NIST. Peak areas were calculated using the MS quantification peak (highest $\mathrm{m} / \mathrm{z}$ peak per compound). The peak area data were normalised and used construction heat maps using multiple experiment viewer (Mev) version 4.9 .0 software. We carried out a hierarchical clustering on all mabisi sample data.

\subsection{Statistical analysis}

The data was analysed using analysis of variance (ANOVA) at 95\% significance level and mean comparisons were performed by Tukey test at $95 \%$ significance level using SPSS version 22 . The PERMANOVA was performed on communities and aroma profiles using the vegan package $(R)$ using the bray distance measure and 10000 permutations. All main effects and two-way interactions were tested using producer, method and cycle as categorical explanatory variables. Further, a KruskalWallis test was performed on the bacterial communities to identify the one that changed the most in relative abundance with time.

\section{Results}

The results of this study are presented in three sections describing (i) the physiochemical properties of the products, (ii) bacterial composition of the mabisi types and (iii) profiles of aroma compounds.

\subsection{Physiochemical properties}

We found that the $\mathrm{pH}$ dropped from the normal $\mathrm{pH}$ of milk ranging from 6.6 to 6.8 to an average value of $4.36 \pm 0.28$ for the three types of mabisi (Fig. 1). Illa type had the highest mean $\mathrm{pH}(4.41)$ while tonga type had the lowest $(\mathrm{pH} 4.33)$ but there were no significant differences among the types of mabisi. However, there were significant differences among products from the different producers, with producer 4 having a higher $\mathrm{pH}$ than the rest $(\mathrm{p}<0.05)$. This could be attributed to a lower temperature in the producer's house particularly, the incubation area, which was on a concrete floor in a cool room during the cold season $\left(12-20^{\circ} \mathrm{C}\right)$. The other producers placed their containers on wooden tables during incubation, which were warmer than the floor (Fig. S2). For the production cycles, only two cycles had significantly different mean $\mathrm{pH}$ values i.e. the first cycle was higher than the $10^{\text {th }}$.

The titratable (TTA) exhibited a similar pattern as the pH (Figs. 1e-g), which when correlated revealed at strong negative relationship $(R=-0.928)$. 

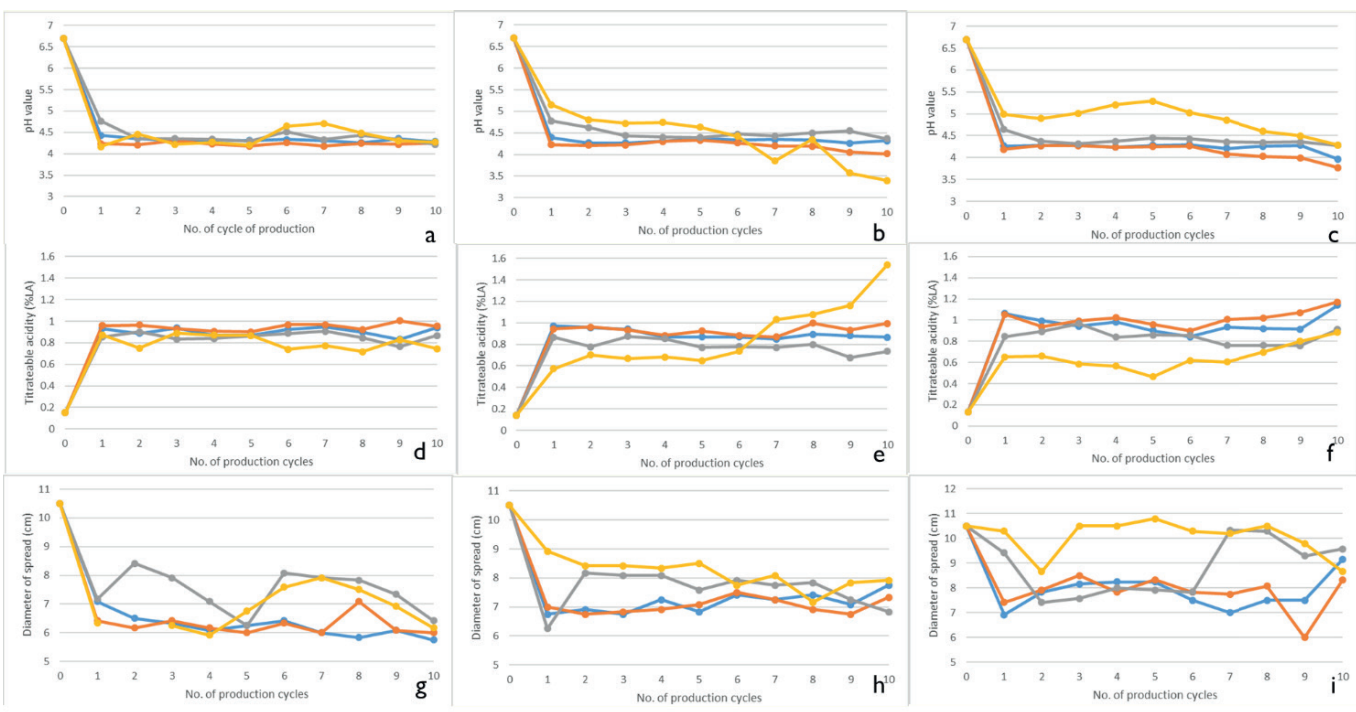

Fig. 1. Changes in pH, TTA and consistency in three types of mabisi produced over a 10 cycle fermentation. 1a-c shows changes in pH for tonga (a), backslopping (b) and illa (c); 1d-f shows changes in TTA; and $1 \mathrm{~g}$-i shows changes in consistency for the three types of mabisi. The colours show the different producers: producer 1-blue, producer 2-orange, producer 3-grey and producer 4-yellow.

The consistency was measured with an Adam's consistometer which measures the diameter of spread of a semi-solid fluid in one minute. The smaller the diameter of spread, the thicker the consistency of the product. The mean consistency was significantly different among the three types of mabisi with tonga type being the thickest $(6.7 \mathrm{~cm})$, followed by backslopping $(7.5 \mathrm{~cm})$ and illa type being the least $(8.6$ $\mathrm{cm})(p<0.05)$ as depicted in Figs. $1 \mathrm{~g}-\mathrm{i}$. There was also a difference between the producers with producers $1 \& 2$ having products with a significantly thicker consistency than products made by the other two producers $(3 \& 4, p<0.05)$. However, the variations observed in consistency of the products from one cycle to another were not significant ( $p>0.05)$, (Table S1).

\subsection{Microbial community composition}

The three types of mabisi were each produced in 10 cycles of repeated production and the $1^{\text {st }}, 6^{\text {th }}$ and $10^{\text {th }}$ cycles were sampled for microbial community composition analysis by $16 \mathrm{~S}$ rRNA amplicon sequencing. The overall bacterial community composition of the fresh milk used as raw material and the three types of mabisi (Fig. 2a) as well as the changes in community composition for three of the selected production cycles for each type of mabisi (Fig. 2b) were analysed. Raw milk had a more diverse bacterial community composition than all three types of mabisi. However, the bacterial communities in tonga mabisi were more complex and diverse than in illa and backslopping mabisi (Fig 2). Tonga mabisi was dominated by the genera: Lactococcus (28\%), Streptococcus (15\%), Klebsiella (15\%), Enterobacter (12\%), Aeromonas (7\%), Acinetobacter (5\%), Citrobacter (4\%), Escherichia (3\%), Buttiauxella (3\%) and Kluyvera (2\%). Other genera were present but at much lower relative abundance. Illa mabisi had a 
larger proportion of Lactobacillus (29\%), Enterococcus (9\%) and Staphylococcus (7\%) than tonga mabisi whereas backslopping mabisi was clearly dominated by Lactobacillus (42\%) and Lactococcus (27\%) with a considerable presence of Leuconostoc (2\%).
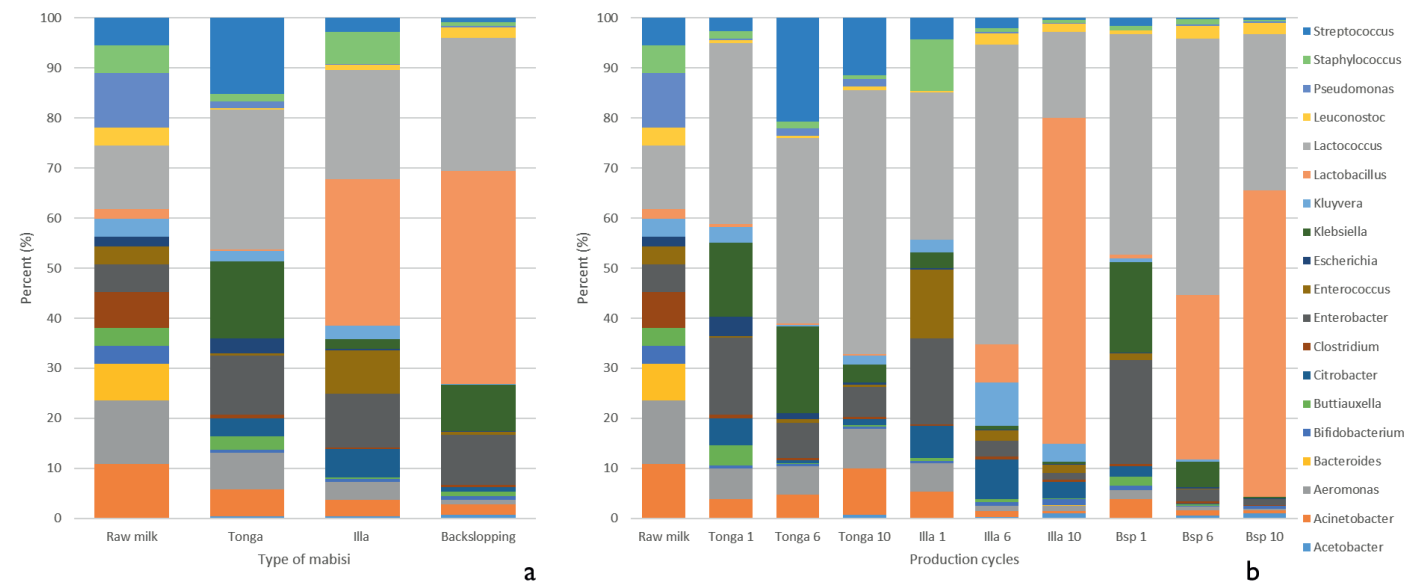

Fig. 2. Bacterial community composition of three types of mabisi: tonga, illa and backslopping (Bsp) mabisi. The figure shows the bacterial community composition of: a) the average composition for each type of mabisi and raw milk, b) three selected production cycle time points $\left(1^{\text {st }}, 6^{\text {th }} \& 10^{\text {th }}\right)$ for each type of mabisi.

Fig. $2 \mathrm{~b}$ shows the bacterial composition of the three types of mabisi at three selected production cycle time points: $1^{\text {st }}, 6^{\text {th }}$ and $10^{\text {th }}$ cycle. Here, we see that tonga mabisi had a fairly stable composition dominated by Lactococcus whose relative abundance increased slightly by $1 \%$ to reach $37 \%$ from the $1^{\text {st }}$ to the $6^{\text {th }}$ cycle but ended with a much higher proportion of $53 \%$ in the $10^{\text {th }}$ cycle. This composition was also similar to the first cycles for both illa and backslopping mabisi. However, substantial changes were observed in the $6^{\text {th }}$ and $10^{\text {th }}$ cycles. The proportion of Lactobacillus and Lactococcus increased to $8 \%$ and $60 \%$, respectively in the $6^{\text {th }}$ cycle of illa mabisi production and the former increased further to $65 \%$ in the $10^{\text {th }}$ cycle while the latter reduced to $17 \%$. In contrast, backslopping mabisi had a higher relative abundance of Lactobacillus (33\%) and a lower relative abundance of Lactococcus (51\%) than illa mabisi in the $6^{\text {th }}$ cycle of production. By the $10^{\text {th }}$ cycle, Lactobacillus increased further to $61 \%$ and Lactococcus reduced to $31 \%$. During this cycle, Lactobacillus clearly dominated both products reducing the other microbes overall proportions. In addition, there was a clear reduction of Streptococcus in the $6^{\text {th }}$ and $10^{\text {th }}$ cycles of production, although an increase in Leuconostoc was also observed.

All three types of mabisi were produced by four different producers and their effect on bacterial community composition of mabisi is shown in Fig. 3 . The bacterial community composition of the $1^{\text {st }}$ production cycles for all three types of mabisi were similar since at this stage they were all essentially tonga mabisi (Fig 3a). However, producers $1 \& 2$ had products with a similar and consistent bacterial community composition in all three types of products which were mainly dominated by Lactococcus (75- 
$91 \%)$. Products from producers $3 \& 4$ on the other hand, had a slightly different composition in their products with Lactococcus still the most important LAB genus but present in lower proportion (4-43\%). The products from Producer 3 were dominated by Enterobacter and the ones from Producer 4 by Klebsiella during this cycle.
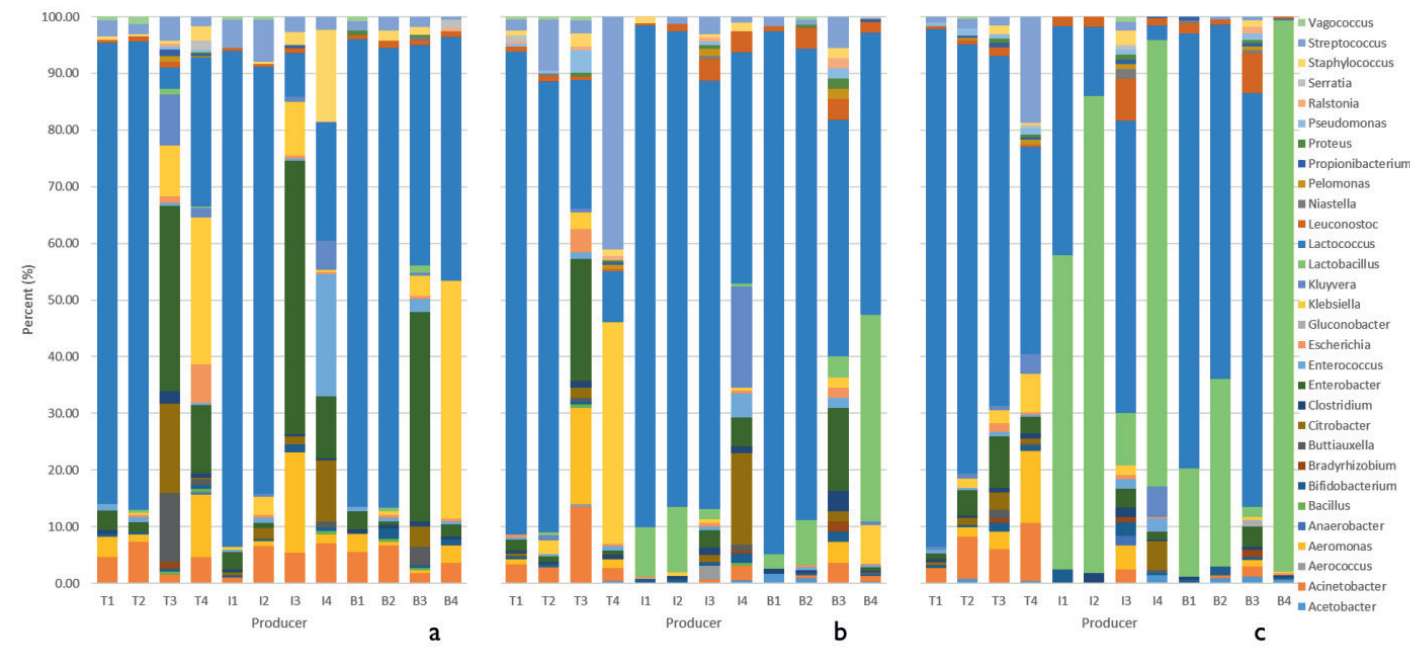

Fig. 3. Bacterial community composition of three types of mabisi: tonga, illa and backslopping mabisi. The figure shows the bacterial community composition of: a) the mabisi sampled from each producer in the $1^{\text {st }}$ cycle, b) mabisi sampled from each producer during the $6^{\text {th }}$ cycle and c) mabisi sampled from each producer during the $10^{\text {th }}$ cycle. Each bar represents a producer and type of mabisi (x-axis): T1-4 producer 1-4 for tonga mabisi, I1-4 - producer 1-4 for illa mabisi and B1-4 - producer 1-4 for backslopping mabisi

We observed a similar pattern of bacterial community composition for tonga mabisi in the $6^{\text {th }}$ production cycle (Fig. 3b) but for illa mabisi, there were increased proportions of Lactobacillus for products of producers $1 \& 2(9-12 \%)$ but lower for products of producers $3 \& 4(<2 \%)$. However, the products of the latter producers had a marked increase in the proportion of Leuconostoc (4\%). This trend was similar for backslopping mabisi except for products of producer 4 having a much higher proportion of Lactobacillus (36\%) and products of producer 2 also having a higher proportion of Leuconostoc (4\%).

In the $10^{\text {th }}$ production cycle, tonga mabisi retained its pattern but there was increased domination by Lactococcus for producers $3 \& 4$ to $62 \%$ and $36 \%$, respectively (Fig 3c). However, for illa mabisi, Lactobacillus surpassed Lactococcus dominance in products from producers 1 (55\%), $2(84 \%)$ \& 4 (78\%) with those from producer 3 having the most Leuconostoc (8\%). Backslopping mabisi also showed increased Lactobacillus proportions but not exceeding Lactococcus for products of producers 1 (19\%) \& 2 (33\%), although for products made by producer 4 , there was nearly $100 \%$ replacement of Lactococcus. Products made by producer 3 maintained a high presence of Leuconostoc (7\%) with little Lactobacillus $(1 \%)$. 
A cluster analysis of the relative abundance of the microbes was carried out on all mabisi types and two main clusters were obtained (Fig. 4). The large cluster on the left had all tonga mabisi regardless of their production cycle or producers as well as all illa and backslopping mabisi from the $1^{\text {st }}$ and $6^{\text {th }}$ cycles with the exception of backslopping mabisi from producer 4 in the $6^{\text {th }}$ cycle. This cluster also included illa mabisi of the $10^{\text {th }}$ cycle from producer 3 . On the other hand, the smaller cluster on the right had all illa and backslopping mabisi from the $10^{\text {th }}$ production cycle with the exception of producer 3 of illa mabisi. However, producer 4 of backslopping mabisi from the $6^{\text {th }}$ cycle was also part of this cluster.

The cluster analysis confirms the observations in Fig. 3 on the bacterial community changes over time in the three types of mabisi but also changes as a function of the producer. This was tested by PERMANOVA carried out to determine the effect of the production method, producer and production cycle (time point) on the bacterial community OTUs. The results corroborated the observed differences in the communities as both producer $(p<0.0001)$ and production cycle $(p<0.0001)$ very significantly affected the variation in OTUs tables (see table S2). Furthermore, the production method was also highly significant $(p<0.005)$. Since each producer only made one mabisi using a specific method only two-way interactions could be tested. However, all possible two-way interaction were significant (see table S2), indicating that indeed a specific method resulted in a different community, when performed by different producers ( $\mathrm{P}$ [producer $\mathrm{x}$ method] < 0.05). Furthermore, the production cycle and producer interacted significantly, indicating that how the product changes in time highly depended on producer (P[producer $x$ cycle] $<0.0005)$. Lastly, also the production method influenced how the communities changed with time ( $P$ [method $x$ cycle] $<0.01)$.

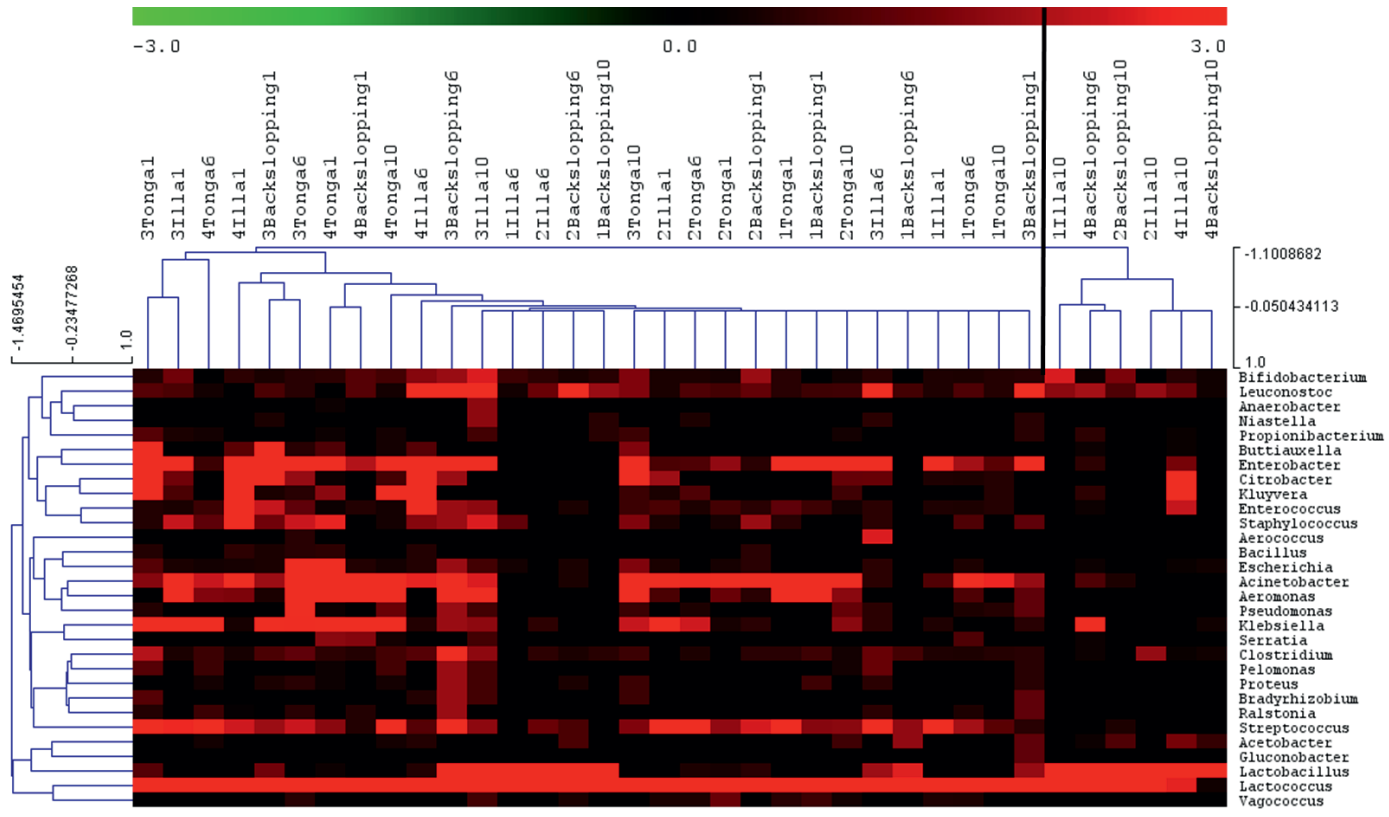

Fig. 4. Heat map of the relative abundance of microbes in three types of mabisi: tonga, illa and backslopping. Each sample is identified by the first, the number of the producer, then production method 
and lastly, number of production cycle. The colour red shows presence and black complete absence. Hierarchical clustering of the samples is also shown in the heat map.

We further, carried out a Kruskal-Wallis test (Table S3) to identify the most critical changes in the bacterial composition over the 10 production cycles and found that the most crucial LAB genera that changed their presence significantly $(p<0.05)$ over time were Lactobacillus and Streptococcus with Leuconostoc on the borderline. The others were Pseudomonas, Kluyvera and Acinetobacter as shown on a heat map (Fig. 5). The other heat map (Fig. 4) also shows that Lactococcus has a consistent presence throughout the production cycles.

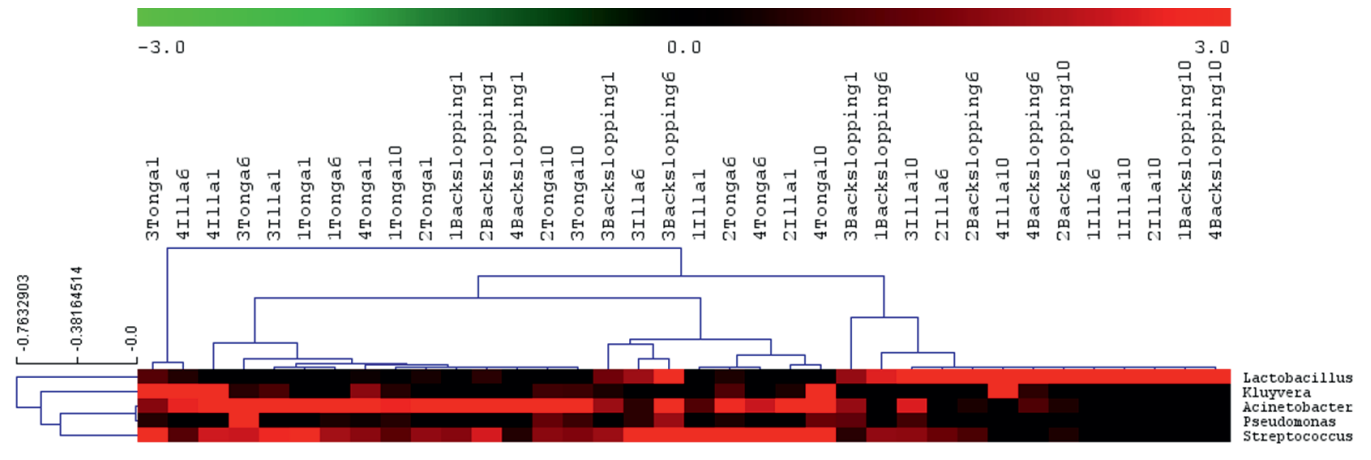

Fig. 5. Heat map on microbes whose relative abundances changed significantly in mabisi over the 10 production cycles. Each sample is identified by the first, the number of the producer, then production method and lastly, number of production cycle. The colour red shows presence and black complete absence. Hierarchical clustering of the samples is also shown in the heat map.

The bacterial diversity scores were calculated for each type of mabisi using the Shannon index and plotted against the production cycle (Fig. 6). The result supports the earlier observation that tonga mabisi remains more diverse after 10 production cycles compared to illa and backslopping mabisi, which both showed lower diversity score after 10 cycles. Producers 3 was the outlier with higher diversity scores in all three products.
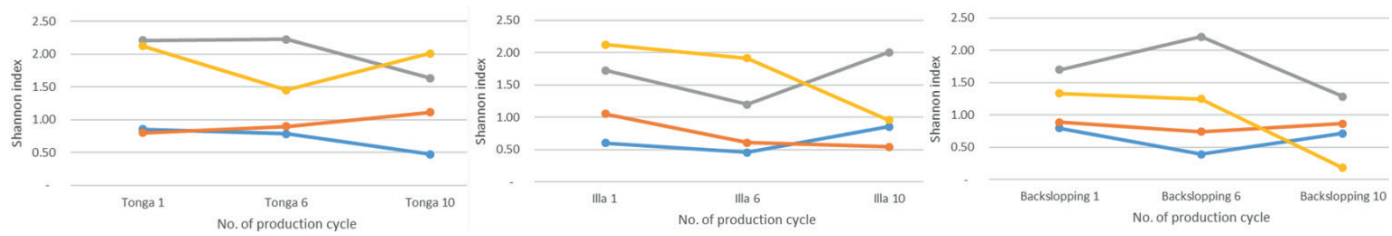

Fig. 6. Shannon index of three type of mabisi: a. tonga, b. illa and c. backslopping mabisi. The colour shows the different producers with blue for producer 1 , orange for producer 2 , grey for producer 3 and yellow for producer 4. 


\subsection{Aroma profiles}

The aroma profiles are shown in a heat map (Fig. 7), which has two main clusters, each subdivided into two sub-clusters. On the right main cluster, there is mainly illa and backslopping mabisi mostly produced during the $6^{\text {th }}$ and $10^{\text {th }}$ production cycles whereas on the left one, there is tonga mabisi and raw milk samples. The sub-clusters on the right show a clear producer effect where producer $1 \& 2$ are on one sub-cluster, producer 3 on another and producer 4 on the last one but there is no clear distinction between production cycle 6 and 10. The left main cluster shows a separation between raw milk and tonga mabisi samples, which also include the samples from the first cycles for both illa and backslopping mabisi.

Similar to the OTU table statistics, a PERMANOVA was performed on the aroma profiles. Again all three main factors had significant effect on the aroma profiles (Producer, $p<0.001$, Method, $p<0.001$, Cycle, $p<0.005$, Table S4). While the community of bacteria depended significantly on the interaction between producer and production method, the aroma profile did not show an significant interaction. Rather, as indicated by Fig. 7, producer and production cycle interacted significantly $(p<0.05)$ as well as production method and production cycle $(p<0.05)$. This indicates that the temporal changes of the aroma profiles differ between producers and production method, but that the aroma profiles per method are more similar between producers than compared to the communities.

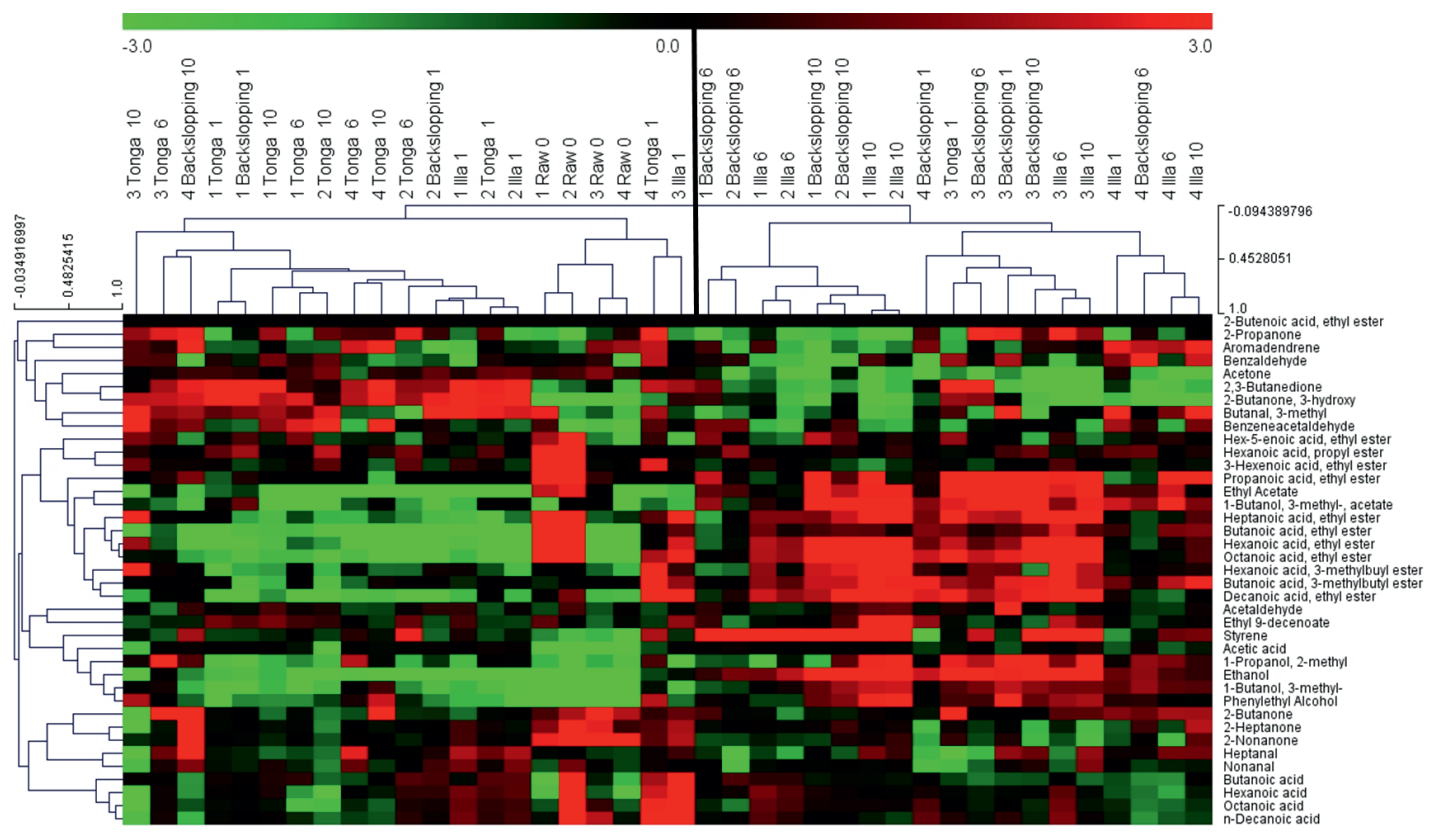

Fig. 7. Heat map of aroma compounds of raw milk and 3 types of mabisi: Tonga, illa and backslopping mabisi. Each sample is identified by the first, the number of the producer, then production method and lastly, number of production cycle. The colour red shows presence and green complete absence. Hierarchical clustering of the samples is also shown in the heat map. 
The main compounds found in all mabisi samples were 4 alcohols, 6 aldehydes, 6 ketones, 5 carboxylic acids, 2 terpenes and 16 esters (Table S5). Illa and backslopping mabisi were mostly dominated by esters, alcohols, terpenes with a few ketones, aldehydes and carboxylic acids whereas tonga mabisi had more ketones than esters, carboxylic acids and aldehydes (Fig. 7).

\section{Discussion \& conclusion}

The changes in microbial community composition were studied for three types of mabisi each made with a different processing method (i.e. tonga, illa and backslopping). For each processing method, the bacterial community profile of mabisi was analysed as function of the number of production cycles, executed by four different producers using their own raw milk in their respective home settings in rural Zambia. We hypothesise that after various rounds of propagation, the species diversity in the bacterial communities will be altered by the selection pressures associated with the different methods of propagation. In our experiments, we measured physiochemical properties of these products at each round of production, we determined bacterial community composition and linked the volatile compounds to these communities. The physiochemical properties are related to organoleptic properties, which are important for product optimisation and for developing production standards for such traditional products.

The analysis of physiochemical properties showed no significant differences in mean $\mathrm{pH}$ among the three types of mabisi and the $\mathrm{pH}$ range obtained in this study is similar to that reported by Schoustra, Kasase [24] in mabisi. Similar pH ranges have been reported in other fermented milk products such as amasi of Zimbabwe and South Africa [20, 21, 23], kivuguto of Rwanda [80], nunu of Ghana [12], argo of Ethiopia [15, 32] and omashikwa of Namibia [18, 19].

Tonga mabisi had the thickest consistency followed by backslopping and finally, illa. The latter had the lowest consistency because its processing involves shaking or agitation several times in a day during the fermentation as compared to the tonga mabisi, which was only shaken once to mix it after the fermentation was complete, i.e. prior to sampling. The shaking step in illa mabisi results in the curd being broken into fine particles, which gives it a smooth flowy consistency, whereas tonga mabisi retains larger curd particles (Fig. S3). The backslopping mabisi consistency was in between the other two types because of shaking to mix the product before removal for consumption and after the addition of raw milk for subsequent fermentation. The stirring or mixing intensity probably has a bearing on the consistency. Each type of mabisi may have its own required level of intensity to produce the desired final product consistency but this requires further investigation. In the case of yoghurt production, the stirring step differentiates set yoghurt from stirred yoghurt on the basis of consistency and viscosity with the former having a thicker consistency [67].

There was also a difference in product consistency among the products of the different producers. Producers $1 \& 2$ made products with a significantly thicker consistency than those from the other two producers ( $3 \& 4$ ). The latters' products also had a visibly higher degree of syneresis, which can lead to thin/light consistency as reported in chapter 4 and by Bille, Buys [19]. This might be attributed to the different breeds of cattle reared by the producers (Fig. S4), the husbandry practices, and in particular their nutrition, which can affect raw milk composition [86, 87]. The cattle for producer $1 \&$ 2 were local indigenous cattle (zebu) cross-bred with exotic beef breeds of Boran and Brahman, while the other two producers had cross-bred dairy Holstein-Friesian with local indigenous cattle. The 
cattle from producers $1 \& 2$ exclusively grazed grass in the flood plains of the Kafue flats, whereas the other two producers supplemented theirs with maize bran and dairy concentrate feeds, especially producer 3, whose operation was semi-commercial. Furthermore, the $\mathrm{pH}$ for both illa and backslopping mabisi produced by producer $4(\mathrm{pH} 5)$ was higher than the rest $(\mathrm{pH}<4.6)$ for the first five cycles of production, which could have affected the coagulation level of the product as it was higher than the isoelectric point of the caseins and hence, gave a thin consistency.

Furthermore, variations were observed in the consistency of the products from one cycle to another but these were not significant $(p>0.05)$. The mean consistency of tonga mabisi was thicker than the one found in an earlier study performed under laboratory conditions (chapter 4) and fell into class 2 ("the thick consistency"), a classification developed in chapter 4. The consistency of backslopping and illa mabisi were classified as class 3 and 4, respectively.

The analysis of bacterial community composition showed that the bacterial composition of raw milk in this study was more diverse than of tonga mabisi, which in turn was more diverse than the other two types of mabisi: illa and backslopping mabisi. Other studies have also reported raw milk with a more diverse microbial community composition than the final fermented product such as kefir [88] and poro cheese [41]. The bacterial community composition of tonga mabisi in this study was consistent with the one reported in chapter 4 and by Schoustra, Kasase [24], which was also similar to amasi from South Africa [38] with slight differences in the genera present at lower relative abundancies such as Serratia, Pseudomonas, Kluyvera and Buttiauxella. The bacterial community composition of illa and backslopping mabisi was largely dominated by Lactobacillus and Lactococcus. These LAB genera were also dominant in barotse mabisi reported in chapter 4 .

The production cycles had a more distinct effect on the bacterial community composition and species diversity of illa and backslopping mabisi than tonga mabisi. Tonga mabisi showed an increase in Lactococcus dominance in the $10^{\text {th }}$ production cycle but still retained a diverse composition with the proportion of other genera summing up to $48 \%$ and a higher Shannon index for ecological diversity (Fig. 6). In contrast, both illa and backslopping mabisi were mainly dominated by Lactobacillus and Lactococcus in the $10^{\text {th }}$ cycle, which accounted for a combined proportion of $82 \%$ and $92 \%$, respectively. The producers had different effects on the bacterial community composition of mabisi, for example products from producers $1 \& 2$ had similar and consistent composition during the various production cycles as well as in the same type of mabisi. The variation between the products from both pairs of producers was apparent in the $1^{\text {st }}$ production cycle, but the $6^{\text {th }}$ cycle products from all producers showed the emergence of Lactobacillus with Lactococcus clearly dominant in illa and backslopping mabisi. By the $10^{\text {th }}$ cycle, products from all the producers were much closer in bacterial community composition of tonga mabisi than in the first cycle and the same was observed for illa and backslopping with the exception of products from producer 3 , which were extremely low in abundance of Lactobacillus in backslopping mabisi. These variations between products from specific producers could be due to a number of factors: temperature fluctuations in the house, raw milk composition, husbandry and hygiene practices on the farm, $\mathrm{pH}$ of the product as well as the starting microbes. These factors have also been reported for other fermented dairy products [87, 89]. However, despite these factors, it is clear that it is not only the producer and production cycle (time) that have a bearing on the bacterial community structure but also the production method as all three types of mabisi have different communities. Moreover, all three factors were highly significant (Table S2). 
The results further demonstrates that the composition becomes less complex over time for both illa and backslopping, which are somewhat similar as they both have a 'backslopping' step in their production. However, tonga mabisi retained a more complex composition with a higher species diversity. Such shifts in microbial populations have also been observed in other artisanal fermented products that involve backslopping: poro [41], fontina [90], parmeasan and kazah [91] cheeses but few are reported on African traditionally fermented milk. Furthermore, it confirms our hypothesis that selection pressure leads to distinct microbial communities in mabisi.

In terms of microbial community functionality, different aroma compounds were produced in tonga mabisi compared to both illa and backslopping mabisi, which had similar compounds in the $6^{\text {th }}$ and $10^{\text {th }}$ production cycles. Tonga mabisi was dominated by Lactococcus and Streptococcus, which can be linked to the volatiles observed in Fig. 7, mainly ketones, aldehydes, carboxylic acids and some esters. On the other hand, illa and backslopping mabisi were dominated by Lactobacillus,

Lactococcus and Leuconostoc, which produced more esters and alcohols than ketones and aldehydes. These two types of mabisi also showed some slight differences in aroma compounds produced between the producers in the $6^{\text {th }}$ and $10^{\text {th }}$ production cycles, which can be linked to their respective, slight differences in microbial species profiles.

In conclusion, the producer, the processing method and production cycle, all had a significant effect on bacterial community composition as demonstrated by the shifts in species diversity in both illa and backslopping mabisi, which changed from a complex diverse community in the $1^{\text {st }}$ production cycle to one dominated mostly by two species (Lactococcus and Lactobacillus) in the $10^{\text {th }}$ production cycle. However, tonga mabisi maintained a diverse and stable bacterial community composition over time, which indicates resilience of the bacterial community for this processing method. All three factors had a significant effect on the aroma profiles but the aroma profiles per method were more similar between producers than compared to the communities.

The production method had an effect on the consistency of mabisi with tonga being the thickest, followed by backslopping and finally, illa mabisi. However, in terms of $\mathrm{pH}$ there were no effective changes once the milk had coagulated with all three types retaining a similar $\mathrm{pH}$ range over time.

This study shows that selection pressure has an effect on species diversity of an eco-system, in this case mabisi, which was produced in a natural environment with little or no controls and demonstrated clear shifts in the bacterial communities after 10 propagation cycles. These results complement what has been achieved through controlled long-term laboratory experiments of single species evolution such as Escherichia coli [92] but its natural setup makes it novel. The findings from this study can be used to design starter cultures for the three types of mabisi based on their established bacterial community composition. 


\section{Supporting material}

Table S1. Physiochemical properties of three type of mabisi

\begin{tabular}{lll}
\hline $\begin{array}{l}\text { Production } \\
\text { method (type of } \\
\text { mabisi) }\end{array}$ & Mean pH & Mean Consistency $\mathbf{( c m )}$ \\
\hline Tonga & $4.33(0.14) \mathrm{a}$ & $6.7(0.78) \mathrm{a}$ \\
\hline Illa & $4.41(0.34) \mathrm{a}$ & $7.5(1.21) \mathrm{b}$ \\
\hline Backslopping & $4.35(0.31) \mathrm{a}$ & $8.6(0.61) \mathrm{c}$ \\
\hline Overall mean & $4.36(0.28)$ & $7.60(1.18)$
\end{tabular}

*Significance is shown by different letter within the columns and brackets show standard deviation

\section{Correlations}

\begin{tabular}{|rl|r|r|}
\hline & & TTA & \multicolumn{1}{c|}{$\mathrm{pH}$} \\
\hline TTA & Pearson Correlation & 1 &,$- 928^{* *}$ \\
& Sig. (2-tailed) & &, 000 \\
& $\mathrm{~N}$ & 40 & 40 \\
\hline $\mathrm{pH} \quad$ Pearson Correlation &,$- 928^{* *}$ & 1 \\
& Sig. (2-tailed) &, 000 & \\
& $\mathrm{~N}$ & 40 & 40 \\
\hline
\end{tabular}

**. Correlation is significant at the 0.01 level (2-tailed).

Table S2. PERMANOVA table using OTU table as dependent variable, listing degrees of freedom (Df), sums of squares, mean squares, $F$ ratio and $p$ value for all main effects and two-way interactions

\begin{tabular}{|c|c|c|c|c|c|}
\hline & Df & $\begin{array}{l}\text { Sums of } \\
\text { squares }\end{array}$ & Mean Squares & F ratio & $P$ value \\
\hline Producer & 3 & 2.08 & 0.69 & 7.74 & $<0.0001$ \\
\hline Method & 2 & 0.51 & 0.25 & 2.83 & 0.0041 \\
\hline Cycle & 2 & 0.80 & 0.40 & 4.45 & $<0.0001$ \\
\hline Producer $x$ Method & 6 & 0.96 & 0.16 & 1.78 & 0.0196 \\
\hline Producer $x$ Cycle & 6 & 1.59 & 0.27 & 2.96 & 0.0002 \\
\hline Method x Cycle & 4 & 0.82 & 0.20 & 2.28 & 0.0052 \\
\hline Residuals & 12 & 1.08 & 0.09 & & \\
\hline Total & 35 & 7.83 & & & \\
\hline
\end{tabular}

Table. S3. Kruskal Wallis test output for the microbes. The most important ones with significant changes over the 10 production cycles are listed in bold. 


\begin{tabular}{|c|c|c|c|c|}
\hline Microbe & Method & df & KW statistic $(\mathrm{H})$ & P-value \\
\hline Kluyvera & (H') Kruskal-Wallis w/ Ties Corr. & 2 & 6.659176 & 0.035808 \\
\hline Acinetobacter & (H') Kruskal-Wallis w/ Ties Corr. & 2 & 9.252049 & 0.009794 \\
\hline Lactobacillus & $\left(\mathrm{H}^{\prime}\right)$ Kruskal-Wallis w/ Ties Corr. & 2 & 10.799043 & 0.004519 \\
\hline Streptococcus & (H') Kruskal-Wallis w/ Ties Corr. & 2 & 6.4851785 & 0.039063 \\
\hline Pseudomonas & (H') Kruskal-Wallis w/ Ties Corr. & 2 & 9.053544 & 0.010816 \\
\hline Acetobacter & $\left(\mathrm{H}^{\prime}\right)$ Kruskal-Wallis w/ Ties Corr. & 2 & 3.7843328 & 0.150745 \\
\hline Aerococcus & $\left(\mathrm{H}^{\prime}\right)$ Kruskal-Wallis w/ Ties Corr. & 2 & 1.0309523 & 0.597216 \\
\hline Aeromonas & (H') Kruskal-Wallis w/ Ties Corr. & 2 & 4.5012465 & 0.105334 \\
\hline Anaerobacter & $\left(\mathrm{H}^{\prime}\right)$ Kruskal-Wallis w/ Ties Corr. & 2 & 1.0309523 & 0.597216 \\
\hline Bacillus & $\left(\mathrm{H}^{\prime}\right)$ Kruskal-Wallis w/ Ties Corr. & 2 & 0.4654088 & 0.792388 \\
\hline Bifidobacterium & $\left(\mathrm{H}^{\prime}\right)$ Kruskal-Wallis w/ Ties Corr. & 2 & 2.6801903 & 0.261821 \\
\hline Bradyrhizobium & (H') Kruskal-Wallis w/ Ties Corr. & 2 & 0.046310432 & 0.977111 \\
\hline Buttiauxella & $\left(\mathrm{H}^{\prime}\right)$ Kruskal-Wallis w/ Ties Corr. & 2 & 2.0522015 & 0.358402 \\
\hline Citrobacter & (H') Kruskal-Wallis w/ Ties Corr. & 2 & 4.964052 & 0.083574 \\
\hline Clostridium & $\left(\mathrm{H}^{\prime}\right)$ Kruskal-Wallis w/ Ties Corr. & 2 & 0.547957 & 0.760348 \\
\hline Enterobacter & (H') Kruskal-Wallis w/ Ties Corr. & 2 & 3.5335512 & 0.170883 \\
\hline Enterococcus & $\left(\mathrm{H}^{\prime}\right)$ Kruskal-Wallis w/ Ties Corr. & 2 & 1.8440319 & 0.397716 \\
\hline Escherichia & $\left(\mathrm{H}^{\prime}\right)$ Kruskal-Wallis w/ Ties Corr. & 2 & 0.78607434 & 0.675004 \\
\hline Gluconobacter & $\left(\mathrm{H}^{\prime}\right)$ Kruskal-Wallis w/ Ties Corr. & 2 & 2 & 0.367879 \\
\hline \begin{tabular}{|l|} 
Klebsiella \\
\end{tabular} & (H') Kruskal-Wallis w/ Ties Corr. & 2 & 2.320005 & 0.313485 \\
\hline Lactococcus & (H) Kruskal-Wallis & 2 & 0.5465465 & 0.760885 \\
\hline Leuconostoc & (H') Kruskal-Wallis w/ Ties Corr. & 2 & 5.35761 & 0.068645 \\
\hline Niastella & (H') Kruskal-Wallis w/ Ties Corr. & 2 & 1.133715 & 0.567305 \\
\hline Pelomonas & $\left(\mathrm{H}^{\prime}\right)$ Kruskal-Wallis w/ Ties Corr. & 2 & 1.8717549 & 0.392242 \\
\hline Propionibacterium & $\left(\mathrm{H}^{\prime}\right)$ Kruskal-Wallis w/ Ties Corr. & 2 & 1.7611974 & 0.414535 \\
\hline Proteus & $\left(\mathrm{H}^{\prime}\right)$ Kruskal-Wallis w/ Ties Corr. & 2 & 1.5937691 & 0.450731 \\
\hline Ralstonia & $\left(\mathrm{H}^{\prime}\right)$ Kruskal-Wallis w/ Ties Corr. & 2 & 0.9371755 & 0.625886 \\
\hline Serratia & $\left(\mathrm{H}^{\prime}\right)$ Kruskal-Wallis w/ Ties Corr. & 2 & 1.2886769 & 0.52501 \\
\hline Staphylococcus & $\left(\mathrm{H}^{\prime}\right)$ Kruskal-Wallis w/ Ties Corr. & 2 & 2.0814524 & 0.353198 \\
\hline Vagococcus & $\left(\mathrm{H}^{\prime}\right)$ Kruskal-Wallis w/ Ties Corr. & 2 & 3.1688914 & 0.205061 \\
\hline
\end{tabular}


Table S4. PERMANOVA table using aroma profiles as dependent variable, listing degrees of freedom (Df), sums of squares, mean squares, $F$ ratio and $p$-value for all main effects and two-way interactions

\begin{tabular}{|l|l|l|l|l|l|}
\hline & Df & $\begin{array}{l}\text { Sums of } \\
\text { squares }\end{array}$ & Mean Squares & F ratio & P value \\
\hline Producer & 3 & 1.50 & 0.50 & 4.78 & 0.0007 \\
\hline Method & 2 & 1.81 & 0.91 & 8.64 & 0.0002 \\
\hline Cycle & 2 & 0.91 & 0.45 & 4.33 & 0.0036 \\
\hline Producer x Method & 6 & 0.78 & 0.13 & 1.24 & 0.2644 \\
\hline Producer x Cycle & 6 & 1.36 & 0.23 & 2.17 & 0.0203 \\
\hline Method x Cycle & 4 & 1.07 & 0.27 & 2.55 & 0.0166 \\
\hline Residuals & 12 & 1.26 & 0.10 & & \\
\hline Total & 35 & 8.69 & & & \\
\hline
\end{tabular}

Table S5. List of all aroma compounds in the three of types of mabisi.

\begin{tabular}{|c|c|c|c|c|c|}
\hline Alcohols & Ketones & Aldehydes & Terpenes & Esters & $\begin{array}{l}\text { Carboxylic } \\
\text { acids }\end{array}$ \\
\hline Ethanol & $\begin{array}{l}\text { 2,3- } \\
\text { Butanedione }\end{array}$ & Heptanal & Styrene & Ethyl Acetate & Acetic acid \\
\hline $\begin{array}{l}\text { Phenylethyl } \\
\text { Alcohol }\end{array}$ & 2-Butanone & Acetaldehyde & $\begin{array}{l}\text { Aromadendre } \\
\text { ne }\end{array}$ & Propanoic acid, ethyl ester & $\begin{array}{l}\text { Butanoic } \\
\text { acid }\end{array}$ \\
\hline $\begin{array}{l}\text { 2-methyl-1- } \\
\text { Propanol }\end{array}$ & 2-Propanone & Nonanal & & Butanoic acid, ethyl ester & $\begin{array}{l}\text { Hexanoic } \\
\text { acid }\end{array}$ \\
\hline \multirow[t]{13}{*}{$\begin{array}{l}\text { 3-methyl-1- } \\
\text { Butanol }\end{array}$} & Acetone & Benzaldehyde & & 1-Butanol, 3-methyl-, acetate & $\begin{array}{l}\text { Octanoic } \\
\text { acid }\end{array}$ \\
\hline & 2-Heptanone & $\begin{array}{l}\text { Benzeneacetaldehy } \\
\text { de }\end{array}$ & & 2-Butenoic acid, ethyl ester & $\begin{array}{l}\text { n-Decanoic } \\
\text { acid }\end{array}$ \\
\hline & 2-Nonanone & 3-methylbutanal & & Hexanoic acid, ethyl ester & \\
\hline & & & & $\begin{array}{l}\text { Butanoic acid, 3-methylbutyl } \\
\text { ester }\end{array}$ & \\
\hline & & & & Hex-5-enoic acid, ethyl ester & \\
\hline & & & & 2-Butanone, 3-hydroxy & \\
\hline & & & & Hexanoic acid, propyl ester & \\
\hline & & & & 3-Hexenoic acid, ethyl ester & \\
\hline & & & & Heptanoic acid, ethyl ester & \\
\hline & & & & Octanoic acid, ethyl ester & \\
\hline & & & & Decanoic acid, ethyl ester & \\
\hline & & & & $\begin{array}{l}\text { Hexanoic acid, 3-methylbuyl } \\
\text { ester }\end{array}$ & \\
\hline & & & & Ethyl 9-decenoate & \\
\hline
\end{tabular}




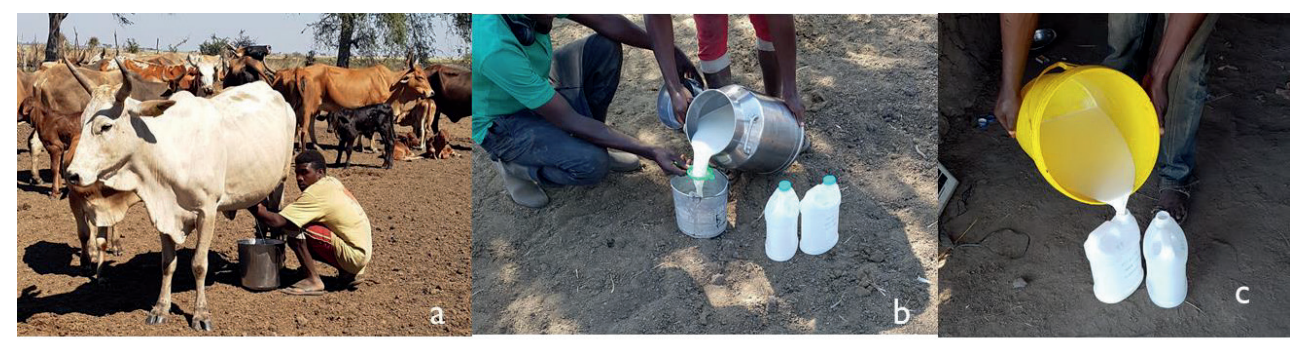

Fig. S1. Milking (a), sieving (b) and filling 2-litre plastic fermentation containers(c)

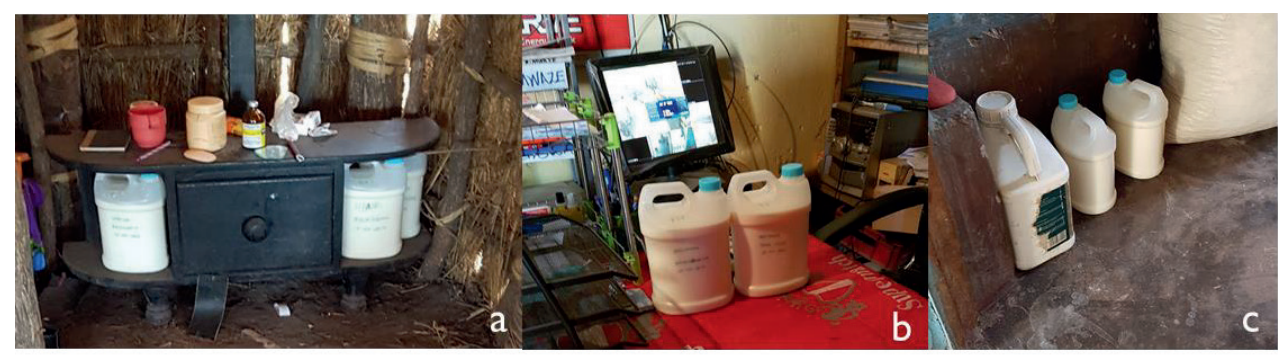

Fig. S2. Incubation areas: a. on a wooden table (producer $1 \& 2$ ), b. wooden table with mat (producer 3) \& c. on a concrete floor (producer 4). 


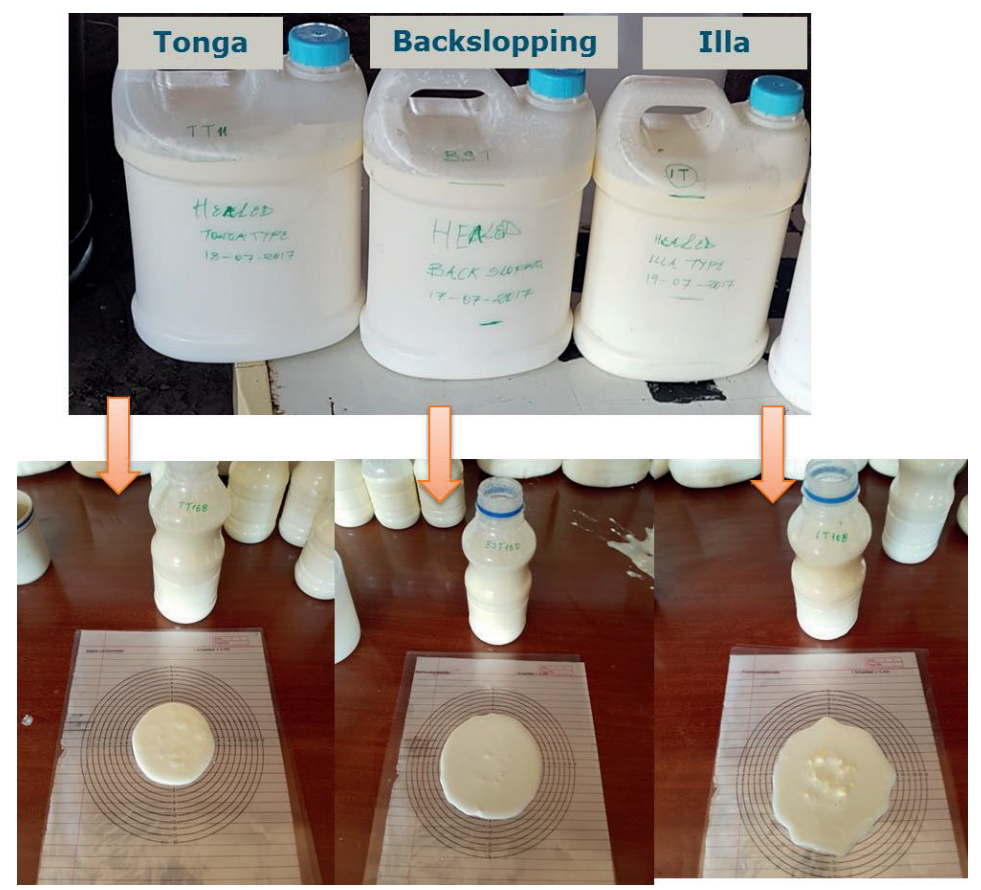

Fig. S3. Appearance and consistencies of three types of mabisi

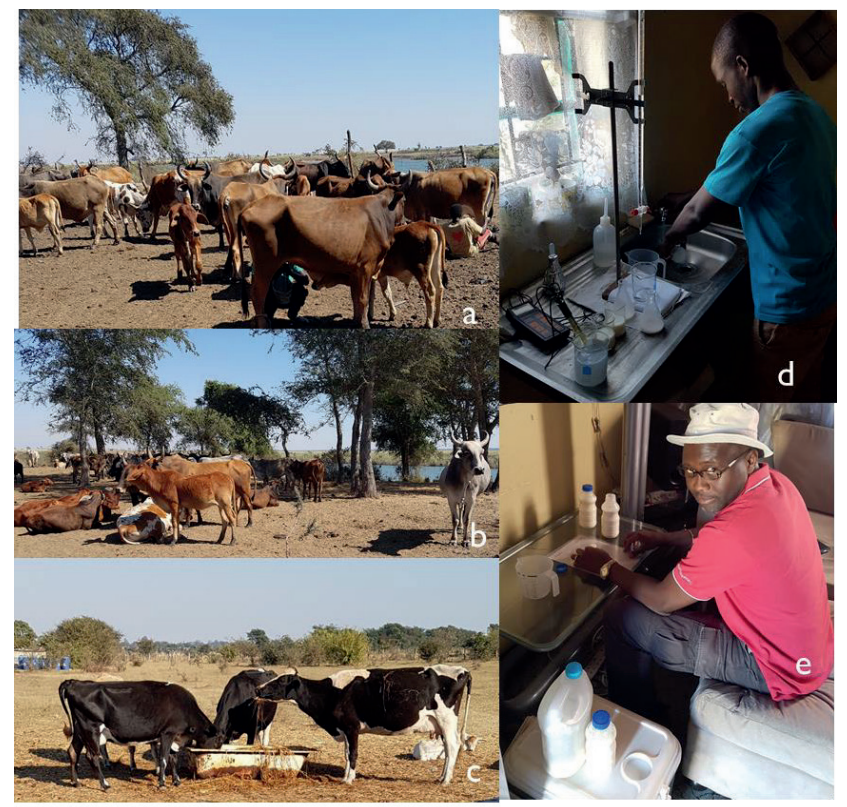

Fig. S4. Breeds of cows: $a$ \& b, local breeds cross-bred with Boran \& Brahman breeds (producers 1 \& 2) and local breeds cross-bred with Holstein-Friesian breeds (producer $3 \& 4$ ). Physicochemical analysis in the field $d \&$ e. 
Chapter 6

\section{General discussion}

Himoonga Bernard Moonga 
Traditionally fermented milk products play an important role in the diet and nutritional security of not only rural households but also an increasing number of urban households in Africa. Just like other fermented dairy products, such as cheese, are important in the western diets, so is mabisi in Zambia. Cheese has been studied extensively and has many varieties, which can be differentiated by place of origin (Emmentaler cheese, Parmigiano reggiano, Gouda cheese, Cheddar, etc.) or production method (soft or hard cheese, un-ripened or ripened cheese) $[35,69,71]$. Moreover, a whole cheese classification system has been developed and is used for various purposes most of which relate to trade and grading of the cheeses to be able to determine the appropriate prices.

Extensive research has been carried out on development of starter cultures and production process optimisation, which has resulted in more assorted cheeses that are standardised and meet consumers expectation $[9,10,65]$. Part of the traditional dairy research has focussed on aroma development, product texture and other key quality attributes $[40,69]$. All-in-all the cheese industry is a global multibillion euro business, which supports various supply chains, intermediaries, retail chains and research institutions.

Traditionally fermented milk products (TFMPs) in Africa have similar potential. There are several types of TFMPs in Sub-Sahara Africa, which include amasi, argo, omashikwa, mursik, kivuguto, nunu and mabisi $[12-16,18,20,23,31]$. Unlike cheese, most of these are fermented milk products that flow, do not require brine for fermentation and are more comparable to yoghurt and kefir than to cheese. Despite a large population of Africans with lactose intolerance, the market penetration of fermented products such as yoghurt suggests that levels of intolerance vary and a good proportion of the population is able to tolerate fermented milk products. This situation supports the market possibilities for newly developed or optimised unique African fermented dairy products.

This thesis describes a systematic and comprehensive study of a TFMP from Zambia known as 'mabisi' with the objective to generate enough information to be able to optimise not only mabisi production but also other similar African fermented dairy products. Mabisi is made through a spontaneous fermentation process of raw milk at ambient temperature, which takes about two days [24,53]. The product has a shelf-life of several days at room temperature. It is a popular product consumed by all age groups in both rural and urban households in Zambia. Therefore, the objectives of this thesis were (i) to determine the existing production practices of mabisi and its current uses, (ii) to characterise the microbes found in the product around the country, (iii) to investigate the effect of fermentation temperature on the microbial community composition and physicochemical properties of mabisi and lastly (iv) to determine the effect of production method and producers on the microbial community composition on three types of mabisi. This chapter aims at consolidating the findings of the research chapters (2-5), highlight and discuss the key issues, and give conclusions and future perspectives.

\subsection{Types of mabisi and its uses}

In chapter 2, the indigenous knowledge of mabisi production practices and the uses of the product were investigated in a country-wide survey, in which it was discovered that there were seven different methods of production as opposed to the suggestion that one unique method exists as earlier reported by Schoustra, Kasase [24]. These methods were coined as tonga, barotse, backslopping, creamy, cooked, illa and thick-tonga types with tonga type identified as the most popular and the one previously reported by Schoustra, Kasase [24]. The names: tonga, barotse and illa relate to either the tribe or location most associated with the type mabisi. The terms backslopping and cooked are terminologies associated with a brief description of how the mabisi type is produced, while the terms creamy and thicktonga are associated with a key sensory property of that mabisi type. This study further identified the key production parameters as type of fermentation container, backslopping, alternate removal of whey and addition of raw milk, agitation (churning), boiling and cooling, and fermentation temperature. Mabisi was found to be a versatile product with a wide range of uses, that is, mostly consumed with maize porridge, boiled grain or tubers, fruits, as a beverage or used for cooking.

\subsection{Product quality and consumer preferences and perceptions}


During the country-wide survey the questionnaire and checklist used to collect data on production practices also included a section with questions on consumer preferences and perceptions. These questions were mainly focussed on product quality attributes, preferred containers and season of production associated with the best quality mabisi.

The quality attribute that was ranked highest by consumers in determining the best quality of mabisi was taste, followed by thickness (consistency) and then appearance (Fig. 1a). Others were aroma, whey presence (syneresis), lumpiness and creaminess. The taste was evaluated on the basis of the degree of sourness, which was divided into three categories: mild, medium and strong. The most preferred taste was medium followed by mild and then strong (Fig. 1b). Consistency (thickness) was also divided into three categories: low, medium and thick consistency. The most preferred was medium followed by thick and lastly, low consistency. From these results, it can be concluded that most consumers preferred mabisi with medium sour taste and medium consistency but this might be quite subjective since there are no numbers to show what medium taste is in terms of $\mathrm{pH}$ and the same is true for consistency. However, it does give a first impression of the characteristics of the most preferred type of mabisi.

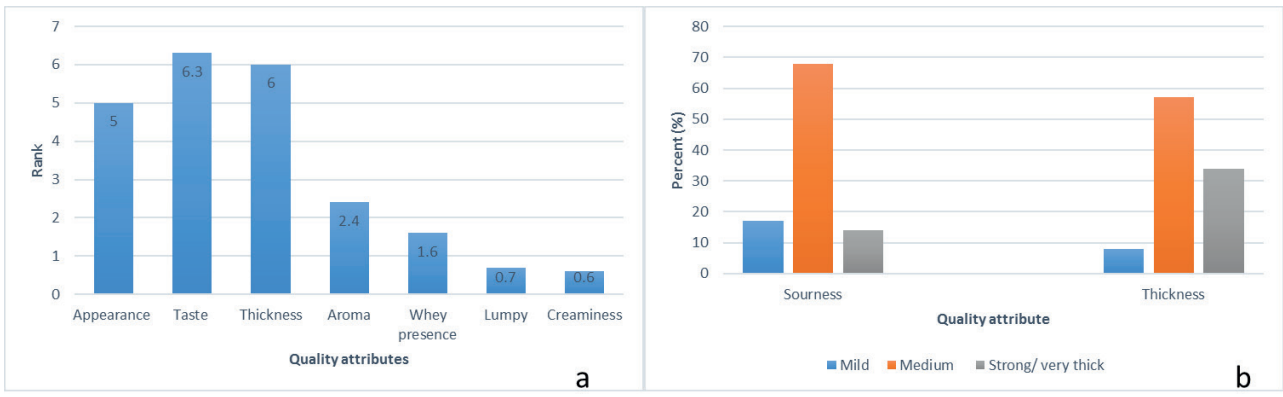

Fig. 1. Consumer ranking scores of the most important quality attributes (a) and consumer preference for mabisi sour taste and consistency (thickness)(b).

The findings from chapter 3 on the $\mathrm{pH}$ of mabisi samples collected around the country show that the $\mathrm{pH}$ ranged from 3-5 with mabisi from Western province having the lowest mean $\mathrm{pH}$ and that from Eastern province the highest. Using these data, the three levels of sourness can be divided into three $\mathrm{pH}$ ranges (Table 1), which when combined, gives more information about the consumer preferences of the product and can be used as target for a production protocol or standard. For consistency, the classification developed in chapter 4 can be used to grade mabisi into four different classes of thickness so that when describing a type of mabisi that has a medium sour taste and consistency, it implies a product with $\mathrm{pH}$ 44.4 and consistency $7-8 \mathrm{~cm}$ diameter of spread (class 3 ). This kind of information is crucial for the development of standards for mabisi as well as for product and price differentiation, which will in the long term improve the regulation of mabisi production and trade. However, these proposed $\mathrm{pH}$ ranges and consistency classes still need to be validated by sensory evaluation to ensure that they are realistic. Consistency could also be validated with viscosity measurements, so that more precise and accurate information can be used.

Table 1. Classification of mabisi acidity/sourness

\begin{tabular}{|l|l|l|l|}
\hline Acidity class & Mild & Medium & Strong \\
\hline pH & $4.5-4.7$ & $4-4.4$ & $<4$ \\
\hline
\end{tabular}

The other aspects considered by the consumers in the survey were the preferred fermentation container and production season. The container that was considered to produce the best mabisi was the calabash, followed by the plastic and metal containers (Fig. 2a). The season they considered produced the best quality mabisi was the cold season while the hot season was associated with high levels of syneresis (i.e. 
higher whey content), which was undesirable (Fig. 2b). These observations about seasonal variation of mabisi quality can be linked to the effect of temperature during fermentation while the use of different containers may also influence fermentation temperature to a smaller extent but probably have a larger effect on the microbial and aroma profile of the product due to the differences in the surfaces and their ability to form biofilms. However, this thesis did not investigate the biofilm formation nor compare microbial profiles from different containers but the effect of temperature was investigated in chapter 4.
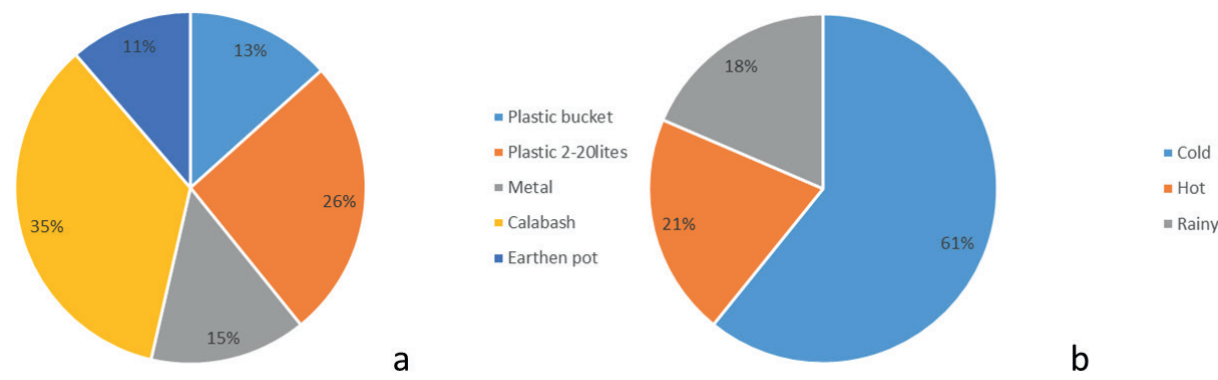

a

Fig. 3. Consumers' preferred type of mabisi fermentation containers (a) and season perceived to produce the best mabisi (b)

Fermentation temperature was also highlighted in chapter 2 in relation with the speed of fermentation by either placing the fermentation container directly in the sun to accelerate fermentation during the cold season or placing it in a water bath to slow down the fermentation rate during the hot season. Thus, the effect of fermentation temperature was investigated in chapter 4 by fermenting mabisi under four different temperature regimes: at tap water temperature $\left(20^{\circ} \mathrm{C}\right)$ to mimic water bath conditions, at room temperature $\left(22^{\circ} \mathrm{C}\right)$, at hot season room temperature $\left(25^{\circ} \mathrm{C}\right)$ and at high temperature $\left(30^{\circ} \mathrm{C}\right)$. The results confirm that higher temperatures reduce total fermentation time to $24 \mathrm{~h}$ at $30^{\circ} \mathrm{C}$. Higher temperatures also lead to higher whey separation also known as 'syneresis', which is undesirable. High levels of syneresis lead to low and poor consistency of the final product with a maximum of $30 \%$ syneresis established as a limit for producing mabisi with a medium consistency that is desired by the consumers as demonstrated in chapter 4. The tap water and room temperature conditions produced mabisi that was classified in the "medium" to "thick" category and $25^{\circ} \mathrm{C}$ was mostly in the "medium" consistency (class 3) (Chapter 4 - Table 4.1). This implies that producers should use temperatures between $20-25^{\circ} \mathrm{C}$ to produce mabisi over a 2-3 day period when using new containers. However, the period may shorten when fermenting in used containers. As a recommendation for household level producers, mabisi should always be fermented in a cool place in the house without disturbance or agitation.

Fermentation temperature was also found to have an effect on $\mathrm{pH}$, which affects the taste of the product. Barotse mabisi fermented at $30^{\circ} \mathrm{C}$ produced a product with a strong sour taste $(\mathrm{pH} \mathrm{3.2)}$ while the one fermented at $25^{\circ} \mathrm{C}$ yielded a product with a medium sour taste $(\mathrm{pH} \mathrm{4.2)}$ after six days of fermentation. The consistency for a product fermented at $30^{\circ} \mathrm{C}$ was thicker and fell in the "very thick" category (class 1) than for the one fermented at $25^{\circ} \mathrm{C}$, which was in the "thick" category (class 2 ). This was due to more syneresis at the higher temperature, which resulted in a lower overall yield of the product at $48 \%$ as opposed to $58 \%$ at $25^{\circ} \mathrm{C}$. This information cannot only be used to design a type of mabisi that targets a particular market for a strong sour and thick barotse mabisi such as Western province, but can also be used for price differentiation since barotse mabisi requires more milk to produce the same quantity of product as tonga mabisi. This is because of whey removal and additional of raw milk during the production of barotse mabisi and hence, a higher price should be paid for it.

In chapter 5, three types of mabisi were investigated: tonga, illa and backslopping. These were all produced by four different producers for up to 10 production cycles for each product type. Illa and backslopping mabisi involve transfer of a portion of mabisi from one batch to the next referred to as 
'backslopping' but illa mabisi also has an agitation (churning) step, which leads to the production of butter. Tonga mabisi on the other hand is a batch wise process of 1-2 days while the other two can be continuous for several months. The mean $\mathrm{pH}$ for all three products was $4.36 \pm 0.28$, which implies that they had a medium sour taste although one of the producers produced illa mabisi with a mild sour taste. The $\mathrm{pH}$ for backslopping and illa mabisi can easily be manipulated by reducing the proportion of mabisi removed for consumption or prolonging the fermentation period by skipping a day or a few hours in order to lower the $\mathrm{pH}$ and produce a strong sour product. The opposite can be done to obtain a mild sour product. In this study, $30 \%$ of the product was retained as starter culture for the next batch.

Consistency was also analysed. Tonga mabisi had the highest consistency, followed by backslopping and lastly, illa mabisi. Tonga mabisi in this study had a thick consistency class (class 2) compared to the mostly medium class found in chapter 4 during the laboratory experiment. The backslopping mabisi had a medium consistency (class 3) while illa had a thin consistency (class 4). Differences in consistency among the products from the different producers were observed with those using milk from dairy breeds Holstein-Friesian cross-bred with local cattle producing lower consistencies while milk from beef breeds, Boran/Brahman crossed with local cattle produced mabisi with thicker consistencies. These differences may be due to variation in raw milk composition $[89,93]$ but further investigation is required.

\subsection{Nutritional composition of mabisi and food security}

Mabisi is a versatile product, which can be consumed either as a beverage or with other food products. Chapter 2 lists the different types of foods that can be consumed with mabisi which include both local and exotic fruits (mango, pawpaw, tamarind), boiled grains (sorghum, millet, rice and maize), porridges, legumes (beans, cowpeas, groundnuts), pumpkins, tubers and root crops (sweet potatoes, potatoes, cassava), confectionary products (bread, cakes) and for cooking (vegetables, fish and meat) (chapter 2 Table 3). The nutritional composition of most of these foods has been established and can be found in literature [94]. However, there is limited information on the nutritional composition of mabisi. In view of the different types of mabisi that exist, there is a need to ascertain the nutritional composition for each type in order to be able to estimate their respective nutritional contribution in the diet.

Although the nutritional composition of mabisi was not analysed in any of the chapters in this thesis, some of the mabisi samples from the country-wide survey were analysed for proximate composition. The nutritional composition of mabisi showed considerable variation depending on the type of product and producer. Generally, mabisi was found to be rich in protein, fat, and minerals, which collectively accounted for $8-14 \%$ of the total solids in the product (Fig. 3). Barotse and creamy mabisi had the highest total solids mainly because of whey removal during production and were probably more nutritious than tonga and backslopping mabisi, which both had lower levels of total solids. These results are based on endpoint samples collected from the farmer (producers) but there is need to validate them through controlled laboratory scale production and analysis for each type.

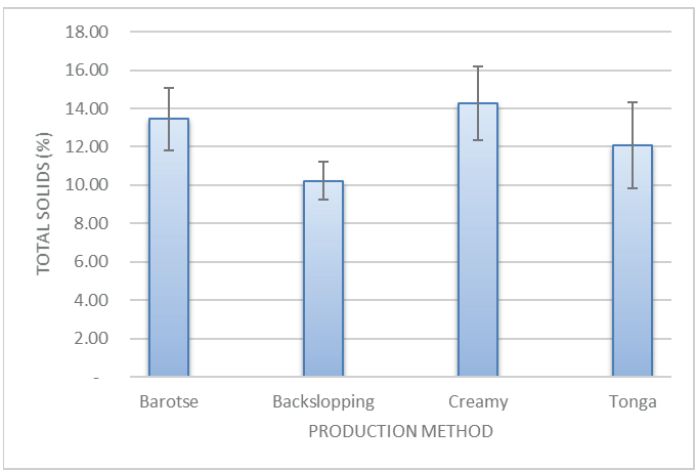

Fig. 3. Total solids of four different types of mabisi: barotse, backslopping, creamy and tonga mabisi. 
The nutritional composition of mabisi shows that the product can make a valuable contribution to the nutritional quality of the human diet by combining its consumption with other foods and given the wide number of uses that were found in the survey. Mabisi intake by children under the age of five has shown positive effects on their gut microbiota [95]. In Africa, postharvest losses of crops are estimated at 50\% of the annual production and these figures include Zambia. Furthermore, it is estimated that $50 \%$ of the milk produced during the peak production period of the rainy season is lost in Zambia. Together with the losses of other crops, this would contribute a substantial amount of nutrients to the diet and help to reduce the under nutrition burden that stands at $40 \%$ stunting of under five children in Zambia [25]. Therefore, mabisi is a potential vehicle that can contribute towards the alleviation of these levels of under nutrition because it is a nutritious product produced at room temperature and remains stable for several days under those conditions.

This thesis has described the different production methods of mabisi and its uses in chapter 2 . The physicochemical properties of some of the mabisi types have also been described in chapters $4 \& 5$ while the nutritional composition has been discussed in this chapter. This information can collectively be used to develop standardised mabisi with established shelf life and nutritional value to improve the nutrition of young children and adults. Furthermore, mabisi-based products in combination with other nutrient rich foods can be formulated for specific age groups especially, the young children under the age of five years. Training and awareness campaigns are also required in the communities about the nutritional benefits of mabisi and about the health benefits of its microbes, as well as ways of mabisi production and uses, and the use of nutrient rich by-products such as whey, which in the current practice is discarded during the production of barotse mabisi especially, in Western province.

\subsection{Microbial community composition of mabisi}

Chapter 3 describes the collection of 168 samples of mabisi around the country and their analysis using $16 \mathrm{~S}$ rRNA amplicon sequencing to determine the microbial community composition. The samples were mostly composed of microbes from two phyla, Firmicutes and Proteobacteria. At genus level, the top 10 most abundant genera were Lactococcus, Lactobacillus, Streptococcus, Kluyvera, Klebsiella, Enterobacter, Citrobacter, Buttiauxella, Aeromonas, and Acinetobacter. At species level, the top 10 was Lactococcus lactis, Streptococcus salivarius subsp. salivarius, Lactobacillus helveticus, Lactobacillus delbrueckii , Kluyvera intermedia, Klebsiella sp. Enterobacter asburiae, Citrobacter sp. and Aeromonas caviae. The most dominant genus and species were Lactococcus and Lactococcus lactis, respectively. The mabisi samples showed differences in the microbial community composition and microbial diversity as a function of the geographical location, production methods, producer, container and $\mathrm{pH}$ of the product.

The geographical locations that were sampled around the country were divided into two main regions: the traditional mabisi production region (TMPR) with more cattle, milk and mabisi production (Western, Southern and Central provinces) and the non-TMPR (Eastern, North-western, Northern, Muchinga and Copperbelt provinces). Products from the TMPR, were found to be dominated by lactic acid bacteria (LAB), Lactococcus, Lactobacillus and Streptococcus while products from the non-TMPR had a more complex and diverse microbial composition with Lactococcus as the main LAB genus driving the fermentation process and a high relative abundance of non-LAB. Furthermore, the main type of mabisi produced in the non-TMPR was mostly, tonga mabisi whereas more variety in the types of mabisi produced (tonga, barotse, backslopping and thick-tonga) was found in the TMPR.

The influence of the production method (type) of mabisi on microbial community composition was tested in chapters $4 \& 5$ where tonga mabisi was found to have a complex and diverse microbial community composition with Lactococcus as the main LAB genus with a high relative abundance of non-LAB genera. In chapter 4 , the microbial community composition of tonga and barotse mabisi fermented at the same temperatures $\left(25^{\circ} \mathrm{C} \& 30^{\circ} \mathrm{C}\right)$ resulted in different outcomes with tonga mabisi having a more complex 
and diverse composition regardless of fermentation temperature. The microbial community composition of barotse mabisi, however, was less diverse and dominated by the LAB genera of Lactococcus and Lactobacillus thus, showing a strong effect of production method on microbial community composition.

This effect was also shown in chapter 5 where three types of mabisi were produced by four different producers. They executed 10 cycles of production of tonga, illa and backslopping mabisi. The microbial community composition of tonga mabisi remained diverse throughout the 10 cycles with minor shifts in Lactococcus and the non-LAB genera. However, large shifts were observed for both illa and backslopping mabisi, which started out with a more complex and diverse composition of tonga mabisi in their first cycle to less diverse composition dominated by Lactococcus and Lactobacillus in the $10^{\text {th }}$ cycle. This shows that the production method applies a significant selection pressure on the microbes in mabisi, which results in different outcomes. The duration of the fermentation may also have a bearing since microbial community composition shifts were observed after 5 days of fermentation in both experiments in chapters $4 \& 5$ from a diverse composition to a less diverse community dominated by species of 2-3 genera.

Another factor influencing microbial community composition of mabisi was related to the producers. The mabisi from traders in local markets was dominated by Lactobacillus whereas the mabisi from the farmers and MCCs was dominated by Lactococcus and Streptococcus in chapter 3. This was tested in chapter 5 where four different producers made three types of mabisi. Differences were observed among producers' products with two producers who had similar cattle breeds and husbandry practices, and who produced their mabisi in a similar environment, having products with similar microbial composition compared to the other two. The study also showed that fermentation temperature for one of the producers influenced the $\mathrm{pH}$ of the product. This in turn affected the microbial community composition. The selection pressure induced by the producers on the microbial community composition of their products was statistically stronger than production method and seems to be influenced by other factors such as temperature and $\mathrm{pH}$.

The effect of fermentation temperature on the microbial community composition of mabisi was investigated in chapter 4 . Fermentation temperature does not have an effect on the composition of tonga mabisi microbial communities, which remain complex and diverse. However, it influenced the microbial community composition of barotse mabisi, which was found to be dominated by Lactococcus at $25^{\circ} \mathrm{C}$ at $\mathrm{pH} 4.2$ and Lactobacillus at $30^{\circ} \mathrm{C}$ with $\mathrm{pH} 3.2$. This study demonstrates that selection pressure applied by the temperature and $\mathrm{pH}$ allowed the growth of species that were more suited to grow at those respective conditions. In this case, the mesophiles dominated at lower temperature while thermophiles dominated at higher temperature. These conditions can thus, be manipulated to produce the desired product in terms of taste and other organoleptic properties.

\subsection{Microbial functionality and aroma compounds}

Fermented dairy products have characteristic aroma and flavour. Cheeses for example, are ripened for several months in order to develop characteristic aroma compounds that are desirable to the consumers. These aroma compounds are volatile compounds that are produced through the enzymatic breakdown of proteins and lipids present in the cheese. The proteolytic and lipolytic enzymes involved during ripening are produced mostly by lactic acid bacteria [65]. For example, Lactococcus lactis biovar. diacetylactis and Leuconostoc mesenteroides produces aroma in cheese while Lactobacillus delbrueckii bulgaricus produces acetylaldehyde in yoghurt from the breakdown of threonine in milk $[40,69,96]$. This demonstrates the functionality of the starter microbes used during the fermentation of these dairy products.

In mabisi production, the fermentation process is predominantly spontaneous with a different microbial community composition for different types of mabisi as described in chapter $3,4 \& 5$. These microbial communities produce different aroma profiles for the different types of mabisi but overall when compared to other African TFMP, mabisi has more esters than amasi and kivuguto [22,80]. Tonga mabisi has the least number of aroma compounds especially the esters compared to the other types of mabisi (chapter 
5). Its aroma compound profile is not affected by differences in fermentation temperature but there can be slight variations between batches of production (chapter 4). Further, it has a complex and diverse microbial composition with the fermenting LAB genera being Lactococcus and Streptococcus over a 1-3 days fermentation period as explained in chapter $3,4 \& 5$.

The barotse, illa and backslopping mabisi all had more aroma compounds than tonga mabisi especially when looking at the esters (chapter 4 \& 5) ). Fermentation temperature was found to have an effect on the microbial community composition of barotse mabisi with Lactococcus dominating at $25^{\circ} \mathrm{C}$ and Lactobacillus dominating at $30^{\circ} \mathrm{C}$ after 6 days of fermentation (chapter 4 ). This in turn produced different aroma compound profiles for the two products. The product fermented at $30^{\circ} \mathrm{C}$ had higher levels of aroma compounds than the one fermented at $25^{\circ} \mathrm{C}$. Furthermore, during the 10 production cycles of backslopping and illa mabisi in chapter 5 , the microbial community composition changed from a complex and diverse composition of the first cycle to less diverse composition dominated by Lactococcus and Lactobacillus during the $6^{\text {th }}$ cycle and ended with more Lactobacillus than Lactococcus in the $10^{\text {th }}$ cycle. Leuconostoc also increased its relative abundance in the $6^{\text {th }}$ and $10^{\text {th }}$ production cycles of these products. These changes in microbial composition resulted in more aroma compounds being produced in the $6^{\text {th }}$ and $10^{\text {th }}$ cycles than the $1^{\text {st }}$ cycle of production, which was essentially tonga mabisi and thus, underscores the differences in aroma profile between tonga mabisi, and backslopping and illa mabisi. This shows a strong link between microbial community composition and the production of aroma compounds with Lactobacillus and Leuconostoc dominated mabisi producing more aroma compounds. However, to distinguish the differences in these products further, a sensory evaluation should be conducted. This will also show the most preferred products whose aroma profiles and microbial are known. Collectively, all this information can be used to design starter cultures for several types of mabisi.

\subsection{Proposed mabisi characteristics and starter culture composition}

This thesis has established that there are seven different types of mabisi produced throughout Zambia and the top three most produced types are tonga, barotse and backslopping mabisi. Details on the processing method of each type are described in chapter 2. Based on the consumer data discussed in this chapter as well as the physicochemical data from chapters 3, 4 \& 5, six products can be proposed for possible product development: tonga, thick-tonga, backslopping, illa and two types of barotse mabisi (a regular and a strong sour). The suggested product characteristics can be further validated and used to evaluate some of the products being produced by MCC or other producers.

Table 3. Proposed starter culture composition and product characteristics of six types of mabisi

\begin{tabular}{|c|c|c|}
\hline Type of mabisi & Product characteristics & Starter culture \\
\hline Tonga mabisi & $\begin{array}{ll}- & \text { pH: } 4.2-4.5 \\
- & \text { Acidic taste: medium } \\
- & \text { Consistency: medium } \\
- & \text { Syneresis: }<30 \%\end{array}$ & Lactococcus, Streptococcus \\
\hline Thick-tonga mabisi & $\begin{array}{ll}- & \text { pH: } 4-4.5 \\
\text { - } & \text { Acidic taste: medium } \\
\text { - } & \text { Consistency: thick } \\
\text { - } & \text { Syneresis: }<5 \%\end{array}$ & $\begin{array}{l}\text { Lactococcus, Streptococcus \& } \\
\text { Lactobacillus }\end{array}$ \\
\hline Strong barotse mabisi & $\begin{array}{ll}\text { - } & \text { pH: } 3.2-4 \\
\text { - } & \text { Acidic taste: strong } \\
\text { - } & \text { Consistency: very thick } \\
\text { - } & \text { Syneresis: }<5 \%\end{array}$ & $\begin{array}{l}\text { Lactococcus, Streptococcus, } \\
\text { Lactobacillus \& Leuconostoc }\end{array}$ \\
\hline Regular barotse mabisi & $\begin{array}{ll}\text { - } & \text { pH: } 4-4.5 \\
\text { - } & \text { Acidic taste: medium } \\
\text { - } & \text { Consistency: very thick } \\
\text { - } & \text { Syneresis: }<5 \%\end{array}$ & Lactococcus, Streptococcus \\
\hline
\end{tabular}




\begin{tabular}{|c|c|c|}
\hline Illa mabisi & $\begin{array}{ll}\text { - } & \text { pH: } 4-4.5 \\
\text { - } & \text { Acidic taste: medium } \\
\text { - } & \text { Consistency: thin } \\
\text { - } & \text { Syneresis: }<35 \%\end{array}$ & $\begin{array}{l}\text { Lactococcus, Streptococcus, } \\
\text { Lactobacillus \& Leuconostoc }\end{array}$ \\
\hline Backslopping mabisi & $\begin{array}{ll}- & \text { pH: } 4-4.5 \\
- & \text { Acidic taste: medium } \\
- & \text { Consistency: medium } \\
\text { - } & \text { Syneresis: }<30 \% \\
\end{array}$ & $\begin{array}{l}\text { Lactococcus, Streptococcus, } \\
\text { Lactobacillus \& Leuconostoc }\end{array}$ \\
\hline
\end{tabular}

The proposed starter cultures are based on the microbial composition, aroma profiles and physicochemical data from this thesis, which suggests three starter cultures for six products. Process conditions and production method would differentiate the products and their characteristics.

The development of starter cultures and maintenance can be expensive and the starters may be beyond the reach of some of the small-scale producers. This thesis has also demonstrated that spontaneous fermentation under specific conditions can still be used to produce these products. And this might be a more affordable option that can be easily be implemented by MCCs and other producers. Control of the quality for the raw milk to ensure that only fresh milk is used and the end point $\mathrm{pH}$ would be crucial for product quality and safety. These controls can easily be achieved by the use of the alcohol test for raw milk quality, which is already being carried out in most MCCs and checking the product endpoint pH to ensure that it is $\leq 4.5$ can also be easily be carried out using $\mathrm{pH}$ meter or $\mathrm{pH}$ colour strips. These processes can be formalised and be used to regulate mabisi production. Moreover, there certain cheeses that are also produced through spontaneous fermentation and/or use of undefined starter cultures [35, 40].

\subsection{Economic potential of mabisi}

This thesis has demonstrated that it is possible to develop several mabisi products. For example, in the previous section, six products have been proposed for product development and optimisation. This would result in product differentiation, which if followed up by the associated price differentiation would ensure profitability for each product. However, a lot of advocacy, marketing and consumer education is required because most consumers think there is only one type of mabisi, which varies considerably in quality. They need to be sensitized that there are different types of mabisi, with different quality attributes and uses. For example, illa mabisi should be a drinking mabisi because of its low consistency. In addition, health benefits and food safety assurances should also be included in the consumers' education package.

One commercial variant of mabisi, 'lacto' is already on the market but consumers prefer the traditional mabisi [97], which is not sold in large retail outlets like supermarkets for legal reasons. Some consumers have doubts about the safety of the traditional mabisi because certain producers do not exhibit high levels of hygiene. However, in terms of taste, the traditional mabisi is preferred and if the production and sales volumes of the commercial variant are anything to go by, then the economic potential of mabisi is huge. Moreover, mabisi production would provide an avenue for reducing the milk losses that are currently prevailing in some of high milk production regions of the country.

\subsection{General conclusions}

This thesis has established that there seven production methods for mabisi spread throughout Zambia which include tonga, thick-tonga, barotse, backslopping, illa, creamy and cooked mabisi (in chapter 2). Tonga mabisi was found to be the most popular and widely produced mabisi variant throughout the country by all ethnic groups. The key production parameters were type of fermentation container, fermentation temperature, backslopping, alternate removal of whey and addition of raw milk, boiling and cooling, fermentation time and agitation (churning). This chapter also describes the hygiene practices and demonstrates that mabisi is a versatile product with various uses as it can be consumed with maize porridge, boiled grains (maize, sorghum, millet, rice) and legumes, boiled tubers and roots, fruits, bread, pasta and can be used for cooking vegetables, fish and meat. 
The microbial community composition of mabisi from across the country was unravelled in chapter 3 . It was found that the top 10 most abundant genera were Lactococcus, Lactobacillus, Streptococcus, Enterobacter, Klebsiella, Kluyvera, Aeromonas, Acinetobacter, Buttiauxella and Citrobacter, which belong to two phyla, Firmicutes and Proteobacteria. The microbial community composition was affected by geographical location, production method, type of producer, fermentation container, $\mathrm{pH}$ and fermentation time. Furthermore, the production of mabisi in the country was divided into two main regions, (i) the traditional mabisi production region (TMPR) and (ii) the non-TMPR. The TMPR was dominated by LAB while the non-TMPR was characterised by a diverse community of non-LAB but with Lactococcus driving the fermentation process in these products. Tonga mabisi had a more complex and diverse microbial composition than the rest.

The fermentation temperature had no effect on the microbial community composition of tonga mabisi which remained complex and diverse with Lactococcus as the main LAB driving the fermentation (chapter 4). However, there was a significant difference in microbial community composition of barotse mabisi fermented at $25^{\circ} \mathrm{C}$ (dominated by Lactococcus) and the one fermented at $30^{\circ} \mathrm{C}$ (dominated by Lactobacillus). Higher incubation temperature $\left(30^{\circ} \mathrm{C}\right)$ led to faster fermentation with the raw milk coagulating into mabisi already after $24 \mathrm{~h}$, however, this temperature produced a product with high syneresis and a low consistency, which was not desirable. The best fermentation temperature range for mabisi with medium to thick consistency was between $20-25^{\circ} \mathrm{C}$.

Three types of mabisi were produced by four different producers over 10 production cycles to determine the effect of production method on microbial community composition in chapter 5 . It was found that the production method had an effect on the microbial community composition with tonga mabisi retaining a more complex and diverse composition than illa and backslopping mabisi after 10 production cycles. The $6^{\text {th }}$ and $10^{\text {th }}$ cycles of illa and backslopping mabisi were dominated by Lactococcus and Lactobacillus. The producers, production method and production cycle, all had an effect on the microbial community composition. Tonga mabisi had the thickest consistency followed by backslopping and illa mabisi had the lowest because of agitation during fermentation.

This thesis has provided new knowledge on the different production methods of mabisi and their associated microbial communities composition and dynamics. And has established process conditions that can be used to produce good quality products that meet consumer expectation. This information is crucial for the development of production protocols and standards that can be used to regulate mabisi production in order to improve its trade and production, which will reduce milk losses, increase income and improve livelihoods of local farmers and producers.

\subsection{Future perspectives}

The studies described in this thesis have identified and characterised the different types of mabisi that are produced in Zambia. Their production processes were described in detail and key process parameters were identified (chapter $4 \& 5$ ). The microbial community composition of mabisi has been elucidated (chapter 3) with several factors identified as the key selection pressure agents that shape the communities' composition.

The top 10 most abundant genera and species have been identified (chapter 3) and a number of microbes have been proposed as candidates for starter culture development (see table 3). However, there is need to isolate these microbes from mabisi and test them as single cultures for functionality: acid, aroma compounds and exopolysaccharide production. They can thereafter be assembled into a community or starter culture, which can be tested as a whole culture and also by single omission of a strain. Furthermore, each of the isolated strains can be investigated for functionality using metabolomics and transcriptomics.

The microbial community composition for mabisi is dominated by $L A B$ but also has substantial relative abundances of non-LAB microbes with varying proportions. In products like tonga mabisi, the non- $L A B$ fractions can be higher than the other types of mabisi dominated by $L A B$ but some of these species are 
also present in much lower proportions. There is need to investigate their role in the community and establish whether there is any horizontal gene transfer among the $L A B$ species themselves and also between them and non-LAB species, which can affect the functionality or resilience of the community.

One of the reasons why mabisi production is not regulated and has no standards developed is the question of its safety. This thesis shows the extensive usage of the product and confidence that its consumers have in the product. However, in order to grow the market and update the provisions for its production in the law and regulations, there is need to ascertain it safety. Several challenge tests have been conducted within the framework of this project $[98,99]$, which have shown that the mabisi microbial community is able to resist invasion by certain pathogens. This work needs to be completed by including more pathogens (including zoonotic species) as well as test the use of raw milk as opposed to pasteurized milk. In addition, the microbiological quality of raw milk that is usually used to make mabisi should be determined in order to realistically ascertain the spiking levels of the pathogens that should be used during challenge tests.

The mabisi production experiments performed in this thesis were limited to small quantities of 0.5-2 litres. However, most producers and MCCs deal with larger volumes of milk starting from 20-litres to several hundreds or thousands of litres. To be able to scale-up production, there is need to carry out production trials using some of the process conditions developed from this thesis that will ensure the production of a standardised product. Therefore, raw milk quality and total solids content should be determined and their effect on product quality ascertained. Furthermore, the shelf life of mabisi should be established and the product should be evaluated for microscopic structure, texture, sensory and consumer acceptability.

Mabisi is produced through a spontaneous fermentation process using different types of containers: calabash, metal and plastic. These containers are made of different materials and this thesis has established that most producers only use water (warm or hot) to clean their containers. This means that there is high likelihood of biofilm formation on the surfaces of these containers. Thus, these can be investigated on the different types of containers by characterising the microbes on the surface and how they influence the microbial communities of the product and whether they can be used in mabisi production as a new application.

The economic potential of mabisi has been discussed in this chapter but there is limited information on quantities of mabisi produced, consumed as well as losses. Market research should be conducted to determine what kind of mabisi the consumer wants, the type of mabisi products desired, pricing and product differentiation. 


\section{References}

1. Smid, E.J., Fermented foods : Products of science and craftsmanship. 2015, Wageningen: Wageningen University, Wageningen UR.

2. Camu, N., et al., Fermentation of cocoa beans: influence of microbial activities and polyphenol concentrations on the flavour of chocolate. Journal of the Science of Food and Agriculture, 2008. 88(13): p. 2288-2297.

3. Westby, A. and B. Choo. CYANOGEN REDUCTION DURING LACTIC FERMENTATION OF CASSAVA. 1994. International Society for Horticultural Science (ISHS), Leuven, Belgium.

4. Montagnac, J.A., C.R. Davis, and S.A. Tanumihardjo, Processing Techniques to Reduce Toxicity and Antinutrients of Cassava for Use as a Staple Food. Comprehensive Reviews in Food Science and Food Safety, 2009. 8(1): p. 17-27.

5. Nout, M.J.R. and J.L. Kiers, Tempe fermentation, innovation and functionality: update into the third millenium. Journal of Applied Microbiology, 2005. 98(4): p. 789-805.

6. Keuth, S. and B. Bisping, Vitamin B12 production by Citrobacter freundii or Klebsiella pneumoniae during tempeh fermentation and proof of enterotoxin absence by PCR. Applied and Environmental Microbiology, 1994. 60(5): p. 1495.

7. Salque, M., et al., Earliest evidence for cheese making in the sixth millennium bc in northern Europe. Nature, 2013. 493(7433): p. 522-525.

8. Yang, Y., et al., Proteomics evidence for kefir dairy in Early Bronze Age China. Journal of Archaeological Science, 2014. 45: p. 178-186.

9. Leroy, F. and L. De Vuyst, Lactic acid bacteria as functional starter cultures for the food fermentation industry. Trends in Food Science \& Technology, 2004. 15(2): p. 67-78.

10. Smid, E. and M. Kleerebezem, Production of Aroma Compounds in Lactic Fermentations. Vol. 5. 2014. 313-26.

11. Hati, S., S. Das, and S. Mandal, 4 - Technological Advancement of Functional Fermented Dairy Beverages, in Engineering Tools in the Beverage Industry, A.M. Grumezescu and A.M. Holban, Editors. 2019, Woodhead Publishing. p. 101-136.

12. Akabanda, F., Owusu-Kwarteng, J., Glover, R., Tano-Debrah, K., Microbiological characteristics of Ghanaian traditional fermented milk product, Nunu. Nature \& Science, 2010. 8(9): p. 178-187.

13. Karenzi, E., Mashaku, A.,Nshimiyimana, A. M.,Munyanganizi, B., \& Thonart, P., Kivuguto traditional fermented milk and the dairy industry in Rwanda. A review. Biotechnologie Agronomie Societe Et Environnement, 2013. 17(2): p. 383-391.

14. Nduko, J., et al., Spontaneously fermented kenyan milk products: A review of the current state and future perspectives. Vol. 11. 2017. 1-11.

15. Gebreselassie, N., et al., A survey on spontaneously fermented buttermilk in Northern Ethiopia. African Journal of Food Science and Technology, 2012. 3: p. 78-89.

16. Gonfa, A., H.A. Foster, and W.H. Holzapfel, Field survey and literature review on traditional fermented milk products of Ethiopia. International Journal of Food Microbiology, 2001. 68(3): p. 173-186.

17. Benkerroum, N. and A.Y. Tamime, Technology transfer of some Moroccan traditional dairy products (Iben, jben and smen) to small industrial scale. Food Microbiology, 2004. 21(4): p. 399-413.

18. Misihairabgwi, J. and A. Cheikhyoussef, Traditional fermented foods and beverages of Namibia. Journal of Ethnic Foods, 2017. 4(3): p. 145-153.

19. Bille, P.G., E. Buys, and J.R.N. Taylor, The technology and properties of Omashikwa, a traditional fermented buttermilk produced by small-holder milk producers in Namibia. International Journal of Food Science \& Technology, 2007. 42(5): p. 620-624.

20. Beukes, E.M., B.H. Bester, and J.F. Mostert, The microbiology of South African traditional fermented milks. International Journal of Food Microbiology, 2001. 63(3): p. 189-197.

21. Mutukumira, A.N., Properties of Amasi, a Natural Fermented Milk produced by Smallholder Milk Producers in Zimbabwe. Milchwissenschaft-Milk Science International, 1995. 50(4): p. 201-205

22. Gadaga, T.H., B.C. Viljoen, and J.A. Narvhus, Volatile organic compounds in naturally fermented milk and milk fermented using yeasts, lactic acid bacteria and their combinations as starter cultures. Food Technology and Biotechnology, 2007. 45(2): p. 195.

23. Gadaga, T.H., et al., A review of traditional fermented foods and beverages of Zimbabwe. International Journal of Food Microbiology, 1999. 53(1): p. 1-11.

24. Schoustra, S.E., et al., Microbial community structure of three traditional zambian fermented products: mabisi, chibwantu and munkoyo. PLoS ONE, 2013. 8(5).

25. Central Statistical Office (CSO) [Zambia], M.o.H.M.Z., and ICF International, Zambia Demographic and Health Survey 2013-14. 2014, Rockville, Maryland, USA.

26. Mumba, C., Pandey, G S, and Jagt van der, C Milk production potential, marketing and income opportunities in key traditional cattle keeping areas of Zambia. . Livestock Research for Rural Development. , 2013. Volume 25, Article \#73.(4).

27. Musika, A Review of the Status of Livestock Production \& Stocking in Zambia 2017, Musika (Making Agricultural Markets work for Zambia).

28. Sybesma, W., R. Kort, and Y.-K. Lee, Locally sourced probiotics, the next opportunity for developing countries? Trends in Biotechnology, 2015. 33(4): p. 197-200.

29. Singh, R.K., et al., Influence of diet on the gut microbiome and implications for human health. Journal of Translational Medicine, 2017. 15(1): p. 73.

30. Kort, R., et al., A novel consortium of Lactobacillus rhamnosus and Streptococcus thermophilus for increased access to functional fermented foods. Microbial Cell Factories, 2015. 14(1): p. 195. 
31. Kebede, A., et al., The effect of container type on the growth of yeast and lactic acid bacteria during production of Sethemi, South African spontaneously fermented milk. Food Research International, 2007. 40(1): p. 33-38.

32. Gebreselassie, N., et al., Chemical composition of naturally fermented buttermilk. International Journal of Dairy Technology, 2016. 69(2): p. 200-208.

33. (MFL), M.o.F.L., Annual Report 2017 2018, MFL - Department of Livestock Development p. 4-5, 16-17.

34. Quigley, L., et al., The complex microbiota of raw milk. FEMS Microbiology Reviews, 2013. 37(5): p. 664-698.

35. Beresford, T.P., et al., Recent advances in cheese microbiology. International Dairy Journal, 2001. 11(4): p. 259-274.

36. Lee, W.J. and J.A. Lucey, Formation and Physical Properties of Yogurt. Vol. 23. 2010.

37. Parker, M., et al., Naturally Fermented Milk From Northern Senegal: Bacterial Community Composition and Probiotic Enrichment With Lactobacillus rhamnosus. Frontiers in microbiology, 2018. 9: p. 22182218.

38. Osvik, R.D.S., Sigmund; Breines, Eva Marie; Hareide, ellinor; Godfroid, Jacques; Zhou, Zhigang; Ren, Pengfei; Geoghegran, Claire; Holzapfel, Wilhelm; Ring $\varnothing$, Einar, Bacterial diversity of aMasi, a South African fermented milk product, determined by clone library and denaturing gradient gel electrophoresis analysis. African Journal of Microbiology Research, 2013. 7(32): p. 4146-4158.

39. Groenenboom, A.E., et al., Bacterial community dynamics in lait caillé, a traditional product of spontaneous fermentation from Senegal. PLOS ONE, 2019. 14(5): p. e0215658.

40. Smid, E.J., et al., Functional implications of the microbial community structure of undefined mesophilic starter cultures. Microbial Cell Factories, 2014. 13(suppl. 1).

41. Aldrete-Tapia, A., et al., High-throughput sequencing of microbial communities in Poro cheese, an artisanal Mexican cheese. Food Microbiology, 2014. 44: p. 136-141.

42. Bogucki, P.I., Ceramic sieves of the linear pottery culture and their economic implications. Oxford Journal of Archaeology, 1984. 3(1): p. 15-30.

43. Feresu, S. and M.I. Muzondo, Factors affecting the development of two fermented milk products in Zimbabwe. MIRCEN journal of applied microbiology and biotechnology, 1989. 5(3): p. 349-355.

44. Mpofu, A., et al., Mutandabota, a Food Product from Zimbabwe: Processing, Composition, and Socioeconomic Aspects. Ecology of Food and Nutrition, 2014. 53(1): p. 24-41.

45. Fernández Ramírez, M.D., et al., Role of cell surface composition and lysis in static biofilm formation by Lactobacillus plantarum WCFS1. International Journal of Food Microbiology, 2018. 271: p. 15-23.

46. Fox, F.W., Some Bantu Recipes from the Eastern Cape Province. Bantu Studies, 1939. 13(1): p. 6574.

47. Heita, L.N. and A. Cheikhyoussef, Dominant Lactic Acid Bacteria and Their Antimicrobial Profile from Three Fermented Milk Products from Northern Namibia. Journal of Biosciences and Medicines, 2014. Vol.02No.09: p. 6.

48. Flint, J.E., The Cambridge History of Africa, c. 1790-c. 1870 Book, 1976. 5: p. 319-350.

49. Tlou, T., A History of Ngamiland, 1750 to 1906: The Formation of an African State. 1985: Macmillan Botswana.

50. Bryant, A.T., The Zulu People, As They Were Before The White Man Came. Book, 1967(2nd Edition ).

51. Erkus, O., et al., Multifactorial diversity sustains microbial community stability. The Isme Journal, 2013. 7: p. 2126

52. Anal, A.K., Quality Ingredients and Safety Concerns for Traditional Fermented Foods and Beverages from Asia: A Review. Fermentation, 2019. 5(1): p. 8.

53. Moonga, H.B., et al., The art of mabisi production: A traditional fermented milk. PLOS ONE, 2019. 14(3): p. e0213541.

54. Bokulich, N.A., et al., Associations among Wine Grape Microbiome, Metabolome, and Fermentation Behavior Suggest Microbial Contribution to Regional Wine Characteristics. mBio, 2016. 7(3): p. e00631-16.

55. Domínguez-Manzano, J., et al., Biofilm formation on abiotic and biotic surfaces during Spanish style green table olive fermentation. International Journal of Food Microbiology, 2012. 157(2): p. 230-238.

57. Caporaso, J.G., et al., QIIME allows analysis of high-throughput community sequencing data. Nature Methods, 2010. 7: p. 335.

58. Bik, E.M., et al., Marine mammals harbor unique microbiotas shaped by and yet distinct from the sea. Nature Communications, 2016. 7: p. 10516.

59. Martin, M., CUTADAPT removes adapter sequences from high-throughput sequencing reads. Vol. 17. 2011.

60. Edgar, G.J., et al., Global conservation outcomes depend on marine protected areas with five key features. Nature, 2014. 506: p. 216.

61. Quast, C., et al., The SILVA ribosomal RNA gene database project: improved data processing and webbased tools. Nucleic acids research, 2013. 41(Database issue): p. D590-D596.

62. Edgar, R.C., Search and clustering orders of magnitude faster than BLAST. Bioinformatics, 2010. 26(19): p. 2460-2461.

63. Altschul, S.F., et al., Basic local alignment search tool. Journal of Molecular Biology, 1990. 215(3): p. 403-410.

64. Axelsson, L., Lactic Acid Bacteria: Classification and Physiology. 3rd ed. Lactic Acid Bacteria: Microbiological and Functional Aspects, ed. S. Salminen, Wright, A.V. and Ouwehand, A.,. 2004, New York: Marcel Dekker.

65. Murtaza, M.A., et al., Cheddar Cheese Ripening and Flavor Characterization: A Review. Critical Reviews in Food Science and Nutrition, 2014. 54(10): p. 1309-1321. 
66. Farkye, N.Y., Chapter 43 - Quark, Quark-like Products, and Concentrated Yogurts, in Cheese (Fourth Edition), P.L.H. McSweeney, et al., Editors. 2017, Academic Press: San Diego. p. 1103-1110.

67. Lucey, J.A., Cultured dairy products: an overview of their gelation and texture properties. International Journal of Dairy Technology, 2004. 57(2-3): p. 77-84.

68. Gripon, J.C., Mould-Ripened Cheeses, in Cheese: Chemistry, Physics and Microbiology: Volume 2 Major Cheese Groups, P.F. Fox, Editor. 1993, Springer US: Boston, MA. p. 111-136.

69. McSweeney, P.L.H., Biochemistry of cheese ripening. International Journal of Dairy Technology, 2004. 57(2-3): p. 127-144

70. Garofalo, C., et al., Bacteria and yeast microbiota in milk kefir grains from different Italian regions. Food Microbiology, 2015. 49(1): p. 123-133.

71. Johnson, M.E., Mesophilic and Thermophilic Cultures Used in Traditional Cheesemaking. Microbiology Spectrum, 2013. 1(1).

72. Mulenga, B., A. Wineman, and N. Sitko, Mulenga, B.P., Wineman, A. \& Sitko, N.J. Climate Trends and Farmers' Perceptions of Climate Change in Zambia. Environmental Management (2016). DOI: 10.1007/s00267-016-0780-5 Follow link below: http://rdcu.be/IRI4. Vol. 59. 2016.

73. AOAC., Official Methods of Analysis of the Association of Analytical Chemists International. 18th ed. Book. Vol. . 2005, Gaithersburg, Maryland: AOAC International

74. Gould, W., Tomato production, processing \& technology. Book, 1992. 3rd Edition p. 334

75. Garcia, E. and J.E. Wayne, Textural Modification of Processing Tomatoes AU - Barrett, Diane M. Critical Reviews in Food Science and Nutrition, 1998. 38(3): p. 173-258.

76. Feresu, S. and H. Nyati, Fate of pathogenic and non-pathogenic Escherichia coli strains in two fermented milk products. Journal of Applied Bacteriology, 1990. 69(6): p. 814-821.

77. Gran, H.M., et al., Occurrence of pathogenic bacteria in raw milk, cultured pasteurised milk and naturally soured milk produced at small-scale dairies in Zimbabwe. Food Control, 2003. 14(8): p. 539544.

78. Walstra, P., The Syneresis of Curd, in Cheese: Chemistry, Physics and Microbiology: Volume 1 General Aspects, P.F. Fox, Editor. 1993, Springer US: Boston, MA. p. 141-191

79. Moyane, J.N.A.I.O., Jideani, The physicochemical and sensory evaluation of commercial sour milk (amasi) products. African Journal of Food Science 2013. 7(4): p. 56-62.

80. Karenzi, E., Fauconnier, M.L., Destain, J., Laurent, P., \& Thonart, P., Technological Features of Selected Kivuguto Strains during Milk Fermentation. Bioengineering and Bioscience 2015. 3(2): p. 1322.

81. Gran, H.M., H.T. Gadaga, and J.A. Narvhus, Utilization of various starter cultures in the production of Amasi, a Zimbabwean naturally fermented raw milk product. International Journal of Food Microbiology, 2003. 88(1): p. 19-28.

82. Rowland, I., et al., Gut microbiota functions: metabolism of nutrients and other food components. European journal of nutrition, 2018. 57(1): p. 1-24.

83. de Vries, F.T. and R.I. Griffiths, Chapter Five - Impacts of Climate Change on Soil Microbial Communities and Their Functioning, in Developments in Soil Science, W.R. Horwath and Y. Kuzyakov, Editors. 2018, Elsevier. p. 111-129.

84. Langenheder, S. and A.J. Székely, Species sorting and neutral processes are both important during the initial assembly of bacterial communities. The ISME journal, 2011. 5(7): p. 1086-1094.

85. Székely, A.J. and S. Langenheder, The importance of species sorting differs between habitat generalists and specialists in bacterial communities. FEMS Microbiology Ecology, 2014. 87(1): p. 102112.

86. Lindmark-Månsson, H., R. Fondén, and H.-E. Pettersson, Composition of Swedish dairy milk. International Dairy Journal, 2003. 13(6): p. 409-425.

87. Galina, M.A., et al., Cheese quality from milk of grazing or indoor fed Zebu cows and Alpine crossbred goats. Small Ruminant Research, 2007. 71(1): p. 264-272.

88. Walsh, A.M., et al., Microbial Succession and Flavor Production in the Fermented Dairy Beverage Kefir. mSystems, 2016. 1(5): p. e00052-16.

89. Barron, L.J.R., et al., Seasonal changes in the composition of bulk raw ewe's milk used for Idiazabal cheese manufacture. International Dairy Journal, 2001. 11(10): p. 771-778.

90. Giannino, M.L., et al., Study of microbial diversity in raw milk and fresh curd used for Fontina cheese production by culture-independent methods. International Journal of Food Microbiology, 2009. 130(3): p. $188-195$

91. Zheng, X., et al., Dynamic correlations between microbiota succession and flavor development involved in the ripening of Kazak artisanal cheese. Food Research International, 2018. 105: p. 733742.

92. Lenski, R.E., Experimental evolution and the dynamics of adaptation and genome evolution in microbial populations. The Isme Journal, 2017. 11: p. 2181.

93. Faria, P.F., et al., Unstable milk occurrence in the semi-arid region and its relation with the physicochemical characteristics of milk. Livestock Research for Rural Development, 2017. 29(1).

94. Hotz C, C., J., Siamusantu, W. and Palaniappan, U., Nutrition Survey in Central and Eastern Provinces Zambia. 2009.

95. Chileshe, J., Talsma, E.F., Schoustra, S.E., Borgonjen-van den Berg, K.J., Handema, R., Zwaan, B.J., \& Brouwer, I.D., Potential contribution of cereal and milk based fermented foods to dietary nutrient intake of 1-5 years old children in Central province in Zambia. 2019.

96. Cheng, H., Volatile flavor compounds in yogurt: A review. Critical Reviews in Food Science and Nutrition, 2010. 50(10): p. 938-950.

97. van de Ven, L., Rick assessment of traditional Zambian drink in Laboratoris of Genetics, Food microbiology \& Food quality design. 2018, Wageningen University 
98. Wangmo, D., Resilience of microbial communities in fermented dairy product-mabisi against invasion, in Laboratories of Genetics \& Food Microbiology. 2017, Wageningen University

99. van der Zon, C., The microbial safety of mabisi, in Laboratories of Genetics \& Food microbiology. 2019, Wageningen University 



\section{Summary}

Fermented dairy products are an important part of the human diet because they provide nutrients and extend the shelf life of raw milk, which is perishable. The most important commercially produced fermented dairy products include: cheese and yoghurt, which derive their origin from artisanal or traditional recipes. These products have a prolonged shelf life of several days under refrigerated conditions for yogurt and several months or years for cheese. The two products account for a multibillion euro business world-wide. In Africa, there are several traditionally fermented milk products (TFMPs) mostly, produced at household level for domestic consumption. These products have potential for product development and commercialisation, and can contribute to food and nutritional security. One of these products is mabisi from Zambia.

Mabisi is made by spontaneous fermentation of raw milk at ambient temperature in a calabash, plastic or metal container for two days. It is widely produced and consumed in Zambia. Mabisi production is traditionally practiced in western, southern and centrals parts of Zambia. Limited research has been conducted on mabisi production with only one study reporting the type of microbes in mabisi from parts of southern and central Zambia, and one production method. However, with population growth and internal migration as well as efforts by both government and stakeholders to increase dairy production, there is need for more research on mabisi to understand the production practices and their effects on the microbes involved in the spontaneous fermentation. Moreover, the Zambian law prohibits the sale of unpasteurised milk but mabisi is made from raw milk and is stable at room temperature for several days. In addition, there are milk losses during the peak production period due to the limited cold chain system and poor road infrastructure.

This thesis describes the seven production methods of mabisi discovered through a country-wide survey, which include tonga, barotse, backslopping, illa, creamy, cooked and thick-tonga mabisi (chapter 1). Tonga mabisi was found to be the most popular and widely produced mabisi variant throughout the country by all ethnic groups. The key production parameters were type of fermentation container, fermentation temperature, backslopping, alternate removal of whey in combination with addition of raw milk, heating and cooling, fermentation time and finally, agitation (churning). This chapter also describes the hygiene practices and demonstrates that mabisi is a versatile product with various uses as it can be consumed with maize porridge, boiled grains (maize, sorghum, millet, rice) and legumes, boiled tubers and roots, fruits, bread, pasta and can be used for cooking vegetables, fish and meat.

Next, the microbial community composition of mabisi from across the country was unravelled (see chapter 3). It was found that the top 10 most abundant genera are Lactococcus, Lactobacillus, Streptococcus, Enterobacter, Klebsiella, Kluyvera, Aeromonas, Acinetobacter, Buttiauxella and Citrobacter, which belong to two phyla, Firmicutes and Proteobacteria. The microbial community composition was affected by geographical location, production method, type of producer, fermentation container, $\mathrm{pH}$ and fermentation time. Furthermore, the production of mabisi in the country was divided into two main regions, (i) the traditional mabisi production region (TMPR) and (ii) the non-TMPR. The products found in TMPR were dominated by $L A B$ while the products from non-TMPR were characterised by a diverse community of non-LAB but with Lactococcus lactis driving the fermentation process in these products. Tonga mabisi had a more complex and diverse microbial community composition than the rest and was widely produced in non-TMPRs. Other types of mabisi produced in the TMPRs include barotse, backslopping, creamy and thick-tonga, all of which were dominated by LAB. The mabisi produced by farmers had more diverse microbial communities composition than that of traders. $\mathrm{Low} \mathrm{pH}(\mathrm{pH}<4)$ mabisi was dominated by LAB especially, Lactobacillus sp. while the high $\mathrm{pH}(\mathrm{pH}>4.5)$ mabisi was dominated by non-LAB with Lactococcus driving the fermentation.

The fermentation temperature, which was one of the key production parameters identified in chapter 2 was investigated in chapter 4 by setting up an experiment with four different fermentation temperatures to mimic seasonal temperature variation and producer practices. Tonga mabisi was fermented at tap water temperature $\left(20^{\circ} \mathrm{C}\right)$, room temperature $\left(22^{\circ} \mathrm{C}\right)$, constant temperatures of $25^{\circ}$ and $30^{\circ} \mathrm{C}$. There was no large effect observed on the microbial community composition of tonga mabisi, which remained 
complex and diverse with Lactococcus as the main LAB driving the fermentation. In addition, the use of single or multiple batches of raw milk for mabisi production as well as the use of a new or previously used container, also did not have an effect on the microbial community composition of tonga mabisi. However, there was a significant difference in microbial community composition of tonga and barotse mabisi. Barotse mabisi incubated at $25^{\circ} \mathrm{C}$ was dominated by Lactococcus and retained moderate $\mathrm{pH}$ of 4.2 whereas the one incubated at $30^{\circ} \mathrm{C}$ was dominated by Lactobacillus and had a much lower pH of 3.2. This confirmed the observation of Lactobacillus dominance in mabisi samples with low pH in chapter 3 . In addition, the barotse mabisi dominated by Lactobacillus $\left(30^{\circ} \mathrm{C}\right)$ produced more aroma compounds than the one dominated by Lactococcus at $25^{\circ} \mathrm{C}$. Higher incubation temperature $\left(30^{\circ} \mathrm{C}\right)$ led to faster fermentation with the raw milk coagulating into mabisi already after $24 \mathrm{~h}$, however, this temperature produced a product with high syneresis and a low consistency which is not desirable. The best fermentation temperature range for mabisi with medium to thick consistency was between $20-25^{\circ} \mathrm{C}$.

The effect of the mabisi producer and production method on microbial community composition of mabisi that was observed in chapter 3, was further investigated in chapter 5 . Three types of mabisi were produced by four different producers over ten production cycles and these included tonga, illa and backslopping mabisi. It was found that the production method had an effect on the microbial community composition with tonga mabisi retaining a more complex and diverse composition than illa and backslopping mabisi after ten production cycles. The $6^{\text {th }}$ and $10^{\text {th }}$ cycles of illa and backslopping mabisi on the other hand were dominated by Lactococcus and Lactobacillus. The producer also had an effect on the microbial community composition as there were differences among the communities from products per producer within a production method. However, this was not the case for the aroma compounds as the compounds for products from different producers within a production method were similar but different among the production methods. This was also the case for the appearance of the products, which could be distinguish based on production method. For instance, all tonga mabisi looked similar regardless of the producer but were different from illa or backslopping mabisi in appearance. Moreover, tonga mabisi had the thickest consistency followed by backslopping and illa mabisi had the lowest consistency because of agitation during fermentation.

In conclusion, this study has established the different production methods of mabisi and its uses. The microbial community composition and the factors that affect them have been elucidated. Finally, the process conditions required to produce good quality mabisi have been established. This knowledge can be used to develop starter cultures for mabisi in order to standardise production. Alternatively, spontaneous fermentation with standardised process conditions can be employed to produce standardised products. Therefore, production protocols and standards can be developed for milk collection centres (MCCs) where local farmers and other producers can process their milk so that their products can reach a wider market, which will in turn reduce milk losses, increase their income and improve their livelihoods. 


\section{Acknowledgements}

What can I say about this PhD journey ...? Simply Awesome!! Over 20 flights, over 15,000km of driving, over six visas \& different rooms, veluloops, several lab outings in three Chair Groups, two PhD trips, many department drinks, the 'stay-ins', 'The Embassy', and more importantly, the Science, the writing, the comments and the publishing. I couldn't have asked for anything better in addition to gaining a title of 'Professor' and 'Ambassador'.

All this wouldn't have been possible without many people playing different important roles, to all of whom I am deeply indebted. Firstly, I would like to express my heartfelt gratitude to my wonderful supervisors, Eddy, Sijmen, Anita and John for their support, patience, counsel and tireless efforts. Eddy, thank you for telling me that there was a lot of scope for research in milk and mabisi in particular during your first visit to Zambia when the WOTRO project was just starting and I was wondering whether to go for mabisi or munkoyo research. Your comments were always thorough and constructive and when I was getting carried away with all sorts of fancy stuff, you reminded me gently to 'keep it simple'. You have been a true mentor in food fermentation, dank u. Sijmen, you always made things happening, always reassuring, always focussed and multi-tasking. To have worked with you during the proposal development of the WOTRO project and getting it funded, then doing a PhD under your supervision was such a fulfilling experience. You moved me from my comfort zone and took me into the domain of microbial ecology \& biology. You lightened many moments when either logistics were a bit cumbersome and the going got tough. Your follow ups in the field in person and by phone were always helpful. Thank you, you are rare species (perhaps a 'Dutchambian'). Anita, the 'Queen mother' or better still 'mummy' as Sydney and I used to call you. I hope he will forgive me for letting the cat out of the bag. Your thorough edits and comments on the use of the Queen's language were invaluable, in additional to your particular attention to detail in terms research, organisational and logistical issues as well as our overall welfare. I'm truly indebted. John, thanks for your support, reassurance and jokes about the PhD confining me to my desk all day. You helped bridge gap between Dutch and Zambian research ideas and facilitated many local processes at UNZA. It was a joy working with you during this journey, especially after having previously worked with you during those days of the two-man Department. Twasanta vingi mwane!! Collectively, the four of you constituted what I called "the dream team" because you complemented each other very well and I am privileged \& honoured to have had the opportunity to grow under your watchful eyes. Twalumba!!!

In the Food Microbiology Group, I would like to thank all the staff, students and colleagues for putting up with me during the last four years, especially with my noisy morning door-to-door routine. Special thanks go to Marcel Z, for your helpful comments and light moments during the PhD trips, Gerda, you always made everything work from flights to name tags on the door and Saint Nicholas presents, you're truly amazing. Judith, you always had a solution in the lab even when you were extremely busy, you could pull a hare out a bag, you're so awesome. Oscar, for all the GC-MS assistance, Tjakko for the nice discussions over some really nice wine, Richard, for the African stories, Heidy, for our water top-up trips, Martine, for our many funny stories about students \& teaching, Marcel T., for all the soccer (Feyenoord) chats, Gerrikke for the baby chats, Wilma for the morning Dutch lessons, Ingrid, for the kitchen intro and giving me equipment, Jeroen, for the dept. drinks, Frank, for the pictures \& food during the PhD trip, Maren, for being jovial and tolerating my German greetings, Jasper, for tolerating my Spanish \& German greetings, Claire, for finding me in China, Irma, for being the super driver in Italy, Pjtor, for providing a bed when it mattered the most, Natalia, for the Spanish lessons and agreeing to be a super paranymp, Esther, for being an awesome office mate and $\mathrm{Zi}$, my brother from a Chinese mother, for rescuing me from the immigration officers. My short-lived office mates, Linda, easy with the hard liquor (not in the morning please), Rebeeca, for fighting with office equipment \& speaking your mind, Anneloes, for being calm \& getting me nice tea and Dennis, for your noisy farts. Alex, for discovering the toilet of the future \& managing 'clean sheets', Angela, for the Dutch medical drama stories, Diego, for the beer making tips $\&$ being a real brave heart, Alberto, for always having a smile \& a joke, Nathalia, for our similar summer taste \& tolerating my Portuguese accent, Alicja, for always being cheerful, Karen, I still owe you a visit for the beer-making, Hasmik, for the encouragement towards the end, Monica, for the lab 
orientation during the early days, Maciej, for our basketball stories, Alecia, for the Italian vibes, Janet, for the portuguese-spanglish especially during crunch times. Ioanna, for your great sense of humour, Diah, for being a workhorse, Ida, for being a good neighbour, Yue, for making me shine with my chinese in China and James Noah, my brother from a Rwandese mother, for giving me helpful tips during this whole journey and agreeing to be my paranymp.

I would like to express my gratitude to the staff, students and colleagues in Food Quality Design for all their support and happy memories. Many thanks go to Vincenzo for always accommodating me in the group, Hein, for our milk discussions \& connections, Frans \& Xandra, for the assistance in the lab with milk analysis, the evergreen Erik, for always smiling \& sparing moments for laughter and Mike \& Geert, for being part of the bandwagon. I also want to thank the other member of staff: Ruud, Pieternel, Edoardo, Nicoletta, Kasper, Matthijs, Jenneke, Teresa and Bea as well as the super ladies of the group, Lysanne, Kimberley and Corine for always being there and ready to help. My thanks also extend to my PhD colleagues, Andriana, Mostafa, Onu, Jonna, Femke, Renske, Folake, Fola, Ayusta, Ranti, Fabiola, Moheb, Hannah, Pieter, Lucia, Nur, Zhijun, Furahisha, James, Ana, Ita, Li, Annelies, Sara, Sine and the Zim team: Juliet, Ruth, Faith, Lesley \& Shingai. Grazie!!

May I also convey my gratitude to the staff, students and colleagues in my third group, Laboratory of Genetics for all the warmth, support and fun moments we shared during this journey. Special thanks go Bas, for your constructive comments and making me feel free in the group, Bart, Duur, Arjan \& Fons, for your interesting questions and interactions and Mark A., for tolerating the noise we made in your office. Many thanks go to a very sweet and soft spoken person, the late Bertha, for the lab orientation and first hands-on guidance with DNA extraction \& PCR, Wytske, for all the logistical support \& facilitation, Joost, for throwing me in the deep-end of the pipeline of microbial data analysis, Suzette, for helping with sample dilutions when I had to run back to Zed, Corrie, Frank, Eric \& Gabriella for your assistance in the lab. To my other colleagues, Jianhua, Jelle, Eveline, Majon, Anna, Alex, Mark Z., Sarah, Erik, Valeria, Claudio, Kim, Margo, Rene, Philip, Job, Roel, Ramon, Mariska, Ben, Cris, Raphael, Jitpanu, Francesco, Krithi, Lennart, Sabine, Tom, Helena, and everyone, I appreciate you all and cherish all the fun we had during the lab outings, pub-quiz and dept. drinks. Dank u!!

I like to extend my gratitude to my $4^{\text {th }}$ unofficial Chair Group, Food Process Engineering (FPE) that I had privilege of sharing the same corridor with. Special thanks go to Remko, for letting me use your coffee machine when ours was moved, it gave me an opportunity to interact with Jos, Karin, Maurice and Martin. Jarno, Anja and Elaine, it was nice running with you in the Veluloop, Eveline, we ran together often and went for a PhD trip together, you were always nice and easy to talk to, Birgit, always serious but with a hidden sense of humour, Victor \& Angelica, the first ones I met in the group, Qinhui, for always smiling, Sicong, for your warm morning greetings, Pattie, we started together with the only important Doctor Demitris K., and my fun crew, Juliana, Elvira and Kostantina, for cheering me on in the final stages. You guys are amazing!!

I wish to also thank Guido and Harry from Food Physics for helping me with the Adam's Consistiometer, it worked wonders in the field.

I would also like convey my heartfelt gratitude to my employer and parent institution, the University of Zambia (UNZA) for allowing me purse this PhD programme. Special thanks go to Late Prof. Drinah Banda-Nyirenda and Dr Antione Nguz for changing my career path to Food Science \& Technology at MSc level, Dr Judith Lungu (former Dean), for giving responsibilities early in my career, Dr Mick Mwala (former Dean), for finally sending out to do this PhD and, Dr Benson Chishala (current Dean) for supporting me throughout this journey. May I also thank my colleagues in the Dept. of Food Science \& Nutrition, Dr Hachibamba (HOD), Dr Nyau (former HOD), Dr Hikeezi, Dr Mwale, Ms Nthani, Mrs Zgambo, Dr Marinda, Dr Kumwenda, Mr Murambiwa, Mr Miyoba, Mr Nkonkola, Mr Sadoki, Mrs Mulonda, Dr Mkandawire, Dr Nkonde and Dr Audain for all your support and for weathering the storm when course loads had to change to accommodate me. To Ian, Moses, Lister and Mrs. Chipeta, thanks for all your support with the work in the lab, it was quite a big job! Many thanks to Prof. Lungu, Prof Kalinda, Prof Tembo, Prof Yerukon, for the encouragement and all the staff in the School of Agricultural Sciences as 
well as the Dept. of Agricultural Engineering. I would like to also acknowledge the Staff Development Office for the their support and Dr Kuntashula for reviewing the questionnaires.

I am indebted to Ministries of Agriculture, and Fisheries \& Livestock of the Government of the Republic of Zambia, for providing information and personnel to assist with data collection during my fieldwork. My gratitude is also extended to my enumerators - Victoria, Jerry, Mweemba, Anita, Hajaya \& Tesfa, my data entry assistants, Eric and Taonga, the Namwala Dairy Cooperative, especially Mr. Nabilwa, Mr. Moyonda and Mr. Mwakamona, for opening their doors for me to carry out the field experiment. Special thanks to all the farmers, traders and Dairy Cooperatives that participated in the survey.

May I also extend my gratitude to the consortium partners of the project: CSK Food Enrichment, Yobafor-life, Tropical Disease Research Centre (TRDC) and Heifer Project International for the smooth collaboration.

I also wish to thank Sainur for his assistance with bioinformatics and the students that I worked with: Liv, Ivana, Loeck \& Charlotte.

My family away from home, the African choir. I am short of words to describe you. The highlights of my stay in Wageningen are filled with moments that we spent together singing, having dinners \& stay-ins, sandwich, dancing, evangelising through song in Arnhem as well as travelling to different places. I am truly grateful to all of you for your love and kindness. Many thanks go to Faith, for inviting me to join the choir, Gium, for inspiring me, James Ajal, a brother from a UG mother, Leah, my student, Sally, the original student, Maureen, the queen of selfies, Harold, the stay-in master, Fola, the nini-guy, Carol \& Josephine, the conductors, Fusta, the food time-keeper, Fausta, the key to Tanga, the evergreen D] Aika, the key to Singida, Roberto Baggio, the master of the chicken wings, Dan K., the Friday enforcer, Mercy, the super dancer, Omare, the chapati master, Esther, the pilau master, Esther Nyari, Mutsva (bebe), Vincent, give it to me, James (invisible), Theresia, the mama nera-nera, Anna, Bernard (Edeman), Rose, Lilian, Levina, Brenda, Mathew, the fast drummer, Gildas \& the mothers, Praxides, Nadin, Neo, the nshima specialist, Ruth, the gwala master, Vedaste, the time-keeper, Thomas, the posho specialist, Juliet, the best soprano, Favour, the party organiser, Michael, the best bass, Joseph, the drummer, Theo, Noella, the best auto, Severin, the travel master, Darius, Brigit UG, Mary-Bridget, my sister, the evergreen Secretary of the embassy, Christella and the Treasurer, Stephanie, the two pose specialists and the Cardinal of rainbows himself, Joshua.

My wider African family and delegates of the Embassy, it such an honour and pleasure to share the finer moments of my stay in Wageningen with you. To the UCAS family, Onu, Emily, Abiola and the new team, Asante. To the Kenyans, Tele, Bilha, Kenana, Jasper, Jared, Joyce, Irene, Helen, Tom, Nathaniel, Claris, Monica and company asante sana, to the Malawians, Steve \& crew Zikomo, the Zim team, Betty, Derrick \& crew tatenda, to the South Africans, Claudine, Neo, Marvin \& crew Siyabonga, to the Sothos, Lerato nitumezi, to the TZ team, asante sana, the Ugandans, Felix, Hilda, Catherine (thanks for coffee \& goat knowledge), Robert (thanks for the room) \& crew webale nyo, to the Nigerians, Joy, Tirafiki \& crew thanxoo, the Ghanaians, Ben, Eugene (thanks for the room), Faustina (thanks for the ethnography knowledge), Nancy, Oteng, Gertrude, Edward, Claudia \& crew thanks, the Ethiopians, Kal, Tesfaye \& crew, the Rwandese, Edward, Doris, Zuhura, Solange \& crew murakoze, the Beninese, Deedi (D. we made it), Imelda \& crew merci, the Cameroonians, Shaphan (thanks for the politics knowledge) \& crew, and all other delegates from rest of Africa and the World at large, thank you, gracias, obrigado, xiexie, dankeschon, efcharisto, terima kasih!!!!!. I cannot mention all of you by name due to the limited space and the side effects of the PhD but you all have special places in my heart.

May I also thank the International Choir led by Tami and the International Catholic Community (ICC) lead by Fr Henri for providing a spiritual home. Many thanks go Pieter, Monica, Birgit, Willem and all congregants for your love \& support.

May I also convey my gratitude to my WUR-Zambian family, the evergreen Chair, Ashley with her medas, van Consilia with the strongholds, van Monze (aka DJ Laz) with sukuluza, van Sichone, James, 
Nyamwaya, with her trraapruupraa moves, van Justina, Kalima (Kalis) with tapali, Marrian with her kopola-wur swag and my all-weather neighbour Siatwiinda with his slick moves. We have to do a nshalale in Zed when we are all back. Mark, Bridget \& the kids, thanks for the dinners and trips to the airport. Ndalumba!!

To all my friends in Zambia, my basketball teammates (Hangovers, Leftovers \& Legends), the UNZA Dons league, the Committee of Management of the Agricultural \& Commercial Society of Zambia (ACSZ) and Panjira Cooperative, thanks for your support.

I would like to acknowledge my PhD nucleus family starting with our first born, our big-young sister, Anneloes, we worked on the same product but had different research questions, which at times were difficult to separate. It was always fun talking about our presentations and agreeing on what each of us would talk about. Thanks for sending out our samples and putting up with us, you blended in perfectly and probably qualify to be a next generation "Dutchambian". Dank u wel, Doc. Justin (JC) the second born, aka "the medicine man" you took us through the ropes of DNA extraction and PCR. There was no dull moment in the lab, it was always full of laughter, a testimony of your use of medicine. I enjoyed our discussions on a broad range of issues and we encouraged each other in a lot of positive ways towards the end such as the cats sitting arrangements, which saw us across the finish line. Natotela sana mukwayi!! And last but not the least, my Siamese twin, Sydney (aka "Sido Sly the Tenacious"), we attended interviews together and started on the same day. You always inspired me with your tenacity, zeal and determination. You were the co-founder of the Embassy with DK \& Aika where you earned your reputation and respect across the continent as the nshima expert. When the going got tough with the experiments, the pipeline \& mobiXterm, we chilled off with a Leffe at the spot and lived to fight another day. Well, here we are. We made it and as fate would have it, we get to defend on the same day, well done mudala and Zikomo Kwambili.

Finally, my family, to my late parents (Ruth \& Ambrose), thanks for the firm foundation you laid so early in my life, which has seen me through to this stage despite the numerous challenges along the way. Mum, the last book you bought me in grade 7 worked and Dad, our last conversation in grade 12 was about your wish for me to make it to university. Well, guess what? I made it and I get to defend a PhD, something you both would have been proud to see. Fortunately, I have new parents, the Mr. \& Mrs. Chirwa who have been supportive throughout this journey and I am eternally indebted. To both the Phiri's and the Chirwa's, thank you for all your support. Naonga chomene!!! To the Hejan clan and bana Zilindi, ndalumba kapati loko basa!! To my siblings, the Moonga's and their spouses, our unity is our strength and this achievement is a testimony of your all-weather support and a glimpse of the greater things we can continue to accomplish together. Ndalumba basa!

Lastly, to my daughter Namoonga ("Namsy-daisy"), sorry I had to leave you at three weeks old, only to return when you were 10 months old with a short visit, which you barely noticed in between. Daddy had to finish a PhD but thanks for your understanding. To my son Hakahuna (Haks), the last four years of your life must have been confusing with my "now you see me, now you don't acts". Fortunately, these acts have come to an end. Daddy is done with the school trips and thanks for remembering me after each trip. You have grown into a good and handsome boy. Finally, my cheerleader, Taonga, you have been rock-solid, a proper cornerstone throughout this journey, you leave me short of words. You have done an amazing job with kids and run the affairs of the home diligently, you're a superwoman. You have really been my pillar, your encouragement, listening ear, patience, understanding and unwavering support has seen me through this journey. Despite the challenges of work, school runs, family issues and running a home, you still had time for me to listen to my joys, lamentations and songs. I am tempted to sing one last one for you, "mbubo sunu chamana, chakali chachikolo mbubo akaka sunu chamana" (it is over, the school task is over). I am forever grateful for everything, your love, tenderness and kindness. 


\section{About the Author}

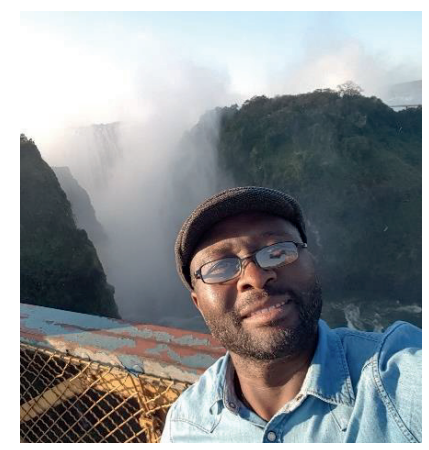

Himoonga Bernard Moonga was born on $10^{\text {th }}$ February 1976 in Monze, Zambia. He did his secondary education at Canisius Secondary School and proceeded to the University of Zambia (UNZA) where he obtained a BSc in Agriculture (majoring in Animal Science) in 2001. He then joined UNZA as a part-time Tutor/Demonstrator in 2002 and was later appointed as Staff Development Fellow (SDF) prior to commencing an MSc programme in Food Technology at Gent University \& Katholike University of Leuven in Belgium. Upon completion, he returned and was appointed Lecturer in the Department of Food Science \& Technology in 2004 where he teaches several courses including technology of: dairy products, fruit \& vegetables products, fermented food products and technical thermodynamics. He served as Head of Department from 2007-2012. His research focus is on product development of dairy products, traditional fermented foods and indigenous fruits \& vegetables, food safety and postharvest handling and processing of horticultural products. He also practices livestock and horticultural farming with onward small-scale processing of poultry \& meat products, dried and frozen fruit \& veg products. He collaborates with dairy and horticultural farmer cooperatives as well as other food processing companies in Zambia. After being the Department's gatekeeper for a few years, he decided to pursue a PhD on Traditional Fermented Milk, Mabisi at Wageningen University in the Laboratory of Food Microbiology in 2015. The PhD research findings are described in this thesis. He has also been involved in several collaborative research projects over the years and some are listed here:

1. Co-researcher - Improving Nutrition through African Indigenous Vegetables (AIVs), a collaboration with Rutgers University funded by USAID, 2018-2019.

2. Co-researcher - Enhanced Nutrition Security through Traditional Fermented Foods in Zambia Project, a collaboration with Wageningen University funded by WOTRO/NWO, $2014-2019$.

3. Co-researcher - Experimental Evolution of Microbial Eco-systems in Traditional Zambian Fermented Products, a collaboration with Wageningen University, funded by the EU, 2014-2017.

4. Co-researcher- Prevention of Aflatoxins pre- and post-harvest under the Peanut Mycotoxins Innovation Laboratory (PMIL), a collaborative research project between UNZA, School of Agricultural Sciences (Departments of Soil Science and Department of Food Science \& Nutrition) and University of Georgia, USA, 2014-2017. Funded by USAID.

5. Lead researcher - Vegetable production and Post-harvest Handling under the CASH project funded by USAID a collaboration with Rutgers University \& ASNAPP, 2012-2014.

6. Co-researcher - Increased Utilization of Cowpea for Health Benefits (CRSP Project) in collaboration with University of Texas A \& M, University of Pretoria and Egerton University, 2010 - 2013.

7. Lead researcher - Product Development and Entrepreneurship Training on Sorghum and Millet based product (CRSP Project). Supported by INTSORMIL in collaboration with University of Nebraska (UNL), 2008 - 2012.

8. Co-researcher - Quality of Honey harvested from Different Beehive Types in Various Location of Zambia in collaboration with Centre for International Forest Research (CIFOR), with support from SIDA, 2008 - 2010

9. Lead researcher - Studies into the Development of Whey-Fruit Juice/Pulp based Beverage, 2010 - 2013. Funded by the National Science and Technology Council (NSTC) of Zambia.

10. Lead researcher - The Physical and Chemical Quality of Raw Milk from the small/medium scale suppliers in Zambia, a collaboration between the Department of Food Science and Technology, University of Zambia and Land O' Lakes Inc, Lusaka). 2005-2006. 


\section{Publications}

\section{Full papers}

I. Moonga, H. B., Schoustra, S. E., Linnemann, A. R., Kuntashula, E., Shindano, J., \& Smid, E. J., The art of mabisi production: A traditional fermented milk (2019). PLoS ONE.

II. Nyau V., Mwanza E.P. \& Moonga H.B., Physico-chemical qualities of Honey Harvested from Different Beehives Types in Zambia (2013). African Journal of Food, Agriculture, Nutrition and Development.

\section{Conference papers}

I. Himoonga Bernard Moonga, Sijmen Schoustra, Anita Linnemann, John Shindano and Eddy J. Smid, Microbial community dynamics of different types of mabisi, a traditional fermented milk at the $8^{\text {th }}$ Congress of European Microbiologists, FEMS from $7^{\text {th }}-11^{\text {th }}$ July 2019 in Glasgow, Scotland, UK.

II. Mataa, M., Siziya, I. N., Shindano, J., Moonga, H. B., and Makungu, B. (2019). Variation in leaf macro- nutrient, anti- nutrient contents associated with maturity in selected Roselle (Hibiscus sabdariffa) genotypes. Paper presented at the Symposium on Seed Politics, held on 9th July 2019, at Confucius Institute, University of Zambia, Lusaka. Zambia

III. Himoonga Bernard Moonga, Sijmen Schoustra, Anita Linnemann, John Shindano and Eddy J. Smid, Influence of production methods on communities of Lactic Acid Bacteria in traditional fermented milk - Mabisi at the 12th International Symposium on Lactic acid Bacteria (LAB 12) from 27th - 31st August 2017 in Egmond, Netherlands.

IV. Sijmen Schoustra, Anneloes Groenenboom, Bernard Moonga, Sydney Phiri, Justin Chileshe, Bas Zwaan, John Shindano and Eddy Smid, Niche exclusion principle and experimental evolution of communities - 12th International symposium on Lactic Acid Bacteria (LAB12), 27-31st August 2017, Egmond, Netherlands.

V. Sijmen Schoustra, Anneloes Groenenboom, Bernard Moonga, Sydney Phiri, Bas Zwaan, John Shindano and Eddy Smid, Eco-evolutionary dynamics in natural communities of fermenting bacteria at the 2017 Congress of European Society of Evolutionary Biology from 20-25th August 2017 in Groningen, Netherlands.

VI. John Shindano, Himoonga Bernard Moonga, Chitundu Kasase, Chima Tamara and Munyinda Kalaluka, Determination of Condensed Tannins and Protein Digestibility and their Relationship to Seed Color in Cowpea Varieties on Zambian Market. Dry Grain Pulses Collaborative Research Support Program (CRSP) Global Pulse Researchers Conference held from $13^{\text {th }}-17^{\text {th }}$ February 2012 at the Lemigo Hotel in Kigali, Rwanda.

VII. Moonga H. B., Nyau V., Chirwa T., Banda M. Studies into the Development of Whey-Fruit Juice/Pulp Based Beverage. National Science and Technology Council Symposium, Mulungushi International Conference Centre, from 18-19th November, 2010 in Lusaka, Zambia

VIII. Moonga H. B., Munyenyembe A., Mkandawire N. L., Shindano J., The Nutritional Value of Packed Opaque Beer. The inaugural National Symposium on Agriculture under the theme: Harnessing the Potential of Agriculture to meet the increasing Demands from a growing Population, University of Zambia, Lusaka, $7^{\text {th }}-8^{\text {th }}$ April 2009.

IX. Moonga H. B., Rombaut R., Dewettinck K., The Effect of Enzymatic Digestion on Polar Lipids and Proteins in Raw Milk. International Conference on Inter-disciplinary Research, by VLIR UNZA IUC Program, University of Zambia, Lusaka, 27 th $-28^{\text {th }}$ Feb 2008. 


\section{Overview of training activities}

Discipline specific activities

\author{
Courses \\ Food Stability \\ Aroma Components in Food \\ Food Fermentation \\ Sensory Evaluation \& Food Preferences
}

Genetics \& Physiology of Food associated Microorganisms

Management of Microbiological Hazards in Food

Food \& Bio-refinery enzymology (Poster presentation)

Food Value Chain Research: Understanding Inter-Organizational

Relationships

Healthy Food Design

Advanced Food Analysis (Poster presentation)

Conferences

9th Dairy Conference: Milk Protein Functionality

Global one health - Annual scientific symposium: Animal \&

human health through research

LAB 12 International Symposium (Oral \& Poster presentation)

Towards healthy \& sustainable food systems in an urbanising world workshop

KNVM Microbial ecology meeting

Fems conferences (Poster presentation)

Alkaline cooking workshop

Traditional fermented foods dissemination workshop (Oral presentation)

Traditional fermented foods to promote food \& nutrition security in Africa academic symposium (Oral presentation)

\section{General courses}

VLAG PhD week

High Impact writing in Science

Project and time management

Introduction to R Statistics

Multivariant Analysis for Food Data/Science

Data Management Planning

Information Literacy including Introduction to EndNote

Bayesian Statistics

Plunge into your Business Plan

\author{
Graduate school/Institute \\ University of Copenhagen (KU) \\ University of Copenhagen (KU) \\ VLAG, Wageningen \\ University of Copenhagen (KU) \\ VLAG, Wageningen \\ VLAG, Wageningen \\ VLAG, Wageningen \\ WASS, Wageningen \\ VLAG, Wageningen \\ VLAG, Wageningen \\ NIZO, Papendal \\ University of Zambia (UNZA), \\ School of Veterinary Medicine
}

KNVM/FEMS, Egmond

2017

WUR, Wageningen

2018

KNVM/FEMS, Nijmegen

FEMS, Glasgow, UK

FQD/FHM/GEN/UNZA,

Chisamba, Zambia

2018

2019

2019

UNZA/GEN/FHM/FQD, Kabwe, Zambia

2019

UNZA/GEN/FHM/FQD, Lusaka, Zambia

VLAG, Wageningen

WIAS, Wageningen

2015

WGS, Wageningen

2015

2015

2015

2015

WGS, Wageningen

WGS, Wageningen

2015

PE\&RC, Wageningen

2015

University of Gent (UG), Gent 
Entrepreneurship in \& outside Science

WGS, Wageningen

2016

Reviewing a Scientific Paper

WGS, Wageningen

2016

Big data in life sciences

VLAG, Wageningen

2017

Scientific publishing

WGS, Wageningen

2017

Brain training

VLAG, Wageningen

2016

PhD Carousel

WGS, Wageningen

2018

Scientific integrity

WGS, Wageningen

2018

Ethics for social sciences

WGS, Wageningen

2018

Writing grant proposals

WGS, Wageningen

2018

Scientific writing

WGS, Wageningen

2019

Efficient writing strategies

WGS, Wageningen

2019

Optional courses \& activities

Preparation of research proposal

FHM, Wageningen

2016

PhD study tour to Italy (oral presentations)

FHM, Wageningen

2017

Weekly group meetings (oral presentations)

FHM, GSS, FQD, Wageningen

2015-2019

$P E \& R C$, Wageningen

2018

PhD study tour to China (oral presentations)

FHM, Wageningen

2019

Organising Stakeholder workshop for the WOTRO project

UNZA/GEN/FHM/FQD, Lusaka,

Zambia

2016

Organising traditional fermented foods symposium \& stakeholder workshop

UNZA/GEN/FHM/FQD, Lusaka,

Zambia

2019

Microbial population biology meetings

GSS, Wageningen

2016-2018 


\section{Funding}

The research described in this thesis was funded by the Netherlands Organisation for Scientific Research, NWO-WOTRO, through a project entitled 'Enhanced nutrition security through traditional fermented foods in Zambia' under the Food \& Business Global Challenges Programme (W08.250.2013.108).

The project was a collaboration between Wageningen University \& Research and the University of Zambia with other partners from the Netherlands, CSK Food Enrichment and Yoba-for-life, and from Zambia, the Tropical Disease \& Research Centre (TDRC) and Heifer Project International.

Cover design by: Dennis Hendriks \& H.B. Moonga (Photos taken by H.B. Moonga \& microbial image courtesy of Themocracy online (Kevin Schultz))

Thesis layout by : H.B. Moonga

Printed by: Digiforce (ProefschriftMaken)

Copyright (c) 2019 H.B. Moonga 



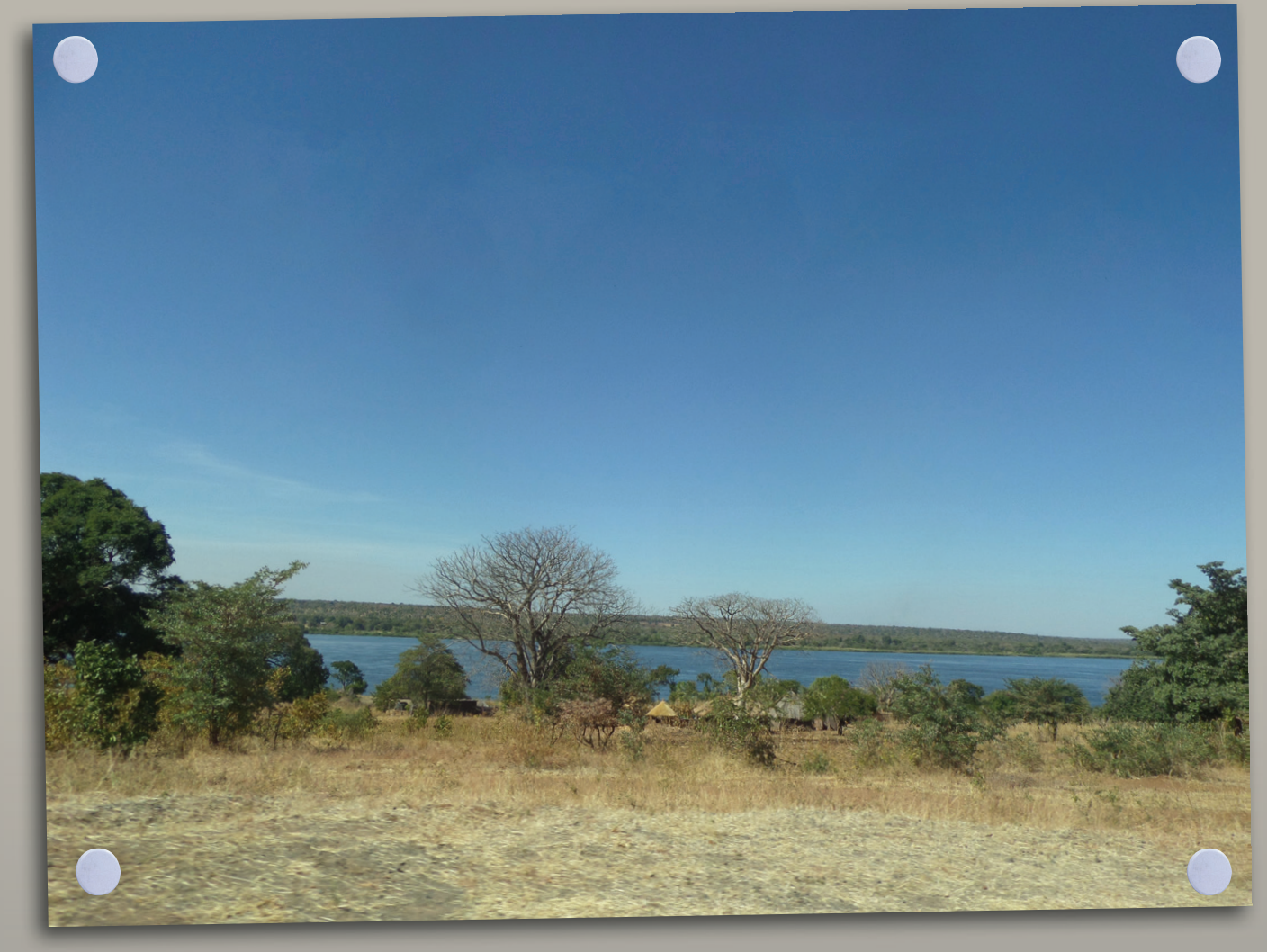

